\title{
Management of Graves' Ophthalmopathy: Reality and Perspectives*
}

\author{
LUIGI BARTALENA, ALDO PINCHERA, AND CLAUDIO MARCOCCI \\ Dipartimento di Endocrinologia e Metabolismo, Ortopedia e Traumatologia, Medicina del Lavoro, \\ University of Pisa, 56124 Pisa, Italy
}

\begin{abstract}
Graves' ophthalmopathy is an debilitating disease impairing the quality of life of affected individuals. Despite recent progress in the understanding of its pathogenesis, treatment is often not satisfactory. In mild cases, local therapeutic measures (artificial tears and ointments, sunglasses, nocturnal taping of the eyes, prisms) can control symptoms and signs. In severe forms of the disease (3-5\%), aggressive measures are required. If the disease is active, high-dose glucocorticoids and/or orbital radiotherapy, or orbital decompression represent the mainstay of treatment. If the disease is severe but inactive, orbital decompression is preferred. Novel treatments such as somatostatin analogs or intravenous immunoglobulins are under evaluation. Re-
\end{abstract}

habilitative (extraocular muscle or eyelid) surgery is often needed after treatment and inactivation of eye disease. Correction of both hyper- and hypothyroidism is crucial for the ophthalmopathy. Antithyroid drugs and thyroidectomy do not influence the course of the ophthalmopathy, whereas radioiodine treatment may cause the progression of preexisting ophthalmopathy, especially in smokers. The exacerbation, however, is prevented by glucocorticoids. In addition, thyroid ablation may prove beneficial for the ophthalmopathy in view of the pathogenetic model relating eye disease to autoimmune reactions directed against antigens shared by the thyroid and the orbit. (Endocrine Reviews 21: 168-199, 2000)
I. Introduction

II. Pathogenesis

III. Management of Graves' Ophthalmopathy: General Principles

A. Whom to treat?

B. How to treat?

C. How to assess the effects of treatment?

IV. Management of Nonsevere Graves' Ophthalmopathy

V. Management of Severe Graves' Ophthalmopathy
A. Established treatments
B. Nonestablished treatments
C. Novel treatments under investigation
D. Miscellaneous treatments
E. Rehabilitative surgery

VI. Summary of Assessment and Treatment of Graves' Ophthalmopathy

VII. Treatment of Hyperthyroidism and the Course of Graves' Ophthalmopathy
A. Antithyroid drug treatment
B. Radioiodine therapy
C. Thyroidectomy
D. Total thyroid ablation

VIII. Treatment of Graves' Hyperthyroidism in Patients with Ophthalmopathy

A. Nonsevere (or absent) ophthalmopathy

B. Severe ophthalmopathy

Address reprint requests to: Luigi Bartalena, M.D., Dipartimento di Endocrinologia e Metabolismo, Ortopedia e Traumatologia, Medicina del Lavoro, University of Pisa, Ospedale di Cisanello, Via Paradisa, 2, I-56124-Pisa, Italy. E-mail: 1.bartalena@endoc.med.unipi.it

* This work was supported in part by grants from the University of Pisa (Fondi d'Ateneo) and from the Ministero della Università e della Ricerca Scientifica e Tecnologica (MURST), Rome, Italy (Project "New Models for the Diagnosis and Management of Graves' Ophthalmopathy").
IX. Prevention of Graves' Ophthalmopathy
A. Natural history of the disease
B. Cigarette smoking
C. Other risk factors

X. Therapeutic Perspectives
A. Anticytokine therapy
B. Somatostatin analogs
C. Colchicine

XI. Concluding Remarks

\section{Introduction}

$\because \mathrm{R}$ RAVES' OPHTHALMOPATHY (GO), the most frequent extrathyroidal manifestation of Graves' disease (1), remains a pathogenetic enigma and a therapeutic dilemma. In its severe expression it is a disfiguring and invalidating disease that profoundly influences and impairs the quality of life of affected individuals (2). Despite recent progress in the understanding of its pathogenesis (3-5) and in its management (6), major controversies still exist in both areas. Even the denomination of this disorder is controversial, and the terms "thyroid eye disease" or "thyroid-associated ophthalmopathy" are both often used. This is because, although mostly associated with Graves' hyperthyroidism, ophthalmopathy may less frequently occur also in patients with hypothyroid Hashimoto's thyroiditis or in euthyroid subjects with no current or past evidence of thyroid hyperor hypofunction (so-called euthyroid Graves' disease) (1, 7).

Because excellent reviews have recently been published on the pathogenesis of ophthalmopathy $(1,3-5)$, only the most recent contributions in this field will be presented, while the discussion will be mostly focused on the management of the disease. Emphasis will be given to the coordinated treatment of the frequently associated hyperthyroidism, and future therapeutic perspectives will be considered. 


\section{Pathogenesis}

It is widely accepted that GO is an autoimmune disorder (1), but its pathogenesis is still incompletely understood (see Refs. 3-5 for review). Support for the concept that GO is of autoimmune origin comes from the associated histopathological changes. There is an increased volume of the extraocular muscles and orbital connective and adipose tissues (1); the extraocular muscles are edematous due to increased production of the hydrophilic glycosaminoglycans (GAGs) in the orbital tissue (3); a marked infiltration of immunocompetent cells (predominantly $\mathrm{T}$ lymphocytes and macrophages; to a lesser extent, B lymphocytes) is detectable $(8,9)$. Infiltrating $\mathrm{T}$ cells are mostly CD4+ $(10,11)$.

According to a leading pathogenetic hypothesis (1), autoreactive $\mathrm{T}$ lymphocytes recognizing an antigen shared by the thyroid and the orbit infiltrate the orbital tissue and the perimysium of extraocular muscles; this process may be facilitated by either circulating or locally produced adhesion molecules (5), the expression of which may be induced by cytokines (12) and be related to the activity of the disease (13). After infiltration of the orbit by $\mathrm{T}$ cells, the shared antigen could then be recognized by a $\mathrm{T}$ cell receptor on CD4 $+\mathrm{T}$ lymphocytes: the finding of a biased usage of the $\mathrm{T}$ cell receptor variable gene $(14,15)$ supports the concept of an antigen-specific immune reaction (9). After antigen recognition, CD4 + T lymphocytes could secrete cytokines that amplify the immune reaction by either activating CD8 + T lymphocytes or autoantibody-producing B cells (16). Phenotypic analysis of T cell clones from the orbital tissue of GO patients has revealed a predominance of $\mathrm{T}$ cells with a Th1 profile (interleukin-2, interferon- $\gamma$, tumor necrosis factor- $\alpha)(17,18)$, but also a Th2 profile of cytokine production (interleukin-4, interleukin-5, interleukin-10) has been reported (18-20). These differences might be related to different stages or activity levels of eye disease $(21,22)$, but they might also reflect differences in experimental methods employed in different studies.

Cytokines induce expression of major histocompatibility complex class II molecules (23) and heat-shock protein-72 (HSP-72), which are important for antigen recognition (5), and of intercellular adhesion molecule-1 (24), which is important for $\mathrm{T}$ cell recruitment. In addition, cytokines stimulate fibroblasts to synthesize and secrete GAGs $(25,26)$, which attract fluid into the retroorbital space, thus contributing to the development of periorbital swelling, proptosis, and extraocular muscle swelling (1). The expansion of the orbital content is also related to cytokine-induced proliferation of fibroblasts (27). Orbital fibroblasts may contribute to perpetuate the ongoing immune reaction in the orbit by protecting infiltrating $\mathrm{T}$ cells from apoptosis (28). Orbital fibroblasts include a subpopulation of cells (preadipocytes), which, under particular hormonal stimulation, differentiate into adipocytes (29) and may contribute to the increased volume of retroorbital adipose tissue.

If the above pathogenetic mechanisms are correct, two major questions arise: 1) Which is the antigen shared by the thyroid and the orbit?; and 2) Which is the orbital cell type targeted by $\mathrm{T}$ cells?

The TSH-receptor (TSH-R), the autoantigen involved in
Graves' hyperthyroidism, is probably a shared antigen (3032). This concept is supported by several lines of evidence. TSH-R transcripts have been demonstrated in the orbital tissues by RT-PCR (33-37), but this technique has a drawback: its sensitivity allows the amplification of virtually any gene due to illegitimate transcription (38). In addition, TSH-R variants have also been detected in orbital tissue (39-42). However, the presence of TSH-R-like immunoreactivity has been shown in orbital and pretibial fibroblasts using antibodies directed to the TSH-R extracellular domain (43-45). More recently, in a sample of orbital fat from a GO patient, the major TSH-R transcripts $(4.6,1.7,1.3 \mathrm{~kb})$ were demonstrated by Northern blot analysis (46). Using in situ hybridization with a digoxigenin-labeled antisense oligonucleotide probe specific for the extracellular domain of the TSH-R, Spitzweg et al. (47) demonstrated specific perinuclear and cytoplasmic TSH-R gene expression in orbital fibroblasts from GO patients and, to a lesser extent, from normal subjects. Intact and variant TSH-R mRNA transcripts were demonstrated by Bahn et al. (48) by liquid hybridization analysis in orbital adipose/connective tissue specimens from GO patients. Ludgate and co-workers (49) reported that, using monoclonal antibodies to the TSH-R produced by genetic immunization (50), immunostaining was obtained in fibroblast-like elongated cells and in adjacent clusters of adipocytes in orbit bioptic samples of GO patients, but not in tissue specimens from pseudotumor or in extraocular muscle samples. Recently, an increased expression of the TSH-R was reported in orbital preadipocytes after differentiation into adipocytes, with a relatively greater TSH-R gene expression in GO than in normal orbital tissue specimens (51).

After overexpression of the extracellular domain of the TSH-R as fusion protein in bacteria (52), a low level of IgG binding was detectable by Western blotting in sera of 3 of 11 GO patients who had negative tests for circulating TSH-R autoantibodies (49). In addition, IgA binding to a degraded fragment of the TSH-R fusion protein was observed in 6 of 11 TSH-R autoantibody-negative GO patients (49). The role of IgA class autoantibodies was previously underscored by Arnold et al. (53), who reported IgA binding to normal orbit and skin fibroblasts.

After xenografting retroorbital tissues from GO patients into severe combined immunodeficient mice, the TSH-R antibody was detected in 7 of 9 xenografted mice (54). When syngeneic TSH-R-primed splenocytes were transferred to BALB/c or NOD mice, destructive thyroiditis with a Th1 cytokine profile occurred in NOD mice, while a Th2 response developed in BALB/c mice together with the appearance of TSH-R antibodies (55). As reported by Ludgate et al. (49), eye changes similar to those found in GO [lymphocyte and mast cell infiltration, an increase in adipose tissue, periodic acid Schiff-positive (PAS+) edema] were observed in 17 of 25 $\mathrm{BALB} / \mathrm{c}$ mice, but not in NOD mice.

A genomic point mutation in codon 52 of the extracellular domain of the TSH-R, leading to a proline-for-threonine substitution, was found in 2 of 22 GO patients and in no normal subjects (56). A higher prevalence of this polymorphism was found among GO patients with other extrathyroidal manifestations of Graves' disease (acropachy, pretibial myxedema) suggesting that it might predispose to more severe 
immune reactions (57). However, the role of this polymorphism in the pathogenesis of GO appears questionable in view of other studies (58-60).

Another possible explanation is that the orbital antigen cross-reacting with a thyroid antigen might be located on eye muscle cells. A $64-\mathrm{kDa}$ antigen shared by the thyroid and the orbit was reported by Salvi et al. (61), but the role and specificity of this antigen have been questioned because of its expression in other tissues $(62,63)$. Wall et al. $(64)$ reported that under nondenaturing conditions a $64-\mathrm{kDa}$ protein, expressed in eye muscle cells but not in skeletal muscle, reacted with serum antibodies present in $67 \%$ of GO patients but not in patients with Hashimoto's thyroiditis or in controls. Recently, the $64-\mathrm{kDa}$ protein was partially sequenced and identified as the flavoprotein subunit of mitochondrial succinate dehydrogenase, with a corrected molecular mass of $67 \mathrm{kDa}$ (65). Autoantibodies reactive with purified succinate dehydrogenase were detectable in $67 \%$ of patients with active GO, $30 \%$ of patients with stable eye disease, 30\% of Graves' patients without clinically apparent ophthalmopathy, and 7\% of normal subjects (65). It has been claimed that the appearance of these antibodies in the circulation might predict the subsequent development of GO (66).

Other eye muscle autoantigens possibly involved in GO include 1) a $63-\mathrm{kDa}$ calcium-binding protein, called calsequestrin, expressed in extraocular muscle and skeletal muscle, but not in the thyroid (67); 2) a 53-kDa protein, identified as another calcium-binding glycoprotein, sarcalumenin, expressed in extraocular muscle and skeletal muscle, but not in the thyroid $(68) ; 3$ ) a different $63-$ to $64-\mathrm{kDa}$ protein, called $1 \mathrm{D}$ protein, cloned from a thyroid cDNA expression library (62), which is expressed in extraocular muscles, skeletal muscles, thyroid, testis, and other tissues $(69,70)$; and 4$)$ a novel eye muscle protein, called G2s, with an estimated molecular mass of about $220 \mathrm{kDa}$, expressed in extraocular muscles, skeletal muscles, and thyroid (68). A higher prevalence of circulating antibodies directed against two porcine eye muscle antigens (64-kDa and 95-kDa) has been found by immunoblotting in GO patients compared with those without eye involvement or to normal controls (71). On the other hand, serum antibodies reacting with several extraocular muscle antigens have been detected in patients with nonspecific orbital inflammation (72).

A role for eye muscle cells in GO has also been suggested by the coexpression of human leukocyte antigen (HLA)-DR and heat shock protein-70 (HSP-70) in eye muscle cells from GO patients (73). Molnar et al. (74) reported the presence of IgA antibodies reacting with eye muscle fibers, with no difference, however, in their prevalence between Graves' patients with or without ophthalmopathy.

Most of the eye muscle antigens are intracellular, ubiquitous, and probably devoid of the disease specificity expected in an organ-specific autoimmune disorder (32). On the other hand, the G2 s protein is a cell-membrane protein and might effectively be involved in primary immune recognition. Antibodies to the other eye muscle antigens might then represent a secondary phenomenon after eye muscle damage and antigen exposure. Recently, evidence of Fas-mediated apoptosis was provided in extraocular muscle tissue from GO patients (75), but this is likely to represent a late event in the course of eye disease, preceding fibrotic changes in eye muscles.

To summarize, the orbital cell target of the autoimmune response in GO remains to be defined, but fibroblasts and adipocytes are more likely to be primarily involved; myocytes might be the object of secondary phenomena concurring with the perpetuation of the autoimmune reaction, although at the current status of knowledge, a primary role also of eye muscle cells cannot be ruled out. The nature of the putative antigen(s) shared by the thyroid and the orbit remains elusive, but many elements support the idea that TSH-R may represent the culprit antigen. The role of numerous eye muscle antigens remains to be clarified. It is conceivable that most of these eye muscle antigens, localized intracellularly, may be expressed only after eye muscle damage. Antibodies directed against these antigens might, therefore, represent not the primary event, but a secondary response and contribute to maintaining rather than triggering the ongoing autoimmune reactions in the orbit.

\section{Management of Graves' Ophthalmopathy: General Principles}

The majority of Graves' patients have a mild and nonprogressive ocular involvement that does not require any specific or aggressive treatment, also because nonsevere GO often tends to improve spontaneously. In a study of 101 patients attending a thyroid-eye clinic over a 5-yr period, 59 patients were judged not to require specific treatment for ophthalmopathy and were included in a study on the natural history of the disease: ophthalmopathy spontaneously regressed with time in two thirds of cases, while it deteriorated only in $15 \%$ of cases (76) (Fig. 1). Bartley et al. (77) found that among the 120 subjects of an incidence cohort study, 89 (74\%) required either no treatment or only supportive measures (Fig. 2). Thus, the two basic questions that must be addressed when evaluating a GO patient are whether he/she needs a specific treatment for eye disease and, in this case, which kind of treatment is indicated.

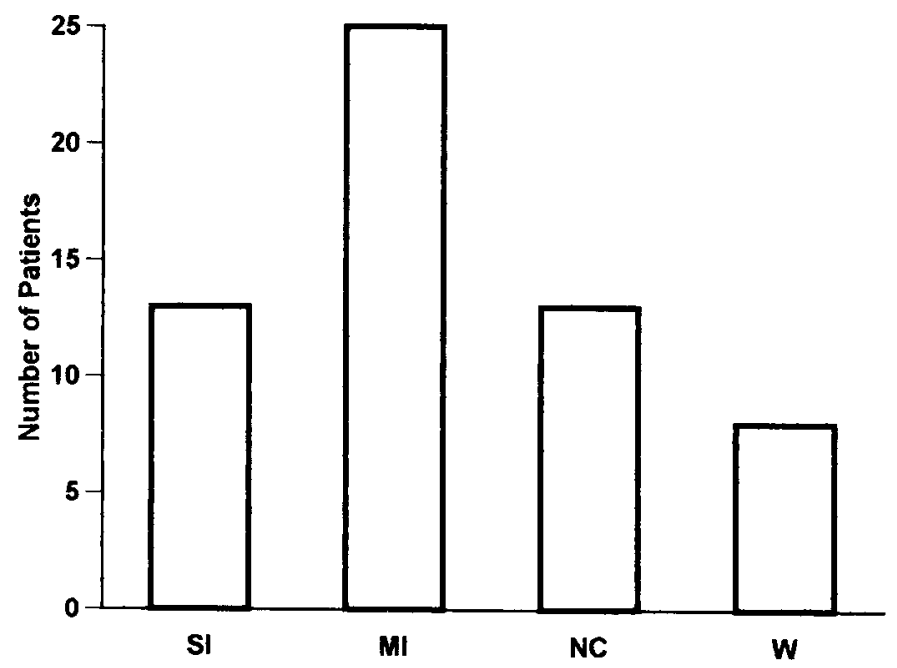

FIG. 1. Natural history of GO. SI, Substantial improvement; MI, minor improvement; NC, no change; W, worsening. [Derived from P. Perros et al.: Clin Endocrinol (Oxf) 42:45-50, 1995 (76).] 


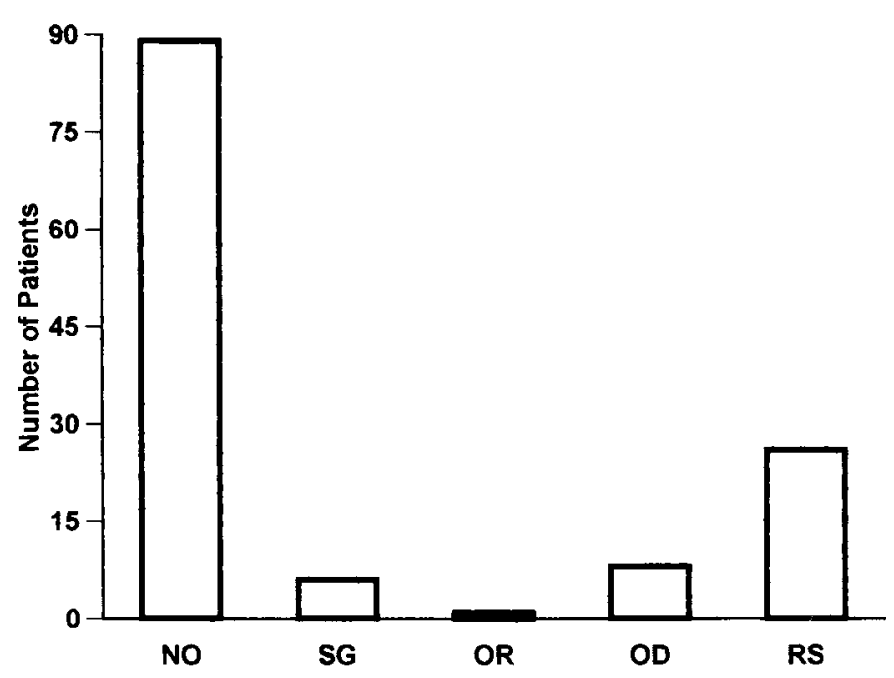

FIG. 2. Treatment of GO in an incidence cohort of 120 patients. NO, No treatment; SG, systemic glucocorticoids; OR, orbital radiotherapy; OD, orbital decompression; RS, rehabilitative (eye muscle and eyelid) surgery. [Derived from G. B. Bartley et al.: Am J Ophthalmol 121: $200-206,1996$ (77).]

\section{A. Whom to treat?}

The decision of whether ophthalmopathy must be treated should rely on the assessment of two different features, the severity and the activity of the disease. Some degree of eye involvement occurs in the majority of Graves' patients and can be either clinically evident or demonstrated only by instrumental techniques, such as CT scan, magnetic resonance imaging (MRI), or orbital ultrasound (1). In an incidence cohort of 120 patients from Olmsted County, Minnesota, eyelid retraction represented the most frequent eye sign, occurring in 108/119 (91\%), followed by proptosis (73/ $117,62 \%)$, and by extraocular muscle dysfunction (51/120, $42 \%)(78)$. However, also eyelid edema, conjunctival injection, and chemosis occurred frequently $(32 \%, 34 \%, 23 \%$, respectively), while signs of optic neuropathy were found only in 7 patients $(6 \%)(78)$. In the same series the most frequent complaints were diplopia in 40 patients $(33 \%)$, pain or discomfort in $36(30 \%)$, lacrimation in $25(21 \%)$, photophobia in $19(16 \%)$, and blurred vision in $9(7 \%)(78)$.

Definition of severity of GO is somehow arbitrary (Table 1). Undoubtedly, optic neuropathy, which can be subclinical and heralded only by changes in the visual evoked potentials (79), depicts per se a situation that can be sight threatening, especially if it is associated with an evident reduction of visual acuity. Marked proptosis may cause secondary exposure keratitis and lead to corneal ulceration or perforation. Thus, the presence of a substantial reduction of visual acuity attributable to optic neuropathy, or the presence of marked degrees of proptosis should be sufficient to define the ophthalmopathy as severe. In this regard, it may be relevant to evaluate variations in the proptosis, which may indicate a progression of the disease. Extraocular muscle dysfunction does not represent a danger for vision, but the resulting diplopia markedly influences daily activities and is responsible for major discomfort for affected individuals, especially if it is constant, i.e., present in all positions of gaze. Accordingly, extraocular muscle impairment, when causing diplo-
TABLE 1. Assessment of severity of Graves' ophthalmopathy

\begin{tabular}{lcll}
\hline \multirow{2}{*}{$\begin{array}{c}\text { Degree of } \\
\text { involvement }\end{array}$} & \multicolumn{3}{c}{ Parameter } \\
\cline { 2 - 4 } & Proptosis $^{a}(\mathrm{~mm})$ & \multicolumn{1}{c}{ Diplopia $^{b}$} & \multicolumn{1}{c}{ Optic neuropathy } \\
\hline Mild & $19-20$ & Intermittent & Subclinical \\
Moderate & $21-23$ & Inconstant & Visual Acuity 8/10-5/10 \\
Marked & $>23$ & Constant & Visual Acuity $<5 / 10$
\end{tabular}

Severe ophthalmopathy: at least one marked, or two moderate, or one moderate and two mild manifestations ${ }^{d}$

${ }^{a}$ Proptosis by exophthalmometer readings or CT/MRI measurements. Median normal value in our Italian population is $15 \mathrm{~mm}$. Normal values show racial variation; accordingly, abnormal values should be considered those $4 \mathrm{~mm}$ or more above the respective median value.

${ }^{b}$ Diplopia: Intermittent, present only when fatigued; inconstant, present in secondary positions of gaze; constant, present in primary and reading positions.

${ }^{c}$ Abnormal visual evoked potentials or other tests, with normal or slightly reduced (9/10) visual acuity.

${ }^{d}$ Patients with severe GO will need either medical or surgical treatment depending on the activity of eye disease.

pia in primary and reading gaze positions, should also be considered as an indicator of the severity of the disease. Soft tissue involvement, either inflammatory or congestive, is in most cases more striking than dangerous, although it disturbs and creates discomfort for the patient. For this reason, except for the rare cases with extremely severe periorbital swelling, conjunctival hyperemia and chemosis, soft tissue involvement should not be sufficient to define the disease as severe. Soft tissue manifestations are, however, relevant to assess the activity of the disease (see below) and for the perception of the disease by the patient. In addition, soft tissue involvement is rarely isolated in severe eye disease and, under most circumstances, is associated with some of the other expressions of the disease.

The ophthalmopathy may be considered severe also on the basis of an overall evaluation of ocular involvement, even though the individual parameters may not be necessarily severe (Table 1). For example, a patient with mild degrees of proptosis (19-20 mm), especially if progressive, inconstant diplopia (i.e., not present in primary or reading gaze positions), subclinical evidence of optic neuropathy, and mildto-moderate degrees of inflammatory (or congestive) soft tissue involvement has an overall ocular situation that can be considered as (moderately) severe. It is evident that this kind of assessment of GO severity is somehow arbitrary and may need to be reconsidered and validated by expanding the use of quantitative measures. Subjective symptoms, for the reasons discussed above, cannot be neglected in the overall assessment of eye status.

A different concept refers to the activity of the disease. The natural history of GO is not completely understood, but it seems that the ophthalmopathy undergoes an initial, active phase of progressive exacerbation, followed by a subsequent partial regression and a static, inactive phase in which the residual manifestations of the disease (e.g., proptosis, strabismus due to fibrotic changes of the extraocular muscles) are unlikely to show any further substantial change (16). If this model is correct, it is evident that the activity of the ophthalmopathy is neither synonymous nor coincident with the severity of the disease. In other words, an individual patient 


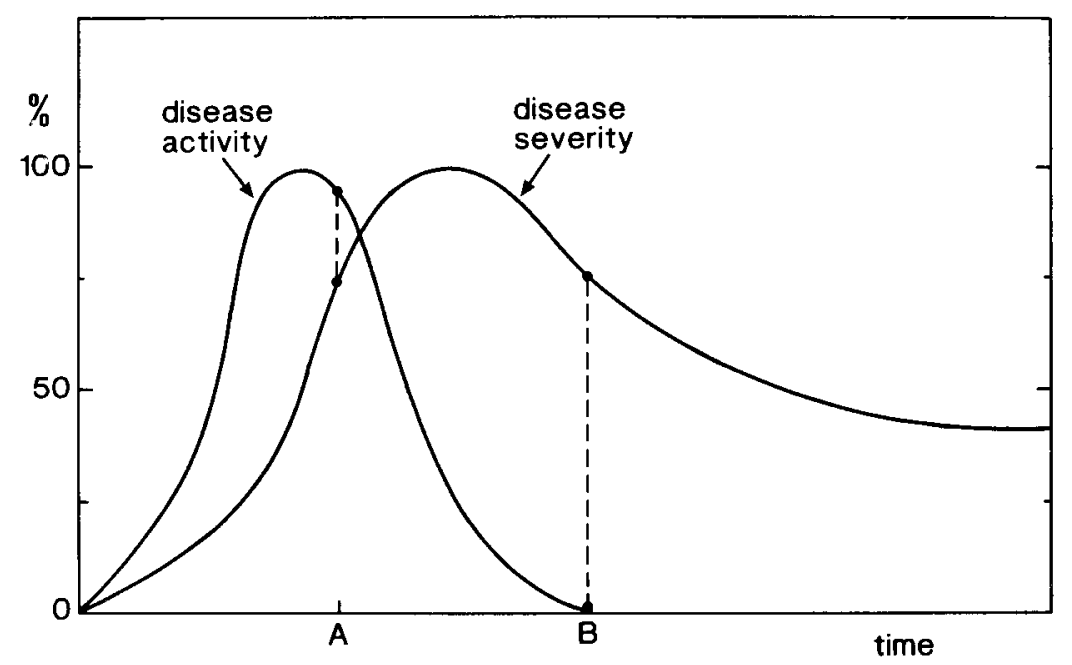

FIG. 3. Hypothetical relationship between disease activity and severity in the natural history of GO. [Reproduced with permission from W. M. Wiersinga and M. F. Prummel: J Clin Endocrinol Metab 80:345-347, 1995 (133). () The Endocrine Society.]

may have severe ocular manifestations, but the disease may have run its course (Fig. 3). To assess the activity of the ophthalmopathy, Mourits and co-workers (80) proposed a clinical activity score (CAS), which in its original formulation included 10 different items (Table 2), mainly, but not solely, reflecting inflammatory changes: giving one point to each manifestation, a score is obtained, with a range from 0 (no activity) to 10 (highest activity). This group recently evaluated the usefulness of this score in predicting the outcome of either radiotherapy or oral prednisone treatment in patients with moderately severe GO (81). They found a significantly higher CAS in the 22 responders than in the 21 nonresponders: using a cut-off point of 4 , CAS could accurately predict the outcome of therapy, since 12 of 15 patients with CAS $>4(80 \%)$ had a favorable outcome of treatment (81). It should, however, be pointed out that 10 of 22 responders $(45 \%)$ had a CAS of 4 or less (81). Thus, it would appear that, while a high CAS is usually predictive of a good response to treatment, a low CAS does not necessarily rule out a possible favorable outcome of therapy. A slightly modified CAS, which does not include some of the items originally proposed by Mourits et al. (80), was indicated by an ad hoc committee of the four Thyroid Societies as a tool to record ocular changes over time after treatment of ophthalmopathy (82) (Table 2). Gorman (83) recently stated that the activity of the ophthalmopathy is indeed difficult to define, and some of the items included in the calculation of CAS, such as periorbital swelling, caruncle edema, and chemosis, may well reflect congestion rather than inflammation.

Other indicators of disease activity have been proposed (Table 3). Prummel et al. (84) evaluated the internal reflectivity of eye muscles on A-mode ultrasonography in a series of 16 patients with moderately severe and untreated GO. They found that GO patients had lower reflectivity than control subjects; among GO patients, reflectivity was lower in responders to immunosuppressive treatment than in nonresponders, and a value of $40 \%$ or less appeared to have a high $(73 \%)$ positive predictive value of subsequent response to treatment (84). The true significance of these findings awaits confirmation in more extensive studies.
Kahaly and co-workers (85-87) reported, in a series of studies, that patients with active GO have increased plasma concentration and urinary excretion of GAG that tend to decrease after immunosuppressive management of the disease. The value of urine or plasma GAG determination in the assessment of GO activity, however, remains to be precisely defined.

A prolongation of $\mathrm{T} 2$ relaxation time at MRI has been found in GO patients with active eye disease, and the response to immunosuppressive therapy has been associated with a decrease in this parameter (88). However, the MRI signal recognizes fluid accumulation and does not necessarily reflect inflammation.

After the initial report by Postema et al. (89) concerning the orbital uptake of $\left[{ }^{111} \mathrm{In}\right]$ octreotide in GO patients, some groups have applied this receptor-mediated scintigraphy (octreoscan) to the evaluation of the disease. While some (89, 90) but not all studies (91-93) found a higher uptake of the tracer in patients with more severe forms of ophthalmopathy, all studies indicated a relationship between the octreoscan positivity and the activity of the disease: the orbital octreotide accumulation was higher in patients with active ophthalmopathy than in those with inactive eye disease $(90$, 91), implying also that GO patients with positive octreoscans might have a successful outcome of medical therapy. In this regard, a positive predictive value of $90-92 \%$ has been reported $(94,95)$. In addition, successful management of ophthalmopathy has been associated with a decrease in orbital octreotide uptake $(90,93)$. However, as recently pointed out by Wiersinga et al. (96), data on the accuracy and precision of this expensive and rather nonspecific technique are too limited to propose it as a mandatory indicator of GO activity or as a tool to identify patients prone to respond to immunomodulatory treatment.

Thus, the reliability of the proposed indicators of activity of GO (CAS, internal eye muscle reflectivity at ultrasound, GAG determination in urine or plasma, T2 relaxation time at MRI, positive octreoscan) must still be demonstrated with certainty. Gorman (83) stated that it may be preferable to define measurable attributes (lid fissure width, range of ex- 
TABLE 2. Clinical activity score

Original formulation $^{a}$

Painful, oppressive feeling on or behind the globe

Pain on attempted up, side, or down gaze

Redness of the eyelids

Diffuse redness of the conjunctiva

Chemosis

Swollen caruncle

Edema of the eyelids

Increase of $2 \mathrm{~mm}$ or more in proptosis in the last 1-3 months

Decrease in visual acuity in the last $1-3$ months

Decrease in eye movements of 5 degrees or more in the last 1-3 months
Revised formulation ${ }^{b}$

Spontaneous retrobulbar pain

Pain on eye movements

Eyelid erythema

Conjunctival injection

Chemosis

Swelling of the caruncle

Eyelid edema or fullness

${ }^{a}$ According to Mourits et al. (80).

${ }^{b}$ As proposed by an ad hoc committee of the four Thyroid Sister Societies (82). The clinical activity score is calculated by assigning one point to each manifestation and summing the points.

TABLE 3. Proposed indicators of the activity of Graves' ophthalmopathy

\begin{tabular}{lll}
\hline \multicolumn{1}{c}{ Parameter } & \multicolumn{1}{c}{ Active GO } & \multicolumn{1}{c}{ Ref. } \\
\hline Clinical activity score (CAS) & CAS of 4 or more & Br J Ophthamol 73:639-644, 1989 \\
Eye muscle reflectivity (EMR) on A-mode ultrasonography & EMR of 40\% or less & Ophthalmology 100:556-561, 1993 \\
Glycosaminoglycan (GAG) serum or urine concentration & Increased levels & Thyroid 8:429-432, 1998 \\
T2 relaxation time at MRI & Prolonged T2 relaxation time & Thyroid 5:185-193, 1995 \\
Octreoscan & High orbital uptake & J Nucl Med 36:550-554, 1995 \\
\hline
\end{tabular}

traocular muscle motion, diplopia fields, volume of extraocular muscle, and connective tissue) rather than to speculate on the activity of the ophthalmopathy. However, identification of active forms of the disease, especially in cases with moderately severe ophthalmopathy, may be crucial for the prediction of the subsequent response to treatment and, therefore, for deciding whether an individual patient needs to be treated medically or surgically. Since a good correlation between octreoscan results and T2 relaxation time at MRI (90) or CAS $(89,93)$ has been reported, it is possible that a combination of the different parameters discussed above may provide a better definition and identification of patients with active GO, but this remains to be established.

To summarize, severity and activity of GO are not synonymous, but both are important in deciding whether a given patient requires treatment for his/her ophthalmopathy and which type of treatment is indicated. Duration of eye disease per se is less relevant for the therapeutic decision, although it is reasonable to assume that long-lasting ( $>2 \mathrm{yr}$ ) eye disease has limited features of activity. If the ophthalmopathy is nonsevere, no aggressive medical or surgical treatment is required, even though the disease shows some signs of activity. If the patient has severe ocular involvement, assessment of the degree of activity is important: patients with active eye disease are likely to respond to medical treatment (especially glucocorticoids and/or orbital radiotherapy), whereas such a treatment is unlikely to be of benefit in patients with inactive GO, who are then candidates for surgical treatment (orbital decompression or rehabilitative surgery) (see Section III.B).

\section{B. How to treat?}

Even though the pathogenetic mechanisms of GO are still incompletely understood, the resulting changes occurring in the orbit, i.e., the swelling of retrobulbar fibroadipose tissue and extraocular muscles and the dysfunction of extraocular muscles, can readily explain the clinical expression of eye disease (4). Proptosis, which can be considered a sort of "nature's decompression" (83), causes stare and, together with lid retraction, exposure keratitis responsible for foreign body/gritty sensation, pain, lacrimation, and photophobia. Extraocular muscle dysfunction causes restriction of eye movements with diplopia and blurring of vision. The increased orbital content may lead to optic nerve compression, with impaired color vision and decreased visual acuity. Inflammation, but also the venous engorgement suggested by the increased size of the superior ophthalmic vein $(97,98)$, coincide with periorbital swelling.

If this is the mechanical basis of GO, treatment should be aimed either at reducing the volume of the orbital content or at increasing the available space in the orbit. The former ("medical decompression") utilizes drugs (e.g., glucocorticoids) or treatments (e.g., orbital radiotherapy) that may reduce the ongoing inflammation by nonspecific actions or by intervening in the putative causes of the disease. Surgical decompression is not intended to act on the etiology of ophthalmopathy, but only on the mechanical effects of eye disease. Supporters of medical decompression underscore the possibility that medical treatment may avoid surgery or reduce the activity of inflammation so as to improve the outcome of subsequent surgery (99). Supporters of surgical decompression emphasize the immediate effectiveness of surgery and the not-infrequent failure or partial effectiveness of conservative approaches. The choice between medical and surgical decompression, in addition to the assessment of GO activity, ultimately depends on several considerations. These include the local availability of experienced orbit surgeons or skillful radiotherapists, the existence of contraindications to glucocorticoid treatment, and the lack of a prompt response of sight-threatening manifestations, such as optic neuropathy, to medical treatment. It should be pointed out that selection of surgical decompression does not exclude the sub- 
sequent need for glucocorticoids or orbital radiotherapy to eliminate the disease. On the other hand, selection of medical decompression does not preclude the subsequent utilization of surgical decompression if functional and/or rehabilitative results are not satisfactory.

In a recent survey of members of the European Thyroid Association, the majority of European thyroidologists selected glucocorticoid treatment for the index case, and 23\% preferred orbital radiotherapy, but orbital decompression was not widely indicated as the first-line treatment (100). Surgical treatment is preferred by prestigious institutions, such as the Mayo Clinic, with a wide experience in this approach. As pointed out in a recent commentary, the wide divergence in the therapeutic approach to GO reflects also the current lack of knowledge as to the best practice (101). It is conceivable that the development of guidelines for the treatment of the eye disease by an ad hoc international committee might make the approach to the management of this disease more uniform and standardized, and improve the outcome of therapy, either medical or surgical. However, more numerous controlled and randomized studies on a large number of patients are necessary before such consensus guidelines can be developed.

\section{How to assess the effects of treatment?}

A great deal of controversy on the results of the treatment of GO reported in the different series depends on several factors. Many available studies have been retrospective and might have introduced biases in the selection of patients, in particular because of the frequent lack of control groups. Control groups of patients not receiving a given treatment are essential to rule out the possibility that observed ocular changes are related to the natural history of the disease. The enrollment of patients with different degrees of severity or activity of the ophthalmopathy might also have contributed to conflicting results.

Of greatest importance is the manner in which the effects of treatment have been assessed in the different series. In many past studies, the assessment of treatment outcome was based mostly on variations of exophthalmometer readings, while other relevant expressions of eye disease were discounted. A substantial improvement was provided by Donaldson et al. (102), who introduced a numerical score (ophthalmopathy index, OI) based on the NOSPECS [N, No signs or symptoms; $\mathrm{O}$, only signs, no symptoms; $\mathrm{S}$, soft tissue involvement; $\mathrm{P}$, proptosis; $\mathrm{E}$, extraocular muscle involvement; $C$, corneal involvement; $S$, sight loss (due to optic nerve involvement)] classification of eye changes of Graves' disease. In this numerical system each class of eye changes received a score from 0 to 3 according to the degree of involvement; after the scores were added, an OI was derived, ranging from 0 to 15 (102). For many years and in many studies, the OI represented the tool for the assessment of the effects of different treatments. Although it undoubtedly represented a major advancement toward a standardization of ocular evaluation, the OI was then criticized, owing to its intrinsic limitations. These included 1) its high dependence on subjective, rather than objective, evaluation; 2) the same weight given to eye manifestations of different severity and danger (e.g., soft tissue changes vs. optic neuropathy); 3 ) the difficulty in recording subtle changes in the different categories of eye involvement; and 4) the fact that patients do not progress from one class to another in a sequential fashion. In other studies, different numerical scores have been used, such as the total eye score, which gave different weight to the various items (103). Alternatively, clinical responses received an overall evaluation (excellent, good, fair, no responses) (102). However, these approaches did not completely solve the problem of standardization of ocular assessment and of the evaluation of treatment results.

An ad hoc committee of the four Thyroid Sister Societies (82) proposed a revised classification of eye changes of Graves' disease, in which the criteria to evaluate the different classes of eye involvement were indicated. Most parameters received a quantitative evaluation, although there was some space left for semiquantitative (CAS) or qualitative (patient's self-assessment) criteria (80). Most importantly, it was stated that 1 ) the NOSPECS classification could be maintained as a mnemonic aid for bedside evaluation of the patient; and 2) NOSPECS-derived numerical scores should no longer be used for reporting results of treatment, which should be described by specific and separate measurements derived from the revised classification of GO. This classification has not been revised since 1992 and needs to be validated. However, among other views, Gorman (83) is of the opinion that, because the proximate causes of GO are the swelling of extraocular muscles and retrobulbar fibro-adipose tissue, and the shortening and restricted contraction of extraocular muscles, assessment of the effects of treatment should basically rely on some relevant measurements, i.e., volume of extraocular muscles, volume of retrobulbar fibro-adipose tissue, proptosis, lid fissure width, range of extraocular motion on perimeter, and quantitation of diplopia fields. Other parameters, such as optic nerve function, periorbital edema, conjunctival injection, and chemosis, although useful to appraise the clinical effectiveness of treatment, should, in Gorman's opinion, be regarded as secondary to the above proximate causes of GO (83). The validity of the CAS has also been criticized because of the difficulty in defining the activity of the disease (83) or the inclusion of symptoms or less readily assessable signs (104). These issues should represent a matter of argument for a new consensus on GO.

To summarize, recent years have witnessed an improvement in the assessment of ocular changes after treatment, owing to the introduction of more objective, quantitative measurements. This trend toward quantitation of changes should be further enhanced and encouraged, ideally as the result of a new consensus among international experts in this field. The standardization of ocular evaluation is crucial for a correct assessment of the results of treatment.

\section{Management of Nonsevere Graves' Ophthalmopathy}

Most patients with Graves' disease have mild ocular manifestations that do not require any aggressive treatment. In these cases the ophthalmologist can suggest simple local supportive measures that are usually sufficient to obtain 
symptomatic relief until eye disease becomes inactive (Table 4 and Ref. 6). A change in sleep position and elevation of the bed may be of some help to reduce periorbital edema; however, it is open to debate whether diuretics, used in the past, are useful in this regard (105). Photophobia can be alleviated by the use of sunglasses; the foreign body/gritty sensation related to a defective tear film is usually controlled by the use of artificial tears or ointments (6). If lagophthalmos is present, as suggested by tearing and eye irritation in the morning, taping the eyelids shut during the night is useful to prevent nocturnal corneal drying (6). Guanethidine or $\beta$-blocking eye drops have been used for eyelid retraction (105). The longterm efficacy of guanethidine eye drops is questionable, and side effects, including ptosis, miosis, vasocongestion, and punctate keratitis, have been reported (105). $\beta$-Blocking eye drops have also been used with variable degrees of success. Prisms may be beneficial for correction of mild diplopia if they are tolerated by the patient (106). In this regard, stick-on prisms allow a greater flexibility than ordinary prisms.

Thus, in patients with nonsevere ophthalmopathy, the most important therapeutic measure is probably to reassure the patient that the chance that his/her ophthalmopathy progresses to more severe forms is very low and the chance of a spontaneous, although in many instances incomplete, regression is high. Elimination of controllable risk factors for the progression of the ophthalmopathy (e.g., smoking) may be very important, even though controlled trials on the effects of smoking withdrawal are lacking (see Section IX. B).

\section{Management of Severe Graves' Ophthalmopathy}

Management of severe GO represents a difficult task that does not constantly provide favorable results. Recent years have seen the proposal of novel treatments that add to the list of established treatments (glucocorticoids, orbital radiotherapy, orbital decompression) (Table 5).

\section{A. Established treatments}

1. Glucocorticoids. Glucocorticoids represent a well established method of treatment of GO (107), employed in the management of this disease for more than $40 \mathrm{yr}$. The drug is often effective on GO owing to its antiinflammatory and immunosuppressive actions, including interference with the function of $\mathrm{T}$ and $\mathrm{B}$ lymphocytes, reduction in the recruitment of neutrophils, monocytes, and macrophages in the inflamed area, inhibition of the function of immunocompe-

TABLE 4. Management of nonsevere Graves' ophthalmopathy

\begin{tabular}{ll}
\hline \multicolumn{1}{c}{ Therapeutic measure } & \multicolumn{1}{c}{ Sign and/or symptom } \\
\hline $\begin{array}{l}\text { Sunglasses } \\
\text { Artificial tears and ointments } \\
\beta \text {-Blocking eye drops }\end{array}$ & $\begin{array}{l}\text { Photophobia } \\
\text { Foreign body sensation } \\
\end{array}$ \\
$\begin{array}{l}\text { Eyelid retraction; } \\
\text { increased intraocular } \\
\text { pressure }\end{array}$ \\
$\begin{array}{l}\text { Nocturnal taping of the eyes } \\
\begin{array}{l}\text { Correction of hyper- or hypothyroidism } \\
\text { Elimination of risk factors (smoking) } \\
\text { Reassurance on the natural history } \\
\text { of the disease }\end{array}\end{array}$ \\
\hline
\end{tabular}

TABLE 5. Management of severe Graves' ophthalmopathy

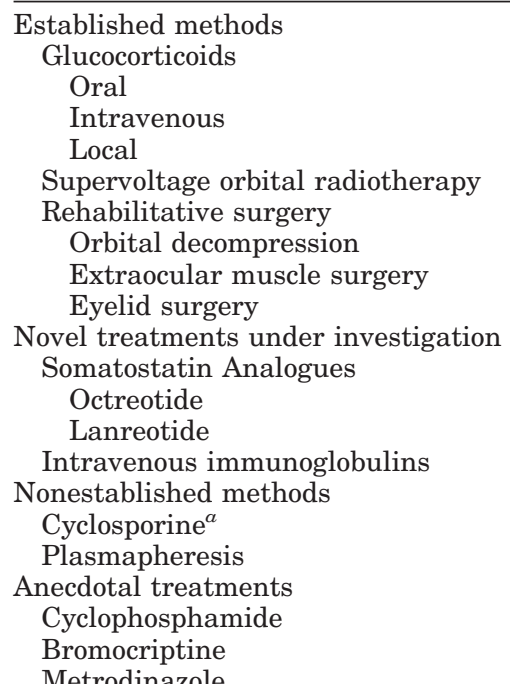

${ }^{a}$ Combination therapy of cyclosporine and prednisone has been shown to be significantly more effective than either monotherapy; this combined treatment may, therefore, be regarded as a second line, alternative method, especially in patients with diabetes mellitus in whom both high doses of glucocorticoids and orbital radiotherapy should be used with caution.

tent cells, and inhibition of the release of mediators, including cytokines (108). In addition, glucocorticoids decrease GAG synthesis and secretion by orbital fibroblasts $(109,110)$.

Glucocorticoids have been used in GO through different routes: oral, local (retrobulbar or subconjunctival), and, more recently, intravenous (6). Oral glucocorticoids have usually been employed at high doses (prednisone, $60-100 \mathrm{mg} /$ day, or equivalent doses of other steroids) and for prolonged periods of time (several months) (6). Many studies have documented a high effectiveness of high-dose oral glucocorticoids on soft tissue changes and optic neuropathy, whereas the decrease in proptosis and the improvement in ocular motility have not always been impressive $(1,6,108)$. Recurrence of active eye disease is a rather frequent problem with oral glucocorticoid therapy, not only when the drug is withdrawn, but also when its dose is tapered down (6). Interestingly, in one study the rate of recurrence was abated when cyclosporine was administered concomitantly with and after glucocorticoid therapy (111). Prummel and co-workers (112) reported that the percentage of a cohort of patients with moderately severe ophthalmopathy who responded successfully to prednisone therapy $(14 / 28$, $50 \%$ ) was not significantly different from that of patients who had favorable responses to orbital radiotherapy alone $(13 / 28$, $46 \%$ ). In summary, favorable effects of high-dose oral glucocorticoids are reported in slightly more than $60 \%$ of cases (range, 40-100\%) (Table 6).

In the last $10 \mathrm{yr}$ or so, glucocorticoids have also been used intravenously (Table 7), by the acute administration of high doses of methylprednisolone acetate $(0.5-1 \mathrm{~g})$ at different intervals. The cumulative dose of steroid ranges $1-21 \mathrm{~g}$ in different studies. In general, favorable effects have been observed on inflammatory signs and optic nerve involvement, whereas the effects on extraocular muscle involvement, and especially proptosis, have not been constantly impressive. 
TABLE 6. Results of oral glucocorticoid therapy for Graves' ophthalmopathy

\begin{tabular}{|c|c|c|c|c|}
\hline \multirow{2}{*}{ Author } & \multirow{2}{*}{$\begin{array}{l}\text { No. of } \\
\text { patients }\end{array}$} & \multicolumn{2}{|c|}{ Responders } & \multirow{2}{*}{ Ref. } \\
\hline & & Number & $\%$ & \\
\hline Hoffenberg & 5 & 2 & 40 & Lancet 1:693, 1958 \\
\hline Evans & 11 & 8 & 72 & Trans Ophthalmol Soc UK 81:657, 1961 \\
\hline Brown & 19 & 15 & 80 & Am J Med 34:786, 1963 \\
\hline Werner & 2 & 2 & 100 & Lancet $1: 1004,1966$ \\
\hline Day & 10 & 10 & 100 & Arch Ophthalmol 79:262, 1968 \\
\hline Mulherin & 2 & 1 & 50 & South Med J 65:77, 1972 \\
\hline Apers & 12 & 6 & 50 & Ophthalmologica 173:163, 1966 \\
\hline Bartalena & 12 & 5 & 42 & J Clin Endocrinol Metab 56:1139, 1983 \\
\hline Kahaly & 20 & 12 & 60 & Eur J Clin Invest $16: 415,1986$ \\
\hline Wiersinga & 44 & 29 & 64 & Ophthalmologica 197:75, 1988 \\
\hline Prummel & 18 & 11 & 61 & N Engl J Med 321:1353, 1989 \\
\hline Prummel & 28 & 14 & 50 & Lancet $2: 949,1993$ \\
\hline Kung & 10 & 6 & 60 & Thyroid 6:381, 1996 \\
\hline Kahaly & 19 & 12 & 63 & Clin Exp Immunol 106:197, 1996 \\
\hline Total & 212 & 133 & 63 & \\
\hline
\end{tabular}

TABLE 7. Results of intravenous glucocorticoid therapy for Graves' ophthalmopathy

\begin{tabular}{|c|c|c|c|c|c|c|}
\hline \multirow[b]{2}{*}{ Author } & \multirow[b]{2}{*}{$\begin{array}{l}\text { No. of } \\
\text { patients }\end{array}$} & \multicolumn{2}{|c|}{ Responders } & \multicolumn{2}{|c|}{ Associated treatments } & \multirow[b]{2}{*}{ Ref. } \\
\hline & & Number & $\%$ & $\begin{array}{c}\text { Oral } \\
\text { glucocorticoids }\end{array}$ & Radiotherapy & \\
\hline Nagayama & 5 & 3 & 60 & 2 & 3 & Acta Endocrinol (Copenh) 116:513, 1987 \\
\hline Kendall-Taylor & 11 & 8 & 73 & 11 & 0 & Br Med J 297:1574, 1988 \\
\hline Dandona & 37 & 32 & 86 & $37^{a}$ & 0 & Br Med J 298:830, 1989 \\
\hline Guy & 5 & 5 & 100 & 5 & 5 & Ophthalmology 96:1048, 1989 \\
\hline Hiromatsu & 15 & 12 & 80 & 15 & 0 & Endocrine J 40:63, 1993 \\
\hline Koshiyama & 8 & 8 & 100 & 0 & 8 & Thyroid 4:409, 1994 \\
\hline Mori & 9 & 3 & 33 & 9 & 0 & Endocrine J 42:442, 1995 \\
\hline Tagami & 27 & 27 & 100 & 27 & 12 & Endocrine J 43:689, 1996 \\
\hline Chang & 22 & 12 & 54 & 22 & 0 & Acta Ophthalmol Scand 75:301, 1997 \\
\hline Matejka & 8 & 7 & 87 & 8 & 0 & Horm Metab Res 30:93, 1998 \\
\hline Colao & 10 & 4 & 40 & 0 & 0 & J Clin Endocrinol Metab 83:3790, 1998 \\
\hline Total & 157 & 121 & 77 & 136 & 28 & \\
\hline
\end{tabular}

${ }^{a}$ Azathioprine was also used in 19 patients.

Mori et al. (113) noted that methylprednisolone acetate treatment ( $1 \mathrm{~g}$ for 3 days repeated twice) was more effective in patients with severe ophthalmopathy than in those with mild disease, especially in those with the highest TSH-R antibody levels before treatment. Interestingly, in an uncontrolled study, the positivity of the orbital scintigraphy with ${ }^{111} \mathrm{In}-$ diethylenetriamine-pentaacetic acid-D-Phe ${ }^{1}$ octreotide appeared to predict the subsequent favorable outcome of glucocorticoid therapy (114).

As summarized in Tables 6 and 7 and in Fig. 4, the results seem to indicate a higher percentage of favorable results in patients treated with intravenous glucocorticoids, compared with patients treated with oral glucocorticoids. However, results must be interpreted with caution for several reasons. First, in almost all published series, intravenous glucocorticoids have been associated with, in the interpulse periods, or followed by (often prolonged) treatment with oral glucocorticoids, making it difficult to ascertain the relative role of the two treatments. In addition, in some studies orbital radiotherapy or azathioprine treatment has been associated with intravenous glucocorticoids. Second, no randomized, prospective study has thus far compared directly the two modalities of glucocorticoid administration. Finally, biases in the selection of patients, especially concerning different de- grees of disease activity and duration, might have influenced the reported results. Therefore, randomized, prospective studies are needed to address the problem of whether the intravenous route actually provides advantages over the oral route, not only in terms of effectiveness, but also in terms of tolerability, side effects, and complications.

A major drawback of systemic glucocorticoid therapy is indeed represented by its possible side effects and complications. Apart from the very common, although transient, cushingoid features, adverse effects, such as diabetes, depression, reactivation of chronic diseases, infections, hypertension, osteoporosis, increased body weight, peptic ulcer, hirsutism, and cataract, have been reported during prolonged glucocorticoid therapy for GO (6), although their precise prevalence is uncertain. In a series of 28 patients receiving oral prednisone treatment, major side effects (severe depression, recurrent herpes zoster infection) occurred in 2 patients, and moderate side effects (hypertension, severe pyrosis, hirsutism, behavioral changes, weight gain, cushingoid face) occurred in 18 (112).

This prompted the evaluation of local (retrobulbar or subconjunctival) glucocorticoid therapy. After discrepant results of uncontrolled studies, in a prospective study we submitted 44 patients to combined treatment with orbital radiotherapy 


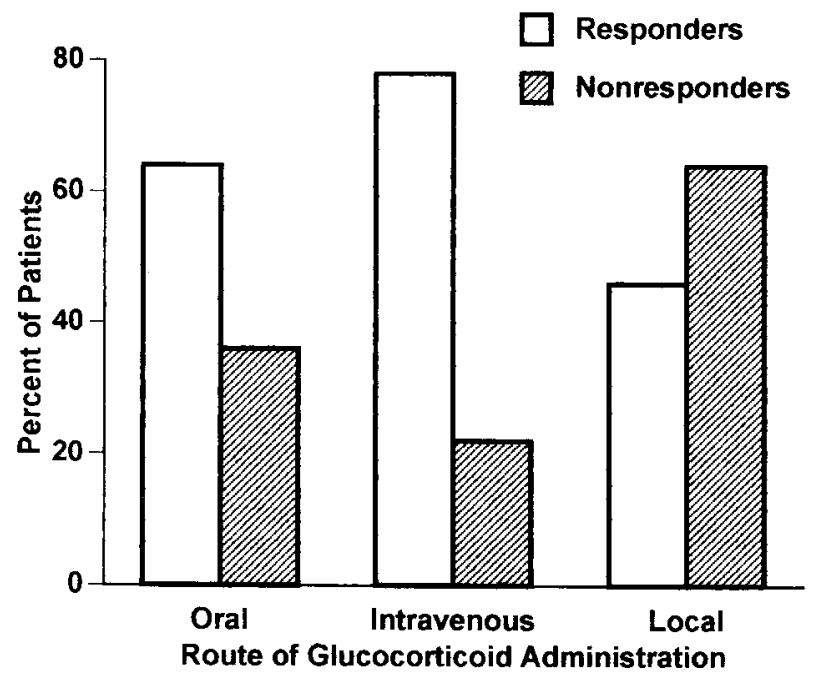

Fig. 4. Overall results of glucocorticoid therapy administered through the oral, intravenous, or local (subconjunctival or retrobulbar) routes on GO. See Section V.A.1 for details of individual studies.

and retrobulbar glucocorticoids (14 injections of $40 \mathrm{mg}$ methylprednisolone acetate at 20- to 30-day intervals): excellent or good results were observed only in 11 patients $(25 \%)$ compared with $60 \%$ of favorable responses in patients receiving oral glucocorticoids (115). As illustrated in Fig. 4, the overall results of local glucocorticoid therapy appear less satisfactory than those obtained with the systemic administration of steroids. However, side effects are limited to transient ocular discomfort or pain; rare cases of conjunctival hemorrhages have been reported. Thus, local glucocorticoid therapy may be considered in patients with active ophthalmopathy and with major contraindications to the systemic administration of glucocorticoids (6).

In summary, glucocorticoids remain a fundamental therapeutic tool for GO. Glucocorticoids are particularly effective on active disease, soft tissue inflammatory changes, and optic neuropathy, but also on extraocular muscle dysfunction (if not associated with fibrotic changes). Proptosis appears to be influenced to a lesser extent by this treatment. A substantial proportion of patients $(20-40 \%)$ respond only partially or do not respond at all to glucocorticoid treatment. It is conceivable that the effectiveness of treatment may be improved by properly selecting patients who are prone to have beneficial results, i.e., those with a high degree of disease activity, with ophthalmopathy of recent onset and/or with evidence of recent progression of eye involvement. If glucocorticoids are selected, the systemic route appears more effective than the local route, although it is more frequently associated with adverse effects. Intravenous administration appears to bear advantages over the oral administration in terms of effectiveness and possibly of side effects, but this remains to be proven by randomized studies. Since recurrences are not infrequent when the drug is tapered or withdrawn, glucocorticoid treatment needs to be continued for several months.

2. Orbital radiotherapy. External radiotherapy has been used for GO for almost $60 \mathrm{yr}$ and still represents a mainstay in the management of the disease (116). It was initially directed to the hypothalamus and the pituitary, based on the assumption that the ophthalmopathy might be due to an exophthalmogenic factor of pituitary origin or to hypothalamic dysfunction (116). Subsequently, irradiation was correctly directed to the orbital tissue, the true target of the pathological process.

The rationale for the use of radiotherapy for GO resides both in its nonspecific antiinflammatory effect and in the high radiosensitivity of lymphocytes infiltrating the orbital space (117). Lymphocytes are generally suppressed with relatively low doses of radiation, and the helper/suppressor $\mathrm{T}$ lymphocyte ratio is also altered by radiotherapy (116). In addition, radiotherapy might also reduce GAG production by orbital fibroblasts (118). Whether the reported effectiveness of orbital radiotherapy in GO is related either to its nonspecific antiinflammatory action, or to specific immunosuppressive effects, or both remains to be clarified.

Many of the limitations encountered with the old orthovoltage apparatus, such as the low energy and the relevant side scatter of irradiation, were overcome by the introduction of high-energy apparatus (cobalt unit and, especially, linear accelerator), which allowed a better collimation, a limited side scatter, and low penumbra (119). Donaldson and coworkers (102) were the first to use a 4-6-megavolt linear accelerator in a group of 23 patients with severe GO, who had an OI ranging from 4 to 12 . Excellent or good results were obtained in 15 patients (65\%), even in those who had previously responded poorly to systemic glucocorticoid treatment; results were less favorable in patients with longstanding eye disease and more frequently satisfactory in patients with a rapid progression of eye disease (102). While all categories of ocular manifestations responded to radiotherapy, long lasting extraocular muscle involvement appeared to be least responsive (102). Beneficial effects, especially on soft tissue changes and optic neuropathy, have been reported in other subsequent studies, while the reduction in proptosis and the improvement in ocular motility, especially if longstanding, have often been less impressive (120). In a large series of 311 patients treated with different radiation doses, factors that apparently influenced the outcome of radiotherapy in a negative manner included male gender, advanced age, need for concomitant treatment of hyperthyroidism, and no history of hyperthyroidism (121).

At present, most centers utilize linear accelerators delivering 4-6 megavolts and use a $4 \times 4$-cm lateral field slightly angled posteriorly to avoid as much as possible irradiation to the contralateral lens. The use of higher energy sources have not proven to be particularly advantageous. The most common delivered dose is 20 grays (Gy) per eye (117); this cumulative dose is usually fractionated in 10 daily doses over a 2-week period to reduce the cataractogenic effect of irradiation (116). Nakahara et al. (122) reported that a cumulative dose of 24 Gy provided better results than a dose of $10 \mathrm{~Gy}$. Recently, Kahaly et al. (123) reported that a therapeutic scheme of 1 Gy per week over a 20-week period was equally effective and possibly better tolerated than the classical 2 -week scheme. The use of higher cumulative doses of radiation (30 Gy vs. 20 Gy) does not produce any increase in the effectiveness of treatment (121). Thus, at present it would 
appear that the dose of 20 Gy should be considered the optimal dose for orbital radiotherapy of GO.

Orbital radiotherapy is usually well tolerated. It may be associated with a transient exacerbation of inflammatory eye signs and symptoms (102), but this is unlikely to occur if glucocorticoids are concomitantly administered (124). Cataract is a possible complication of irradiation to the lens, but fractionation of the dose should maintain the radiation exposure of the lens below the threshold dose for radiationinduced cataract (116). Radiation retinopathy is an extremely rare complication of radiotheraphy (125); probably errors in dosage calculation and radiation technique account for most of the few reported cases (126), but some cases remain unexplained (127). Systemic microvascular disease due to diabetes mellitus or to previous chemotherapy may increase the risk for radiation retinopathy. Tallstedt et al. (128) reported increased retinopathy in all 3 patients who had diabetic retinopathy before radiotherapy. Thus, although there is no consensus view on this issue, it is reasonable to regard this condition as a contraindication to orbital radiotherapy for GO (117). Transient blindness attributed to nonvascular involvement of the optic nerve was reported in one patient (129).

A major concern relates to the possibility that orbital radiotherapy may be carcinogenic. Snijders-Keilholz et al. (130) calculated a theoretical risk of $1.2 \%$ for the occurrence of secondary tumors. This view is not shared by other authors (131), who estimated a theoretical risk of $0.3 \%$. A proper answer to this question should be provided by a careful reevaluation of patients with a long (15-20 yr or more) follow-up period after irradiation. So far, no case of secondary tumor after orbital radiotherapy for GO has been reported in the literature (117). Nevertheless, it seems prudent to avoid irradiation in young (possibly $<30 \mathrm{yr}$ ) patients.

In summary, the available studies have reported, with few exceptions, overall favorable effects of orbital irradiation in about $60 \%$ of GO patients (Table 8 ). It should be mentioned that in a recent double-blind prospective study in which 42 patients received orbital radiotherapy only to one orbit, no significant differences were observed between the treated and the untreated orbit (132). It is possible that these negative results are related to the selection of patients, because only patients with mild-to-moderate GO were enrolled (132).

According to most studies, orbital radiotherapy is especially effective on soft tissue inflammatory changes and recent extraocular muscle involvement, but also on optic neuropathy. It should be mentioned that the effects of orbital radiotherapy may take several days to weeks to become manifest. Accordingly, orbital radiotherapy, especially if used alone, may not represent the ideal treatment in patients with optic nerve compression and increasing visual field loss. Proptosis is often scarcely responsive to irradiation. As for glucocorticoids, orbital radiotherapy is more effective in patients who have active eye disease with recent progression. Orbital radiotherapy, when properly performed, appears to be a safe procedure with limited side effects.

3. Orbital radiotherapy combined with glucocorticoids. Orbital radiotherapy and systemic glucocorticoids can be used for GO either alone or in combination. Prummel and co-workers (112) reported in a randomized study that orbital radiotherapy and oral glucocorticoids, used as a single therapeutic agent, had similar effectiveness on the ophthalmopathy. This led the Dutch group to propose that orbital radiotherapy be considered the treatment of choice in patients with moderately severe GO, i.e., without sight-threatening manifestations, in view of its better tolerability compared with glucocorticoid therapy (133). In two randomized, prospective studies we showed that orbital radiotherapy combined with high-dose oral glucocorticoids was more effective than either orbital radiotherapy alone (134) or oral glucocorticoids alone (124). In addition to these synergistic effects, the combined

TABLE 8. Results of supervoltage orbital radiotherapy for Graves' ophthalmopathy

\begin{tabular}{|c|c|c|c|c|}
\hline \multirow{2}{*}{ Author } & \multirow{2}{*}{$\begin{array}{c}\text { No. of } \\
\text { patients }\end{array}$} & \multicolumn{2}{|c|}{ Responders } & \multirow{2}{*}{ Ref. } \\
\hline & & Number & $\%$ & \\
\hline Donaldson & 23 & 15 & 65 & J Clin Endocrinol Metab 37:276, 1973 \\
\hline Covington & 7 & 5 & 71 & Radiology 122:797, 1977 \\
\hline Trobe & 6 & 3 & 50 & Arch Ophthalmol 96:1199, 1976 \\
\hline Teng & 20 & 7 & 35 & Clin Endocrinol (Oxf) 13:545, 1980 \\
\hline Grauthoff & 10 & 8 & 80 & Strahlentherapie $154: 469,1980$ \\
\hline Fritsch & 15 & 3 & 20 & Strahlentherapie 157:305, 1981 \\
\hline Yamamoto & 9 & 4 & 45 & Endocrinol Jpn 29:495, 1982 \\
\hline Brennan & 14 & 10 & 71 & Am J Ophthalmol 96:195, 1983 \\
\hline Hurbli & 63 & 35 & 56 & Am J Ophthalmol 99:633, 1985 \\
\hline van Ouwerkerk & 24 & 14 & 60 & $J$ Endocrinol Invest 8:241, 1985 \\
\hline Olivotto & 28 & 19 & 68 & Int J Radiat Oncol Biol Phys 11:2085, 1985 \\
\hline Pigeon & 21 & 12 & 51 & Horm Res 26:172, 1987 \\
\hline Palmer & 29 & 14 & 48 & Int J Radiat Oncol Biol Phys 13:1815, 1987 \\
\hline Wiersinga & 39 & 25 & 64 & Ophthalmologica 197:75, 1988 \\
\hline Sandler & 35 & 25 & 71 & Int J Radiat Oncol Biol Phys 17:823, 1989 \\
\hline Appelqvist & 18 & 4 & 25 & Strahlenter Onkol 166:190, 1990 \\
\hline Marcocci & 13 & 5 & 38 & J Endocrinol Invest 14:853, 1991 \\
\hline Lloyd & 36 & 33 & 92 & Am J Ophthalmol 113:374, 1992 \\
\hline Prummel & 28 & 13 & 46 & Lancet $2: 949,1993$ \\
\hline Nakahara & 31 & 13 & 42 & Radiology 196:857, 1995 \\
\hline Seegenschmiedt & 60 & 49 & 82 & Front Radiat Ther Oncol 30:218, 1997 \\
\hline Total & 529 & 316 & 60 & \\
\hline
\end{tabular}


regimen exploits the prompter effects of glucocorticoids and the more sustained action of irradiation. The inclusion of glucocorticoids prevents radiation-associated transient exacerbation of ocular manifestations, while the inclusion of orbital radiotherapy probably reduces the prevalence of recurrences of eye disease, not infrequently observed when glucocorticoids are withdrawn. Thus, we suggest that in patients with severe GO, defined according to the criteria indicated in Table 1, this combined therapeutic regimen should be employed, if conservative therapy, rather than orbital decompression, is selected.

4. Orbital decompression. Orbital decompression is, with glucocorticoid therapy and orbital radiotherapy, a milestone in the treatment of GO. Its aim is to provide, through the removal of part of the bony components of the orbit, an increased space for the increased orbital content (1). Although it does not act on the pathogenetic mechanisms of the ophthalmopathy, it is very effective on proptosis and on the other ocular manifestations caused by venous congestion.

In the past, the surgical approach to the treatment of GO was limited by the risks of surgery and, therefore, indications for decompression were mostly represented by marked proptosis and by optic nerve compression, especially if no beneficial effect was obtained with glucocorticoids and/or orbital radiotherapy. In reviewing the records of 428 consecutive eye surgery patients at the Mayo Clinic, Garrity et al. (135) noted that the indications for orbital decompression were: optic neuropathy in 217 patients (51\%), severe orbital inflammation in $116(27 \%)$, proptosis in 90 (21\%), and glucocorticoid side effects in 5 (1\%). However, rehabilitative (cosmetic) surgery represented the indication for orbital decompression in several studies (136-138), as well as in $20 \%$ of cases in a survey of American ophthalmologists (139).

Several techniques, aimed at removing portions of one to four walls of the orbit, have been used (1). The four-wall technique is rarely used and may be considered in cases of very severe ophthalmopathy. The lateral approach is of limited effectiveness, because the removal of the lateral wall alone is usually associated with a limited decrease in proptosis (1). The superior (transfrontal) approach removes the roof of the orbit and is effective, but nowadays it is rarely used because of the risks associated with this procedure, i.e., intracerebral hemorrhage, damage to the frontal lobe, meningitis, and sensation of pulsation behind the globes (140).

The inferior (transantral) approach is still very popular. This technique has been modified to remove also the lateral wall of the orbit, although it is mainly aimed at the floor and the medial wall of the orbit (140). In a large series from the Mayo Clinic, Garrity et al. (135) reported that 402 of 453 eyes (89\%) with visual acuity worse than $20 / 20$ improved or remained the same; defects of the visual field ameliorated or regressed in 245 of 269 eyes (91\%), preoperative papilledema was reduced in 99 of 105 eyes (94\%), and preoperative exposure keratitis improved in 178 of 195 eyes (92\%). The average decrease in proptosis was $4.7 \mathrm{~mm}$ and was sustained over an extended follow-up period (135). This technique has the advantage that there is no external scar, and decompression of the orbital apex, where the optic nerve is mostly compressed, is very effective (140). Complications are not infrequent. In a large series (135), sinusitis occurred in 18 patients $(4 \%)$, lower eyelid entropion in $38(9 \%)$, numb lip in $23(5 \%)$, cerebrospinal fluid leakage in 15 patients $(3.5 \%)$, and frontal lobe hematoma in $1(0.2 \%)$. The major drawback of this procedure is the high incidence of postoperative diplopia, which may affect up to two thirds of patients with no diplopia before surgery (135). Nunery et al. (141) noted that postoperative diplopia was rare among patients who had no preoperative diplopia ( 1 of 25 patients, $4 \%$ ), while worsening of preexisting diplopia was very frequent (22 of 36 patients, $61 \%$ ). Tallstedt (140) noted an incidence of new postoperative diplopia in 32 of 63 patients (51\%) operated on by the transantral approach at the Karolinska Hospital.

Removal of the floor and the medial wall can also be accomplished by an anterior approach through a transconjunctival or translid incision (140). This approach appears to be associated with a lower incidence of worsening of diplopia, because it is more difficult to remove the posterior part of the ethmoid, thus avoiding the prolapse of the posterior portion of the orbital content (140). In a review of American ophthalmologists, this technique was associated with a $6 \%$ worsening of diplopia, compared with $41 \%$ after transantral decompression (139). Postoperative worsening of diplopia was observed in 5 of 33 patients (15\%) evaluated by Hutchinson and Kyle (142) after a two-wall operation using the translid approach. The translid approach is simpler and less morbid than the transantral technique, but it seems to be associated with a lower recession of the proptosis (143).

Removal of portions of three walls (floor, medial, and lateral walls) can be accomplished by either combining the transantral (or translid) decompression with lateral decompression or by the coronal approach. In the latter, a skin muscle incision is made from ear to ear $1 \mathrm{~cm}$ behind the hair border; after incision of the periosteum, the subgaleal flap is turned down to the supraorbital rim, the periorbita is incised in all quadrants, and then the lateral wall, most of the ethmoid, and the medial portion of the floor are removed (138). This technique was reported to be associated with a greater reduction of proptosis and lower prevalence of postoperative diplopia compared with the transantral technique (138). It was observed that balancing the decompression and preserving the medial orbital strut between the ethmoid sinus and the orbital floor may minimize the risk of postoperative diplopia (144). In a large, retrospective study (138), the mean decrease in proptosis was $4.3 \mathrm{~mm}$ (range $0-10 \mathrm{~mm}$ ), the largest reduction being observed in those patients who had the highest $(>27 \mathrm{~mm})$ preoperative Hertel readings. Complications were limited to 13 cases $(10 \%)$, including damage of the infraorbital $(n=2)$ or supraorbital $(n=1)$ nerves, temporary unilateral hypoesthesia $(n=6)$, enophthalmos $(n=1)$, and asymmetry $(n=3)(138)$. Thus, it seems that the coronal decompression technique is safe and effective and bears a low risk of postoperative diplopia compared with the two-wall transantral approach. In patients with severe optic nerve involvement, it may be less advantageous than the transantral technique, because the orbital apex is less effectively decompressed by the coronal approach.

A different approach to decompress the orbital content may be represented by the removal of orbital fat through medial-upper and lateral-lower anterior orbitotomy. An av- 
erage decrease in proptosis of $1.8 \mathrm{~mm}$ was found (range $0-6$ $\mathrm{mm})$, the largest average reduction $(3.3 \mathrm{~mm})$ being observed in patients with preoperative Hertel readings greater than 25 mm (145). Side effects were limited to temporary motility impairment of the inferior oblique muscle in two patients (145). With few exceptions $(146,147)$, this procedure seems to produce a rather limited decrease in proptosis. In mild to moderate cases, orbital lipectomy was associated with eyelid surgery, with good esthetic and functional improvement and no complications (148).

In summary, orbital decompression is a very effective therapeutic procedure for GO. It is beneficial for most expressions of the disease, with particular regard to proptosis and optic neuropathy, but also to congestive manifestations of the disease. The choice between medical and surgical treatment of ophthalmopathy relies, among other factors, on the availability of a skillful orbit surgeon. Increasing expertise in this field has expanded the indications for orbital decompression, which is currently carried out not only for sight-threatening conditions, but also for rehabilitative purposes. The selection of the different surgical techniques depends not only on the experience of the orbit surgeon, but also on the clinical situation of the patient. If optic nerve compression is severe, the transantral approach is probably better, because it allows a more marked decompression of the nerve at the orbital apex. The three-wall coronal approach is preferable in patients who do not have severe optic neuropathy and do not have preoperative diplopia, because the risk of new postoperative diplopia is lower than with the transantral approach. Irrespective of the surgical technique, orbital decompression does not solve the problem of preoperative diplopia, and a relevant proportion of patients will need extraocular muscle correction surgery (see below).

\section{B. Nonestablished treatments}

1. Cyclosporine. The autoimmune origin of GO prompted the attempt to use immunosuppressive drugs for this disease. The experience is, however, limited to small series of patients treated with azathioprine, cyclophosphamide, or the immunomodulatory agent, ciamexone, usually in uncontrolled trials (6).

The immunosuppressive drug that has been more thoroughly evaluated in the management of GO is cyclosporine. This drug affects both humoral and cell-mediated immune reactions, since it inhibits cytotoxic $\mathrm{T}$ cell activation and antigen presentation by monocytes and macrophages, but it also induces activation of $\mathrm{T}$ suppressor cells and inhibits production of cytokines (149). Although cyclosporine seems to be more effective on the early immune response (e.g., after organ transplantation) than on an already established immune response (e.g., in autoimmune disease), the above actions might explain the observed effectiveness in autoimmune diseases, especially if of recent onset (150).

Several reports have evaluated the effectiveness of cyclosporine administration in GO. Although the initial report showed a dramatic improvement of ocular conditions in 2 patients treated with the drug (151), these positive effects of cyclosporine were not uniformly confirmed in later studies (6). In a controlled, randomized, and prospective study, Ka- haly et al. (111) compared the effects of oral prednisone with those of oral prednisone combined with cyclosporine; prednisone was stopped in both groups after 10 weeks. Inflammation regressed in both groups, but proptosis decreased more in the cyclosporine-prednisone group; likewise, diplopia ameliorated more effectively in this group (111). In addition, the favorable effects of treatment were more persistent in the cyclosporine-prednisone group, since only 1 of the 20 patients of this group had a relapse compared with 8 patients in the other group (111). Side effects attributable to cyclosporine were rather frequent in this study, including one case of Klebsiella pneumonia, four cases of hypertension, four cases of increased liver enzymes, and several minor effects, such as hirsutism, paresthesias, and swelling of the gums; however, all appeared to be reversible (111).

In the other randomized trial on the effects of cyclosporine on GO, two groups of 18 patients each were treated with either cyclosporine or prednisone (103). During the 12-week period of treatment, a response, as assessed by a decrease in the extraocular muscle enlargement, a decrease in proptosis, an improvement in visual acuity, and a decrease in total eye score, was observed in 11 patients treated with prednisone and only in 4 patients treated with cyclosporine (103). Interestingly, retreatment of nonresponders of both groups with a combination of the two drugs (using a lower dosage of prednisone) was often associated with a therapeutic response (103). In this study, cyclosporine was better tolerated than prednisone, but 6 cases of hypertension, 1 case of diverticulitis requiring drug withdrawal, and 1 case of irreversible rise in serum creatinine levels could be attributed to cyclosporine (103).

In summary, the use of cyclosporine has been reported in several studies, but only two of them $(103,111)$ were randomized and controlled. Thus, the favorable effects of cyclosporine reported in some uncontrolled studies must be interpreted with caution. The study by Prummel et al. (103) indicated a lower efficacy of cyclosporine compared with prednisone as a single-agent treatment, but both Prummel et al. (103) and Kahaly et al. (111) suggested that a combination of cyclosporine and prednisone may be more effective than either treatment alone. Thus, the use of cyclosporine might be maintained, in association with glucocorticoids, in patients who are resistant to glucocorticoids alone and in whom the persistent activity of the disease warrants a continuing medical intervention. Side effects of cyclosporine are not negligible; some of them can be severe, calling for caution in the use of this drug (e.g., doses lower than $7.5 \mathrm{mg} / \mathrm{kg} /$ day).

2. Plasmapheresis. The rationale for the use of plasmapheresis in the treatment of GO was represented by the assumption that this procedure might remove either immunoglobulins or immune complexes possibly involved in the pathogenesis of the disease, reproducing the beneficial effects observed in other autoimmune disorders. In addition, plasmapheresis might affect plasma viscosity and complement components.

Favorable results with this procedure were observed, in the first report, in 4 of 7 patients with rapidly progressive ophthalmopathy; the three treatment failures were attributed to the long duration of the disease with the likely associated fibrotic changes (152). Likewise, Glinoer et al. (153) reported 
a marked clinical improvement in 8 of 9 patients, especially regarding soft tissue changes, proptosis, intraocular pressure, and visual acuity, with a significant decrease in the mean OI. The patients were submitted to 4 plasmapheresis sessions over a period of 5-8 days and were subsequently treated for 3-6 months with a combination of prednisolone and azathioprine; three patients had a recurrence of ophthalmopathy $1 \mathrm{yr}$ after treatment, requiring a second course of plasmapheresis (153). Favorable results were also reported by Berlin et al. (154), who observed a reduction of the OI in $9(69 \%)$ and of subjective symptoms in $10(77 \%)$ of 13 patients; azathioprine was concomitantly administered to 8 patients, and 2 patients needed further sessions of plasmapheresis. In contrast, unfavorable effects of plasmapheresis were reported in other series $(155,156)$.

In summary, plasmapheresis provided conflicting results, since both favorable effects and treatment failures were reported. No study on the effects of plasmapheresis was randomized and controlled, and the interpretation of results is made even more difficult by the frequent concomitant (or subsequent) treatment with glucocorticoids or immunosuppressive drugs (azathioprine or cyclophosphamide). In addition, recurrences of eye disease requiring further courses of plasmapheresis were relatively frequent. Thus, plasmapheresis should be regarded as a "desperate" treatment for severe GO, when all other therapies have failed (157).

\section{Novel treatments under investigation}

1. Somatostatin analogs. As mentioned above (see Section III.C), somatostatin receptors can be visualized in vivo in the orbital tissue of GO patients by [ ${ }^{111} \mathrm{In}$-DTPA-D-Phe ${ }^{1}$-octreotide scintigraphy (octreoscan) (158). Patients with active ophthalmopathy have a higher orbital uptake of the tracer than those with inactive ophthalmopathy (90), and uptake can be decreased by specific treatments of ophthalmopathy $(89,90)$. Thus, it was suggested that positive octreoscans might reflect the activity of the ophthalmopathy and predict its response to treatment (159).

The use of the somatostatin analog, octreotide, was first reported in GO patients by Chang et al. (160); in an uncontrolled study 6 patients were treated with octreotide $(0.1 \mathrm{mg}$ three times daily for 3 months), with an improvement of extraocular muscle function and soft tissue involvement (159). In a prospective study, Krassas et al. (161), using the same dose of the drug and the same duration of treatment, reported an improvement of ocular conditions in 6 of 12 patients in both eyes and in 1 patient in one eye, but in the remaining 5 patients eye disease was unaffected by treatment. It is worth noting that 7 of 8 control GO patients who were not treated with octreotide did not show any improvement, and 1 patient had a deterioration of eye disease during the follow-up period (161). Interestingly, octreoscan was positive in those patients who had a favorable therapeutic response, but negative in all but 1 patient in whom octreotide treatment was a failure (161).

In an open randomized study, Kung et al. (162) treated 8 GO patients with octreotide $(0.6 \mathrm{mg} /$ day for 3 months $)$ and compared the effects of the drug with those achieved in a control group with glucocorticoids. Octreotide was effective in decreasing soft tissue inflammation and in ameliorating symptoms of the disease, but glucocorticoid treatment appeared to be associated with a greater reduction in the CAS and had a more marked effect on extraocular muscle size, as assessed by MRI (162). In an uncontrolled study, 10 patients were treated with octreotide ( $0.3 \mathrm{mg} /$ day for 3 months) (163): although the authors claimed that 8 patients responded to this treatment, a critical reappraisal of their data seems to suggest that no more than 5 patients had a real improvement in ocular conditions, proptosis being only minimally affected (163). Amelioration of eye disease was associated with a decrease in serum intercellular adhesion molecule 1 (ICAM-1) concentration, suggesting a reduced endothelial and fibroblast activation (163).

A drawback of octreotide is represented by its short halflife, which requires repeated injections during the day. To overcome this limitation, new long-acting somatostatin analogs have been developed. One of these, lanreotide, was recently employed at a dose of $40 \mathrm{mg}$ im every other week for 3 months in $5 \mathrm{GO}$ patients (164). Favorable responses were reported in all 5 patients, whereas only 1 of the 5 matched controls treated with placebo showed minor improvements of ocular conditions (164). Recently, the same research group reported in a nonrandomized study an improvement of ocular conditions in 10 patients with moderately severe GO (all selected among those with positive octreoscans): 5 patients were treated with octreotide $(0.1 \mathrm{mg} \mathrm{sc}$ three times daily for 3 months), and 5 with lanreotide (30 mg im every 2 weeks for 3 months) (165). No differences were found with the 2 somatostatin analogs, whereas no improvement of eye disease occurred in 4 untreated GO patients (166).

In the above studies, side effects of somatostatin analog therapy were, in general, limited to mild gastrointestinal symptoms occurring during the first week of treatment.

The mechanism of action of somatostatin analogs is not fully understood. The interaction of the drug with the somatostatin receptors located on the surface of different cell types in the orbit might inhibit several important functions, such as the local release of insulin growth factor I (166) or cytokines (3), which appear to be relevant in triggering and/or maintaining the ongoing reactions in the orbital tissue of patients with ophthalmopathy.

In summary, the results of the few published series (Table 9) seem promising, and there is a rationale for the use of these drugs. However, the number of patients treated so far is too limited, and only one study was randomized. Therefore, it is difficult to draw definite and sound conclusions on the real effectiveness of somatostatin analogs, and properly controlled studies enrolling a larger number of patients (and possibly different doses of the drug) are needed. The high cost of this treatment must also be taken into account.

2. Intravenous immunoglobulins (IVIGs). High-dose IVIGs have been used effectively in a number of autoimmune diseases. Although their mechanism of action is incompletely understood, IVIGs might exert their beneficial actions by several mechanisms. These include blockade of idiotypic epitopes by antiidiotypic antibodies, down-regulation of immunocompetent cells by suppression of Fc $\gamma$ receptors, in- 
TABLE 9. Results of somatostatin analog therapy for Graves' ophthalmopathy

\begin{tabular}{lccrll}
\hline \multirow{2}{*}{ Author } & $\begin{array}{c}\text { No. of } \\
\text { patients }\end{array}$ & \multicolumn{2}{c}{ Responders } & & Analog \\
\cline { 3 - 5 } & & Number & $\%$ & & Ref. \\
\hline Chang & 6 & 6 & 100 & Octreotide & Br Med J 304:158, 1992 \\
Krassas & 12 & 5 & 58 & Octreotide & Clin Endocrinol (Oxf) 42:571, 1995 \\
Kung & 8 & 5 & 62 & Octreotide & Thyroid 6:381, 1996 \\
Ozata & 10 & 5 & 50 & Octreotide & Thyroid 6:283, 1996 \\
Krassas & 5 & 5 & 100 & Octreotide & Thyroid 9:47, 1999 \\
Krassas & 5 & 5 & 100 & Lanreotide & Eur J Endocrinol 136:416, 1997 \\
Krassas & 5 & 100 & Lanreotide & Thyroid 9:47, 1999 \\
Total & 51 & 38 & 75 & & \\
\hline
\end{tabular}

hibition of cytokine release or modulation of cytokine receptors, and solubilization of immune complexes. In addition, the beneficial effects of IVIGs in autoimmune disorders might be related to the fact that IVIG preparations contain transforming growth factor- $\beta$, an immunosuppressive cytokine, as well as other molecules, such as CD4 and shed surface molecules from lymphocytes (167).

In a randomized study, the effects of IVIGs either alone or in association with orbital radiotherapy were evaluated in two groups of 7 GO patients, and the results were compared with a "historical" group of 12 patients previously treated with oral glucocorticoids and orbital radiotherapy (168). IVIGs were administered at a dose of $400 \mathrm{mg} / \mathrm{kg} /$ day for 5 consecutive days; the cycle was repeated three times at 3 -week intervals (168). Favorable results were reported in the 3 groups, with no significant differences among them; excellent/good clinical responses were observed in $71 \%$ of patients treated with IVIGs, independently of the addition of orbital irradiation; the prevalence of side effects was higher in patients treated with glucocorticoids (168).

In a subsequent randomized trial, the effect of IVIGs was compared with that of oral prednisolone (169): in this study 19 patients received $1 \mathrm{~g}$ IVIG/kg body weight for 2 consecutive days every 3 weeks for 20 weeks. The authors reported a similar percentage of successful treatments in the two groups $(62 \%$ in the IVIG group, $63 \%$ in the prednisolone group); IVIG therapy was associated with a greater decrease in thyroid autoantibody titers and a lower prevalence of adverse effects (169).

In contrast to these favorable results, Seppel et al. (170) reported that in 10 patients treated with $4 \mathrm{~g}$ IVIG/day for 5 consecutive days for 5 times at 4-week intervals, no significant changes in ocular involvement occurred, since only 3 patients showed some decrease in the OI; in addition, no changes of CT findings were found (170).

Finally, the effects of IVIG and glucocorticoids were investigated in a prospective, nonrandomized study involving 34 patients (171). The percentage of patients responsive to treatment did not differ in the 2 groups $(76 \%$ in the IVIG group, $66 \%$ in the glucocorticoid group), but the prevalence of adverse effects was higher in patients receiving glucocorticoids (171). In general, the above studies showed favorable effects on soft tissue inflammatory changes, proptosis, and extraocular muscle involvement.

In summary, positive results with the use of IVIGs were reported in three studies, two of which originated from the same group, while negative results were observed in one study. The number of patients so far treated is limited and only two studies were randomized. Thus, randomized and properly controlled studies involving a higher number of patients are needed to demonstrate unequivocally the effectiveness of this therapeutic approach. In addition, although the reported side effects were limited, the potential risks related to the use of plasma-derived products must always be kept in mind. Finally, the economic burden on health systems related to the high cost of this treatment must be taken into account.

\section{Miscellaneous treatments}

Bromocriptine has occasionally been reported to have beneficial effects in forms of GO resistant to conventional medical, radiotherapeutic, or surgical treatments $(172,173)$. This effect has been attributed to a possible antiproliferative effect on immunocompetent T lymphocytes. A few patients were found to derive a transient benefit from metrodinazole therapy (174). It is, however, difficult to establish the effectiveness of these agents from anecdotal reports on a limited number of patients in uncontrolled studies.

The beneficial effects of acupuncture, suggested by a Chinese study (175), were not confirmed in a more recent randomized study (176).

\section{E. Rehabilitative surgery}

Rehabilitative surgery plays an important role in the management of GO. We discussed in Section V.4 that orbital decompression has a role in the rehabilitation of GO patients. In addition, many patients require extraocular muscle or eyelid surgery to correct diplopia or eyelid retraction that have not been affected by medical or surgical treatment of the ophthalmopathy. Thus, rehabilitative surgery is crucial to improve not only the cosmetic appearance of the patient, but also the function of his/her eyes.

1. Extraocular muscle surgery. Extraocular muscle surgery is carried out with the aim of reducing diplopia. It is very difficult for diplopia to be corrected in all positions of gaze, and restoration of single binocular vision in the primary and reading positions must be considered a success. Timing of surgery is crucial, because it should not be carried out when $\mathrm{GO}$ is active and the muscle is inflamed, but when the muscle has undergone fibrotic changes and the disease has been inactive for $4-6$ months $(1,6)$. It should be mentioned that a recent report evaluating 8 patients submitted to extraocular 
muscle surgery during the active phase of GO and followed for 16 months thereafter showed that surgery may be followed by long-term alignment also in patients who do not have burnt out disease (177).

The inferior rectus is the muscle that most frequently needs corrective surgery, followed by the medial rectus, the superior rectus, and, rarely, the lateral rectus (178). Extraocular muscle surgery is carried out to recess the most affected, restricted muscle, and can be performed by fixed or adjustable sutures. With the latter procedure, the suture is tied like a shoelace and can be adjusted when the patient is awake by pulling up the muscle or releasing it, until a satisfactory field of single binocular vision is obtained (179). It is not uncommon that more than one surgical procedure is required to achieve a satisfactory result. Among 290 patients undergoing extraocular muscle surgery, $171(59 \%)$ required 1 operation, $87(30 \%) 2$ operations, and $35(12 \%) 3$ or more operations (178). Mourits et al. (180) found that among 38 patients operated on with the technique of fixed sutures, $27(71 \%)$ recovered a useful field of single binocular vision after 1 operation, and $7(18 \%)$ after 2 or more operations. Treatment failures may be due to the fact that extraocular muscles of Graves' patients are taut and bleed excessively, postoperative scarring may be considerable, and eyelid swelling may make access to the operative field difficult (180). Eyelid retraction and exotropia may occur as a consequence of strabismus surgery (181). The technique of adjustable sutures might reduce the number of surgical procedures by allowing a postoperative fine tuning of muscle recession, avoiding large undercorrections and overcorrections (182). However, controlled studies designed to determine the advantage of adjustable sutures compared with fixed sutures are lacking.

According to some authors (178), but not to others (140), the release of the fibrotic eye muscle may be associated with an increase in proptosis. Therefore, in patients with moderate proptosis, preliminary orbital decompression, performed before extraocular muscle surgery, may be considered (178).

In summary, extraocular muscle surgery is effective in restoring single binocular vision in functional positions of gaze in the majority of patients. It is required in $20-70 \%$ of patients after treatment of severe GO (1). It must be performed when the disease has been inactive for several months, and it may require prior decompression. The patient should be informed that more than one surgical procedure is often needed.

2. Eyelid surgery. Upper eyelid retraction can be related to overreaction of the superior rectus or levator muscles that might be secondary to the contracture of the inferior rectus muscle (179). Lower lid retraction is thought to be related to overreaction of the inferior rectus muscle (179). Eyelid surgery can be performed as an emergency procedure (tarsorraphy) in patients with exposure keratitis and corneal ulceration (6), but it is more frequently carried out for rehabilitative reasons or to correct eyelid malposition after medical treatment or orbital decompression (6). As for extraocular muscle surgery, eyelid surgery should, with the exception of emergency tarsorraphy, be postponed until the ophthalmopathy has been stable and inactive for 4-6 months; eyelid surgery represents the last step if extraocular muscle surgery is also required (183).

A single injection of $40 \mathrm{U}$ of botulinum toxin A into the glabelar muscles, corrugator supercilii, and, sometimes, procerus has been reported to induce a flattening of the glabelar region and improvement of the medial eyebrow contour and glabelar furrowing (184). This suggests that reversible chemodenervation of the glabelar muscles might be considered, as an alternative to eyelid surgery, in the rehabilitation of patients with upper lid retraction and overacting protractors resulting in a thyroid frown.

Surgical techniques for upper lid retraction include recession of Muller's muscle, levator aponeurosis recession, levator myotomy, and temporary or permanent canthorrhaphy (179). In many instances the excision or recession of Muller's muscle is sufficient, while the recession of the levator muscle may also be carried out if upper lid retraction is more pronounced. For lower lid retraction, the most effective technique is probably the recession of the lid retractors followed by the insertion of a scleral or cartilage graft as a spacer (1). Scleral grafting for upper lid lengthening does not appear to have any distinct advantage over the other lengthening techniques (185). These procedures have approximately $90 \%$ success in achieving a normal lid level, but secondary surgery may be required in cases of undercorrection or overcorrection (180). Herniated orbital fat can be concomitantly removed (179).

\section{Summary of Assessment and Treatment of Graves' Ophthalmopathy}

To summarize data presented in the previous sections on the assessment of GO and its treatment (Table 10), the first step is to establish whether GO is severe and active. In nonsevere GO, supportive measures are usually sufficient, even if eye disease has some degree of activity. If GO is severe, the degree of activity of eye disease must be assessed. Active and

TABLE 10. Suggested treatment for Graves' ophthalmopathy as a function of disease severity and activity

\begin{tabular}{|c|c|c|}
\hline $\begin{array}{c}\text { Ocular } \\
\text { involvement }\end{array}$ & Degree of activity & Treatment \\
\hline Nonsevere & Active & Supportive measures ${ }^{a}$ \\
\hline Nonsevere & Inactive & Supportive measures ${ }^{a}$ \\
\hline Severe & Active & $\begin{array}{l}\text { High-dose glucocorticoids }{ }^{b} \\
\text { Orbital radiotherapy }{ }^{b} \\
\text { Orbital decompression }\end{array}$ \\
\hline Severe & Inactive & $\begin{array}{l}\text { Orbital decompression }^{d} \\
\text { Eye muscle surgery } \\
\text { Eyelid surgery }\end{array}$ \\
\hline
\end{tabular}

${ }^{a}$ See Table 4 . These measures can be considered as an ancillary aid also in patients with severe ophthalmopathy.

${ }^{b}$ Glucocorticoids can be given either orally or intravenously (see Section V.A.1), alone or in combination with orbital radiotherapy (see Section V.A.3).

${ }^{c}$ Orbital radiotherapy can be used alone or in combination with high-dose glucocorticoids (see Sections V.A.2 and V.A.3).

${ }^{d}$ Orbital decompression can also be utilized in nonsevere ophthalmopathy for rehabilitative (cosmetic) reasons (see Section V.A.4).

${ }^{e}$ Eye muscle surgery and eyelid surgery, if necessary, should represent the last steps of management of Graves' ophthalmopathy and follow orbital decompression, when the latter is required (see Sections V.E.1 and V.E.2). 
severe GO can be treated either medically (in general, by high-dose glucocorticoids and/or orbital radiotherapy) or surgically (orbital decompression). It must be kept in mind that medical treatment does not rule out the possibility (or the need) of subsequent surgical decompression and vice versa, if the ophthalmopathy remains active despite either treatment. If the ophthalmopathy is severe, but has a limited degree of activity, orbital decompression is preferred, because medical treatment has a low effectiveness. Rehabilitative surgery to correct residual manifestations of the disease, i.e., extraocular muscle impairment and eyelid retraction, is carried out eventually, after medical or surgical decompression, only when there is firm evidence that the ophthalmopathy has been inactive for several months. Eye muscle surgery should precede eyelid surgery. Orbital decompression can also be considered a form of rehabilitative surgery in cases of cosmetically unacceptable proptosis.

\section{Treatment of Hyperthyroidism and the Course of Graves' Ophthalmopathy}

GO may occur before, concomitantly with, but also after the onset of hyperthyroidism (7). Thus, in many instances the onset of eye disease follows the institution of treatments aimed at controlling or curing hyperthyroidism. This makes it difficult to establish whether the occurrence, amelioration, or aggravation of the ophthalmopathy is related to the natural history of the disease or is treatment induced. The information on the effects of treatment of hyperthyroidism on GO is, therefore, often conflicting, contradictory, and unclear.

An important point is that thyroid status per se, or, more likely, TSH-R activation that can occur in both hyperthyroidism (via TSH-R antibody) and hypothyroidism (via TSH), can influence the course of eye disease. DeGroot et al. (186) evaluated 264 patients treated with radioiodine and followed for up to $10 \mathrm{yr}$ thereafter. They found that the chance of having a progression of the ophthalmopathy was significantly higher in patients who required two or more doses of radioiodine than in those becoming hypothyroid after the first dose (186). In the former group, progression of GO occurred in $15 / 127$ patients $(12 \%)$, whereas in the latter group eye disease progressed in $2 / 48$ patients (4\%) (186). These results might also be interpreted as due to the negative effects of repeated radiodine treatments (see below). The relationship between persistent hyperthyroidism and worsening of eye disease was reported also by Gwynup et al. (187). On the other hand, Karlsson et al. (188) noted that among 30 patients referred for severe ophthalmopathy, eye disease occurred in 9 cases after radioiodine therapy (associated with a rise in TSH-R antibody levels) and in 3 cases after a temporary withdrawal of thionamides (associated with a rebound of abnormal thyroid stimulation), but in 15 cases it manifested after a period with elevated serum TSH levels. Thus, the above studies suggested that both hyper- and hypothyroidism may account for progression of GO.

This concept appears to be supported by other studies. In a series of $87 \mathrm{GO}$ patients, 54 receiving methimazole therapy were euthyroid at the time of referral and did not show any substantial ocular change over the next 5 months (189). At variance, the remaining 33 patients, who were hyperthyroid at the time of referral, showed a general improvement of ocular conditions with antithyroid drug treatment in the same period of time (189). In another study Prummel et al. (190) reported that when patients were subdivided into 4 groups according to the increasing severity of eye disease, a greater prevalence of Graves' patients with abnormal thyroid function was found in the subgroups with more severe GO.

If abnormal thyroid status can affect the course of GO, what is known about the effects of different treatment modalities for hyperthyroidism? The relationship between the type of treatment of hyperthyroidism and the outcome of eye disease is not completely clear, due to the limited knowledge of the natural history of the ophthalmopathy, the retrospective and uncontrolled features of the majority of studies evaluating the effects of thyroidectomy, radioiodine, or antithyroid drugs, and the nonstandardized methods for the evaluation of ocular changes (191).

\section{A. Antithyroid drug treatment}

As mentioned above, restoration of euthyroidism by thionamides has been reported to be associated with an amelioration of eye disease (189), but it is unclear whether this result is related to a direct effect of thionamides, to thionamide-induced normalization of thyroid status, or to the natural history of eye disease. In a recent, randomized and prospective study on the effect of radioiodine and methimazole on nonsevere ophthalmopathy, we found that among 148 patients treated with methimazole, 3 of the 74 patients with preexisting ophthalmopathy (4\%) had an improvement and 4 patients in the whole group $(3 \%)$ had a worsening of eye disease (192). At variance, Gwynup et al. (187) reported that propylthiouracil therapy was associated more often with a progression of eye disease than other treatment of hyperthyroidism, although this conclusion was based only on changes in exophthalmometer readings. Thus, it would appear that antithyroid drug therapy does not substantially affect the course of the ophthalmopathy and should not be considered a disease-modifying treatment.

The major problem posed by antithyroid drug therapy is represented by the large number of recurrences after drug withdrawal. In a recent study on 306 Graves' patients treated with methimazole, a relapse of hyperthyroidism occurred in 194 patients $(63 \%)$, especially in young subjects, with large goiters $(>40 \mathrm{ml})$ and high TSH-receptor antibody levels $(>30$ $\mathrm{U} /$ liter) at diagnosis (193). Although the use of of high-dose thionamides combined with TSH-suppressive doses of $\mathrm{L}_{-} \mathrm{T}_{4}$ and followed by prolonged $\mathrm{L}-\mathrm{T}_{4}$ treatment alone was claimed to lower dramatically the rate of recurrence of hyperthyroidism in Japan (194), these encouraging results have not been confirmed in more recent studies (195-199). Recurrence of hyperthyroidism due to Graves' disease is accompanied by a reactivation of thyroid autoimmunity heralded by the increase in the circulating TSH-R antibody and other thyroid autoantibody levels (191). Although the link between thyroid autoimmune phenomena and orbital autoimmune phenomena, responsible for GO, remains to be definitely proven (see Section II), it is conceivable that the exacerbation of thyroid 
autoimmune reactions may adversely affect the course of the ophthalmopathy (191). This might also be the case in the presence of spontaneous fluctuations of thyroid status due to imperfect control of thyroid function by thionamides (200).

\section{B. Radioiodine therapy}

Radioiodine therapy is a well established method of treatment of Graves' disease-related hyperthyroidism and represents the most widely used treatment in the United States (201). The relationship between radioiodine therapy and the course of GO is a matter of controversy and has been the object of several recent reviews (202-204). Results are often conflicting owing to the retrospective and nonrandomized features of many studies, the lack of appropriate control groups, the lack of standardized methods of ocular evaluation, and the inclusion of patients with different degrees of disease severity, duration, and activity.

Few randomized and controlled studies on this issue are available. In one study, we treated a small cohort of patients with Graves' hyperthyroidism and mild or no ophthalmopathy with either radioiodine alone or radioiodine associated with a 3-month course of oral prednisone $(0.4-0.5 \mathrm{mg} / \mathrm{kg} /$ day, initial dose) (205). Progression of ophthalmopathy was observed in 9 of 26 patients (35\%) with eye involvement before radioiodine therapy; in the group receiving prednisone also, progression did not occur, and preexisting ophthalmopathy improved in most cases (205). Although it was randomized, our study did not include a control group of patients receiving methimazole treatment.

In a subsequent randomized, controlled study Tallstedt $e t$ al. (206) found that the frequency of development or progression of ophthalmopathy was similar in patients treated with thionamides (4 of 38 patients, $10 \%$ ) or with thyroidectomy ( 6 of 37 patients, $16 \%$ ), but significantly higher in those receiving radioiodine therapy (13 of 39 patients, $33 \%, P=$ $0.02 v s$. the other treatments). This study was criticized (202) because the prevalence of smokers was higher in the radioiodine group than in the other groups and because the radioiodine-treated group did not receive $\mathrm{L}-\mathrm{T}_{4}$ replacement therapy promptly, but were treated only after a variable period of hypothyroidism, which might have been a confounding factor. As a matter of fact, the same group subsequently reported that the prompt administration of $\mathrm{L}-\mathrm{T}_{4}$ and the avoidance of untreated postradioiodine hypothyroidism was associated with a decrease in GO development after radioiodine (45 of the 248 patients, $18 \%$, receiving levothyroxine when hypothyroid; 27 of the 244 patients, $11 \%$, treated with $\mathrm{L}^{-\mathrm{T}_{4}} 2$ weeks after radioiodine; $\left.P=0.03\right)(207,208)$. Vàzquez-Chàvez et al. (209) randomly assigned a group of 40 Graves' patients to treatment with either radioiodine or thyroidectomy; patients were followed up for 2 to 162 months; there were no differences in the ocular conditions between these two groups, however, based only on exophthalmometer readings.

In a prospective, randomized study we assigned $450 \mathrm{pa}-$ tients with hyperthyroidism due to Graves' disease and mild or no ophthalmopathy to treatment with either radioiodine alone, methimazole, or radioiodine followed by treatment with oral prednisone (192). Among the 150 patients treated with radioiodine alone, progression of the ophthalmopathy was observed in 23 cases (15\%) shortly after radioiodine administration, and this was persistent only in $8(5 \%)$ who subsequently required treatment for ophthalmopathy (192). Progression of eye disease was not observed in the group treated also with prednisone; in this group preexisting eye disease improved in two thirds of cases, and treatment with methimazole did not influence the course of the ophthalmopathy (Fig. 5) (192). In this study thyroid status did not affect the outcome of the ophthalmopathy, because postradioiodine hyper- or hypothyroidism was promptly corrected with the appropriate therapy. It has been argued that these results do not definitively support the role of radioiodine therapy, because the progression of the ophthalmopathy after radioiodine administration might simply be coincidental, reflecting the natural history of the disease $(202,210)$. On the other hand, the different outcome in the methimazole group might reflect a beneficial effect of the antithyroid drug therapy, which would then be the true disease-modifying treatment (211). However, while patients in both radioiodine and methimazole groups were pretreated with methimazole, progression occurred only in the former group.

Admittedly, progression of ophthalmopathy after radioiodine does not occur in the majority of patients. This suggests that other risk factors or cofactors for the progression of eye disease must contribute to this outcome: smoking (212), high pretreatment $\mathrm{T}_{3}$ values $(206)$, high serum TSHreceptor antibody $(188)$ and TSH $(188,213)$ levels, and preexisting ophthalmopathy $(192,205)$ are recognized risk factors for the deterioration of eye disease after radioiodine. The search for and identification of other risk factors should allow a better coordinated treatment of high-risk patients (214). In high-risk patients oral prednisone should concomitantly be administered for 3 months to prevent radioiodineassociated progression of ophthalmopathy and to cure preexisting ophthalmopathy $(192,205)$.

The development or progression of GO after radioiodine therapy might be due to the release of thyroid antigens after radiation injury and to subsequent exacerbations of autoim-

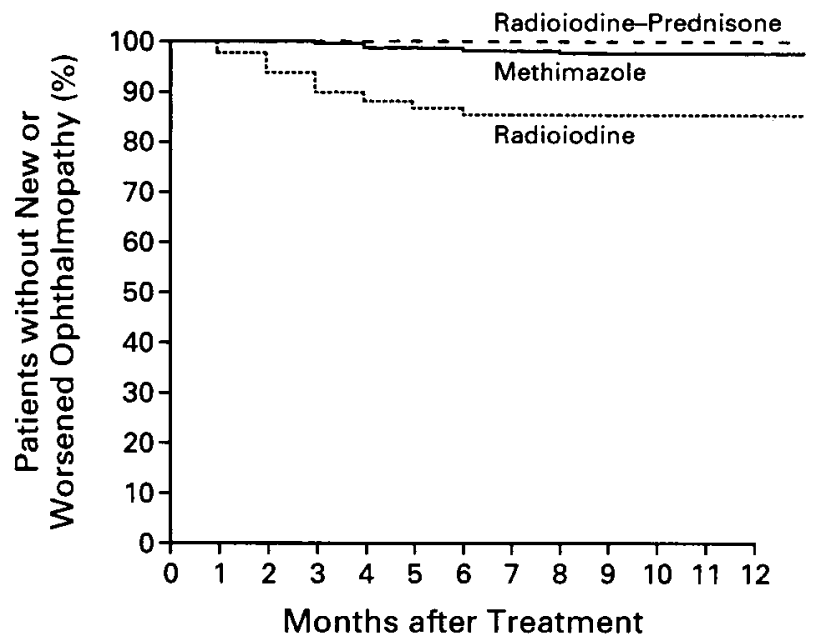

FIG. 5. Kaplan-Meier plots of the development or progression of GO in patients with Graves' hyperthyroidism treated with radioiodine, radioiodine and prednisone, or methimazole. [Reproduced with permission from L. Bartalena et al.: N Engl J Med 338:73-78, 1998 (192). (c) Massachusetts Medical Society. All rights reserved.] 
mune reactions directed toward antigens shared by the thyroid and the orbit (1). This is similar to the mechanisms postulated for the occurrence of eye disease after irradiation of the neck for nonthyroidal disorders $(215,216)$ or after thyroid-destructive processes (217). Radioiodine therapy for differentiated thyroid carcinoma is followed by the release of thyroperoxidase in the circulation (218), but demonstration of this phenomenon in Graves' disease is hampered by the interfering presence of autoantibodies. Radioiodine therapy is followed by an increase in concentration and activity of TSH-receptor antibodies (219) and by peripheral blood T cell activation (220); a prolonged increase (lasting $>2 \mathrm{yr}$ ) in thyroid autoantibody production has been described after radioiodine therapy (221).

It seems that the possible negative effects of radioiodine on the ophthalmopathy may modify the attitude of many endocrinologists with respect to the use of radioiodine therapy in patients with clinically relevant eye disease. In a recent survey carried out among European endocrinologists, in the treatment of recurrent hyperthyroidism after antithyroid drug therapy, thyroidectomy was selected by $43 \%$ of respondents, a second course of antithyroid drugs by $32 \%$, and radioiodine by only $25 \%$ (100). In other words, when ablative therapy was selected, the preference went to surgery rather than to radioiodine therapy. We do not share the view that radioiodine therapy should be avoided in patients with ophthalmopathy (222). This is because progression of GO does not occur in the majority of cases and can be prevented by concomitant prednisone therapy $(192,205)$. In addition, ablation of the thyroid might in the long run prove useful for the long-term outcome of eye disease (see Section VII.D).

In summary, radioiodine treatment seems to be associated with a possible progression of preexisting ophthalmopathy, especially in smokers. Progression does not occur in the majority of patients and can be prevented by concomitant glucocorticoid treatment. The possible side effects of glucocorticoids, and the need to complete the relatively short course of drug treatment once radioiodine treatment has been given, should be discussed thoroughly with the patient before radioiodine is chosen as the definitive treatment for hyperthyroidism.

\section{Thyroidectomy}

Although it is not so open to debate as radioiodine therapy, the issue of whether thyroidectomy affects the course of GO is also unsettled. This might, at least partly, be due to the different surgical approaches (subtotal vs. total thyroidectomy).

In the large retrospective study by Sridama and DeGroot (223), development of new ophthalmopathy after subtotal thyroidectomy occurred in 7\% of cases, and progression of preexisting ophthalmopathy occurred in 19\%: these figures are similar to those observed with the other hyperthyroidism treatment modalities. Frilling et al. (224) evaluated 78 patients with preexisting ophthalmopathy who underwent subtotal thyroidectomy: they observed a marked improvement in 54 $(69 \%)$, ocular conditions did not change in $18(23 \%)$, and 6 patients $(8 \%)$ had a progression of the ophthalmopathy after surgery. These authors attributed the positive results to early intervention ( $<2 \mathrm{yr}$ ) after the onset of eye disease (224).

Tallstedt et al. (206) in a prospective and randomized study found that in patients aged 20-34 yr randomly assigned to treatment with either methimazole or subtotal thyroidectomy, progression of ophthalmopathy occurred in 4 of 27 patients $(15 \%)$ receiving methimazole and in 3 of 27 patients (11\%) treated surgically; among patients aged 35-55 yr, randomly assigned to either of the two above treatments or to radioiodine therapy, progression of ophthalmopathy occurred in 6 of 37 patients (16\%) treated surgically, compared with 4 of 38 patients $(10 \%)$ treated medically and 13 of 39 patients $(33 \%)$ treated with radioiodine. Thus, thyroidectomy did not appear to increase the risk of GO progression compared with antithyroid drugs and carried a lower risk compared with radioiodine therapy (206).

In 21 patients treated by subtotal thyroidectomy by Fernàndez-Sànchez et al. (225), none had a progression of ophthalmopathy and the condition improved in 17 cases (81\%); these results compared favorably with those observed in a group of 24 patients treated with radioiodine therapy. Patwardhan et al. (226) evaluated the course of ophthalmopathy in 81 Graves' patients (50 with preexisting ophthalmopathy) who underwent subtotal thyroidectomy from 1980 to 1992: eye manifestations improved in 27 of the 50 patients (54\%) with preexisting GO; eye disease did not develop or progress in any patient with or without preoperative eye involvement.

Winsa et al. (227) recently evaluated retrospectively a large series of 173 Graves' patients who underwent either subtotal $(\mathrm{n}=157)$ or total $(\mathrm{n}=19)$ thyroidectomy. Eye disease worsened in 9 of 56 patients $(16 \%)$ treated by subtotal thyroidectomy and 1 of $17(6 \%)$ patients treated by total thyroidectomy, who had preoperative clinically evident ophthalmopathy, while new ophthalmopathy developed in 2 of 101 patients $(2 \%)$ treated by subtotal thyroidectomy and 0 of 2 patients treated by total thyroidectomy (227). Thus, as a whole, progression of ophthalmopathy occurred in 12 patients $(7 \%)$, more frequently among those who had clinically evident eye disease before surgery (227). No substantial effect on GO was observed by Miccoli et al. (228) in 140 surgically treated Graves' patients, independently of the extent of thyroid resection. Abe et al. (229) observed that among 18 patients treated by subtotal thyroidectomy, GO progressed in $1(6 \%)$, improved in $3(17 \%)$, and did not change in the remaining 14 (78\%); these results compared favorably with those observed after radioiodine therapy.

We recently reviewed the effects of near-total thyroidectomy in a case-control prospective study involving 30 patients with mild or no ophthalmopathy (230). Our results confirm that surgery has no relevant role in the progression of GO, which occurred only in one patient (who had preexisting ophthalmopathy) (230). Accordingly, we also believe that, at variance with radioiodine treatment, glucocorticoid coverage has no role after thyroidectomy for Graves' disease.

To summarize the above data, thyroidectomy per se seems to carry a very low risk, if any, of causing GO progression. The available data do not show any substantial difference between the effects of subtotal or total thyroidectomy on the outcome of ophthalmopathy. Glucocorticoid treatment is not necessary after thyroid surgery. 


\section{Total thyroid ablation}

If the hypothesis that $\mathrm{GO}$ is related to orbital autoimmune reactions directed toward antigen(s) shared by the thyroid and the orbit (1) is correct, the complete ablation of thyroid tissue might be important for the removal of both the thyroid-orbit cross-reacting autoantigens (antigen deprivation) and thyroid-autoreactive T lymphocytes (199). The importance of total thyroid ablation on the decrease of thyroid autoimmune phenomena finds support in the observation that after thyroidectomy and radioiodine therapy in autoantibody-positive patients with thyroid cancers, serum antithyroglobulin and anti-thyroid peroxidase autoantibodies become undetectable or decrease in patients with no evidence of residual (or metastatic) thyroid tissue, but they do not change or increase in patients with persistent neoplastic disease (231). On the other hand, if orbital autoantigens are not cross-reactive with the thyroid, total thyroid ablation would have a limited relevance for the course of the ophthalmopathy (232). In addition, if ophthalmopathy is well established and/or long lasting, it is conceivable that orbital autoimmunity might proceed independently of the persistence or removal of thyroid tissue. Therefore, also in this case, total thyroid ablation might not influence favorably the course of eye disease even in the presence of a real link between thyroid and orbital autoimmunity.

Treatment of hyperthyroidism by radioiodine therapy or thyroidectomy is rarely followed by the complete ablation of thyroid tissue, even in patients who develop hypothyroidism and require $\mathrm{L}_{-} \mathrm{T}_{4}$ replacement. DeGroot (233) reported that most of 40 patients, treated with radioiodine therapy followed by replacement therapy for hypothyroidism, still had nonsuppressible thyroid radioiodine uptakes of $2-24 \%$ when therapy was discontinued for 2 days. In an uncontrolled study, DeGroot and Benjasuratwong (234) described 15 patients, 14 of whom were hypothyroid after either radioiodine therapy $(n=13)$ or thyroidectomy $(n=1)$. These patients were treated with further radioiodine doses to obtain thyroid ablation, defined as a thyroid radioiodine uptake less than $1 \%$. The patients continued other treatments for ophthalmopathy, if required. The results showed beneficial effects of total thyroid ablation in 11 of 15 patients, those with more recent eye disease, while the remaining 4 patients, those with long lasting ophthalmopathy, did not respond (234). The apparent improvement occurred 4-24 months (mean 9 months) after thyroid ablation was achieved (234). DeGroot (233) reported similar favorable results in a larger series of more than 40 patients.

Admittedly, the two cited studies by DeGroot's group $(233,234)$ are uncontrolled and cannot firmly support the idea that total thyroid ablation is beneficial for GO. However, they can, at least, support the opportunity of properly performed randomized and controlled prospective studies to evaluate this hypothesis. In this regard, probably the best approach to achieve total thyroid ablation might be represented by a combination of thyroidectomy and radioiodine therapy, similar to the management of differentiated thyroid cancer. A further consideration deriving from DeGroot's studies $(233,234)$ is that this might represent a logical approach in the management of GO patients early in the course of the disease. Future studies addressing this problem will help to clarify the role of total thyroid ablation in GO management.

\section{Treatment of Graves' Hyperthyroidism in Patients with Ophthalmopathy}

Two relevant questions must be addressed before analyzing the issue of the choice of the therapeutic approach of hyperthyroidism in patients with GO: 1) Should the presence of ophthalmopathy influence the choice of the treatment for hyperthyroidism?; and 2) Should ablative or nonablative therapy for hyperthyroidism be selected in patients with eye disease (Table 11)?

We have reviewed in previous sections the effects of antithyroid drugs, radioiodine therapy, and thyroidectomy on the course of GO. It appears that while thionamides do not affect the course of eye disease and might be associated with an amelioration of eye symptoms, radioiodine therapy may cause, in a minority of cases, a progression of ophthalmopathy. This risk is unlikely in patients who undergo thyroidectomy. Does this mean that radioiodine should not be used in GO patients? In a recent editorial in the New England

TABLE 11. Ablative or nonablative therapy for Graves' hyperthyroidism in patients with Graves' ophthalmopathy?

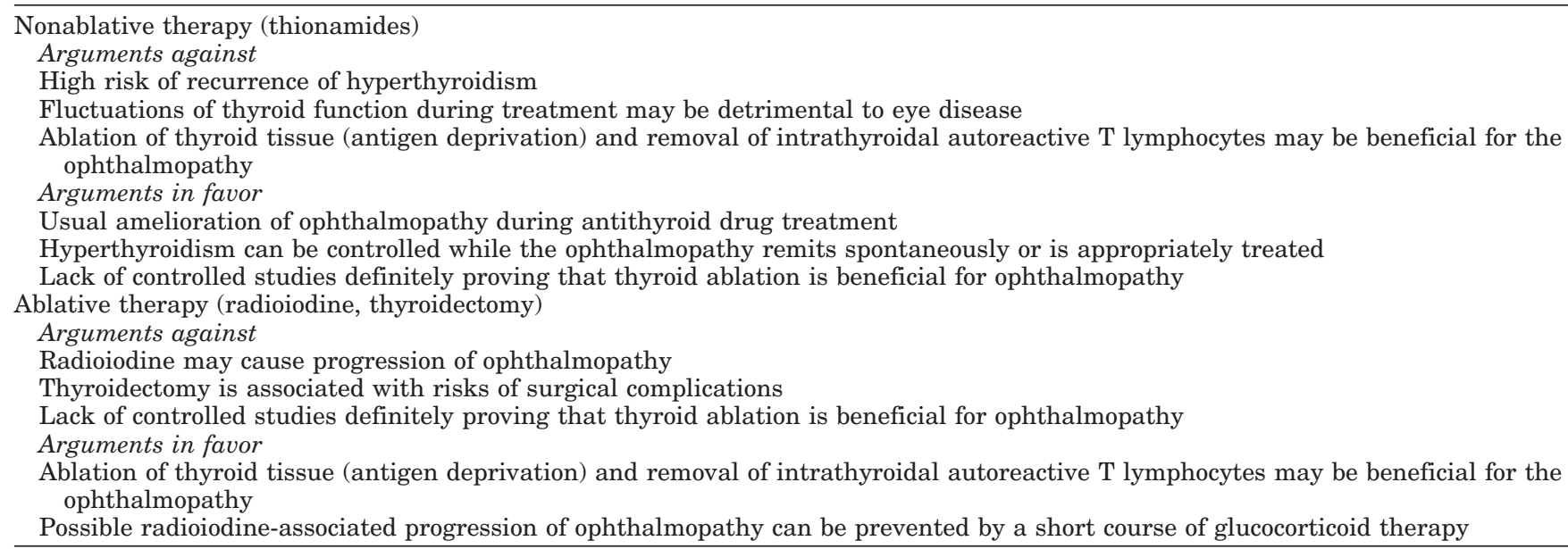


Journal of Medicine, Wiersinga (211) expressed the opinion that in patients with ophthalmopathy, it may be prudent to manage hyperthyroidism with antithyroid drugs, which do not influence the course of eye disease. This approach would not prevent concomitant treatment of severe ophthalmopathy by either medical or surgical therapy and may be reasonable in nonsevere GO in that it allows eye disease to run its natural course.

On the other hand, a disadvantage of antithyroid drug therapy is the high rate of relapses when the treatment is discontinued (193); recurrence of hyperthyroidism and, in general, the continuing thyroid activity might be associated with a risk of progression of ophthalmopathy (188). We mentioned that one third of European endocrinologists indicated antithyroid drugs as the treatment of choice for relapsed hyperthyroidism in the presence of ophthalmopathy (100), with a trend to avoid radioiodine therapy in view of the possible progression of eye disease after this treatment. As discussed above, however, radioiodine therapy can be considered a relatively safe treatment for GO, because high-risk patients can advantageously be treated by a relatively short course of middle-dose oral prednisone, a treatment shown to prevent radioiodine-associated ocular progression (and to cure preradioiodine ophthalmopathy) $(192,205)$. Radioiodine seems to cause the development of new ophthalmopathy only rarely; as discussed above, it appears reasonable to assume that the presence of ophthalmopathy should not be considered as a contraindication to thyroidectomy if otherwise indicated. It should be noted that the above discussion relates to patients with mild ocular involvement, because no randomized clinical trial has so far been performed on the effects of antithyroid drugs, radioiodine, and thyroidectomy on severe GO.

In summary, the currently available published data suggest that the presence of eye involvement should not be regarded as a condition influencing the choice of the method of treatment of hyperthyroidism. This choice should be made on the basis of established criteria (goiter size, age, first episode vs. recurrence of hyperthyroidism, etc.) (235), which are largely independent of ophthalmopathy. Selection of a definitive treatment of hyperthyroidism by radioiodine or thyroidectomy might have, in the long run, a beneficial effect on the course of eye disease. This might be related to the ablation of thyroid antigens and the removal of thyroid autoreactive T lymphocytes (199).

A coordinated approach to the management of hyperthyroidism and ophthalmopathy is influenced by the degree of ocular involvement. Our method of coordinated treatment of hyperthyroidism and ophthalmopathy is indicated below (Table 12); we fully understand that it may be a matter for debate.

\section{A. Nonsevere (or absent) ophthalmopathy}

The choice of treatment of hyperthyroidism should be based on established criteria (235). If antithyroid drugs or thyroidectomy is selected, no specific measures are required for the ophthalmopathy, except for the local treatment outlined in Section IV (6). If hyperthyroidism is treated by radioiodine therapy, this is followed, in patients with signs and symptoms of ocular involvement, by a 3-month treatment with oral prednisone $(192,205)$, especially in the presence of other risk factors (e.g., cigarette smoking). Special care should be used to correct promptly postradioiodine hypothyroidism or persistent hyperthyroidism.

\section{B. Severe ophthalmopathy}

In this case management of hyperthyroidism and treatment of ophthalmopathy should be carried out concomitantly and proceed independently of each other. We favor, for the reasons discussed above, the use of a definitive treatment of hyperthyroidism by radioiodine or thyroidectomy in these patients $(191,200)$. Their eye disease should also be promptly managed by the appropriate medical or surgical treatment without delay.

\section{Prevention of Graves' Ophthalmopathy}

\section{A. Natural history of the disease}

The natural history of Graves' ophthalmopathy is incompletely understood, but it is well established (although unexplained) that severe forms of the disease account for no more than $3-5 \%$ of cases (1). Genetic predisposition to GO, extensively studied especially for human leukocyte antigen associations, has so far been poorly characterized, and discrepant results have been reported (see Refs. 236 and 237 for review). The disease tends to be more severe in older patients, and men tend to be more severely affected than women (238-240). Perros and co-workers (76) reported that a spontaneous improvement of ocular conditions occurred in $64 \%$ of patients, and eye disease remained stable in $22 \%$ and deteriorated in $14 \%$ (Fig. 1). The overall age-adjusted incidence rate in a population-based cohort study in Minnesota

TABLE 12. Coordinated treatment of Graves' hyperthyroidism and ophthalmopathy

\begin{tabular}{|c|c|c|}
\hline Ocular involvement & $\begin{array}{l}\text { Selected therapy for } \\
\text { hyperthyroidism }\end{array}$ & Therapy for GO \\
\hline \multirow[t]{3}{*}{ Nonsevere } & Antithyroid drugs & Supportive measures ${ }^{a}$ \\
\hline & Radioiodine therapy & Middle-dose oral glucocorticoids ${ }^{b}$ \\
\hline & Thyroidectomy & Supportive measures ${ }^{a}$ \\
\hline \multirow[t]{3}{*}{ Severe $^{c}$} & Antithyroid drugs & High-dose glucocorticoids and orbital radiotherapy (or orbital decompression) ${ }^{d}$ \\
\hline & Radioiodine therapy & High-dose glucocorticoids and orbital radiotherapy (or orbital decompression) ${ }^{d}$ \\
\hline & Thyroidectomy & High-dose glucocorticoids and orbital radiotherapy (or orbital decompression) ${ }^{d}$ \\
\hline
\end{tabular}

\footnotetext{
${ }^{a}$ See Table 4.

${ }^{b}$ Prednisone, $0.4-0.5 \mathrm{mg} / \mathrm{kg} / \mathrm{day}$ (or equivalent), withdrawn over 3 months (191).

${ }^{c}$ Treatment of severe GO should be carried out without delay independently of the type of treatment for hyperthyroidism.

${ }^{d}$ See Table 11.
} 
was 16 cases/100,000 population/yr for women and 2.9 cases/100,000 population/yr for men (241).

Most interestingly, the disease seems less common and less severe than in the past. Perros and Kendall-Taylor (242) reviewed the clinical records of the first 100 consecutive patients diagnosed as having Graves' disease at the beginning of each decade (1960-1990) at their large thyroid clinic. They found a significant decrease in the prevalence of relevant eye manifestations from $57 \%$ in 1960 to $35 \%$ in 1990; likewise, there was also a decline in the prevalence of the severe forms of the disease (242) (Fig. 6). The reason for this trend is unclear. On one hand we have the earlier diagnosis of hyperthyroidism and its prompter correction by the endocrinologist, and, on the other hand, there is increased attention of the ophthalmologist to the possible link between initial and mild ocular changes and thyroid dysfunction. Obviously, this trend will have to be encouraged to unravel subclinical thyroid and ocular involvement.

\section{B. Cigarette smoking}

Cigarette smoking has been associated with minor and not unequivocal variations in thyroid function tests, the pathophysiological significance of which is uncertain $(243,244)$. An increased prevalence of smokers in patients with Graves' hyperthyroidism has been observed by most (245-247), but not all, research groups (248). A relationship between cigarette smoking and the occurrence of autoimmune thyroiditis, with one exception (249), was not found by most groups (246, $247,250,251)$. The reason for this difference between two related autoimmune diseases is unclear; it is possible that the relationship between cigarette smoking and Graves' disease is unrelated to a direct effect of smoking on the immune system.

What about the effect of cigarette smoking on GO? A first report by Hagg and Asplund (252) showed, in a small series of 12 GO patients, that $83 \%$ of them were current smokers, a much higher figure than that observed in Graves' patients without ophthalmopathy $(46 \%)$ or in control subjects (31\%). In a subsequent cross-sectional study reviewing the smoking

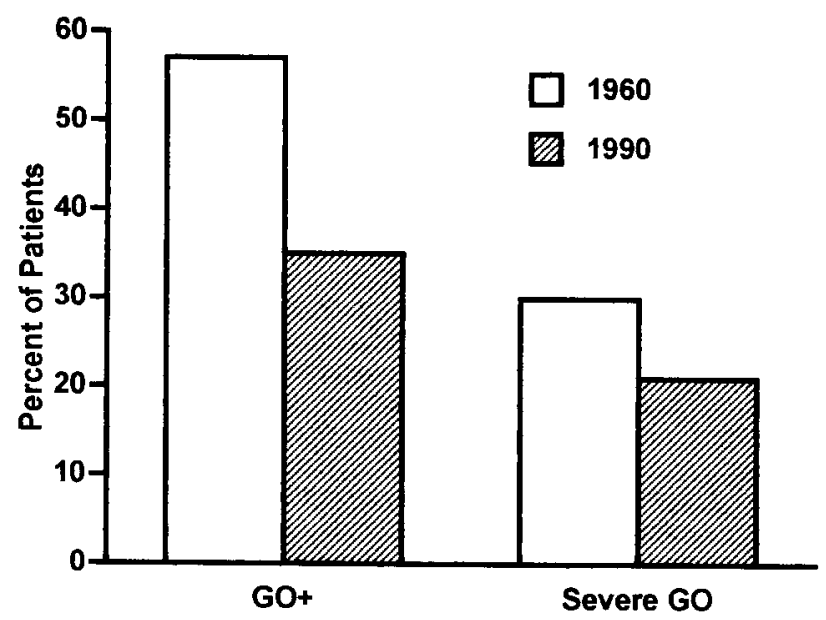

FIG. 6. Prevalence of $\mathrm{GO}(\mathrm{GO}+)$ and of severe forms of the disease in the first 100 consecutive Graves' patients referred to the same thyroid clinic in 1960 and 1990. [Derived from P. Perros and P. KendallTaylor: Thyroid 8:423-425, 1998 (242).] habits of 1,730 women, we found that, while the prevalence of smokers was about $30 \%$ in patients with nontoxic goiter, toxic nodular goiter, and Hashimoto's thyroiditis, smokers represented $48 \%$ of 167 patients with Graves' disease without ophthalmopathy and $64 \%$ of 307 patients with ophthalmopathy (246) (Table 13). In addition, the prevalence of heavy smokers was higher in patients with more severe ophthalmopathy (252). These results were subsequently confirmed by other studies $(248,253-255)$. Prummel and Wiersinga (245), in a consecutive entry case-control study, observed that smoking greatly increased the risk for GO, but also Graves' patients without ophthalmopathy were more often smokers than control subjects (Table 13). In addition, among GO patients, smokers had more severe eye disease than nonsmokers, although there was no association between the number of cigarettes smoked per day or the duration of smoking and the severity of eye disease (244).

Recently, Pfeilschifter and Ziegler (256) prospectively followed 253 patients with a recent onset of Graves' hyperthyroidism and found that cigarette smoking was associated with a 1.3-fold increased incidence of clinically relevant GO and with 2.6-fold and 3.1-fold increases in the incidence of proptosis and diplopia, respectively. In this study the current number of daily cigarettes, but not lifetime cigarette consumption, was an independent risk factor for GO development. In addition, former smokers had a lower risk for the occurrence of eye disease than current smokers with a comparable lifetime tobacco consumption (256). Tellez et al. (257) observed that the prevalence of ophthalmopathy was higher in Caucasian patients than in Asian patients (42\% vs. $7.7 \%)$, and, after correction for the ethnic factor, smokers had a risk of 2.41 of developing ophthalmopathy relative to nonsmokers $(P=0.02)$.

We recently reviewed the outcome of mild ophthalmopathy after radioiodine therapy and the response of severe ophthalmopathy to orbital radiotherapy and systemic glucocorticoids in relation to smoking habits (212). Among patients with mild ophthalmopathy, we found that after radioiodine therapy, eye disease progressed in 4 of 68 nonsmokers $(5 \%)$ and in 19 of 32 smokers $(23 \%, P=0.007)$ (212). The combination of radioiodine therapy with a short course of oral prednisone was associated with an improvement of ophthalmopathy in 37 of 58 nonsmokers $(64 \%)$ and 13 of 87 smokers $(15 \%, P<0.001)$ (212). Among patients with severe ophthalmopathy treated with orbital radiotherapy and high-dose glucocorticoids, a response to treatment was observed in 61 of 65 nonsmokers (94\%) and 58 of 85 smokers (68\%, $P<0.001)$ (Fig. 7) (212).

Thus, it seems evident that cigarette smoking can profoundly influence the occurrence and the course of eye disease and also impair its response to orbital radiotherapy and glucocorticoids. Smoking might do this by direct irritative actions on the eyes; however, this might account for inflammatory changes, but not for the increased volume of the extraocular muscles and retrobulbar fibroadipose tissue.

Smoking might affect immunological reactions possibly involved in the pathogenesis of eye disease, by altering the structure of the TSH-R and making it more immunogenic, by hampering restoration of tolerance to autoantigens shared by the thyroid and the orbit, or by sensitizing the orbital tissue 
TABLE 13. Prevalence of smokers among patients with Graves' ophthalmopathy

\begin{tabular}{lccl}
\hline \multicolumn{1}{c}{ Author } & $\begin{array}{c}\text { No. of } \\
\text { patients }\end{array}$ & $\begin{array}{c}\% \text { of } \\
\text { smokers }\end{array}$ \\
\hline Hagg & 12 & 83 & Ref. \\
Bartalena & 307 & 64 & Br Med J 295:634, 1987 \\
Shine & 85 & 62 & L Endocrinol Invest 12:733, 1989 \\
Balazs & 38 & 95 & Lancet 2:754, 1990 \\
Tellez & 52 & 44 & Clin Endocrinol (Oxf) 36:291, 1992 \\
Winsa & 62 & 48 & Acta Endocrinol (Copenh) 128:156, 1993 \\
Tallstedt & 24 & 79 & Acta Endocrinol (Copenh) 139:147, 1993 \\
Prummel & 100 & 41 & JAMA 269:479, 1993 \\
Pfeilschifter & 52 & & Clin Endocrinol (Oxf) 45:477, 1996 \\
Total & 732 & 67 & \\
\hline
\end{tabular}

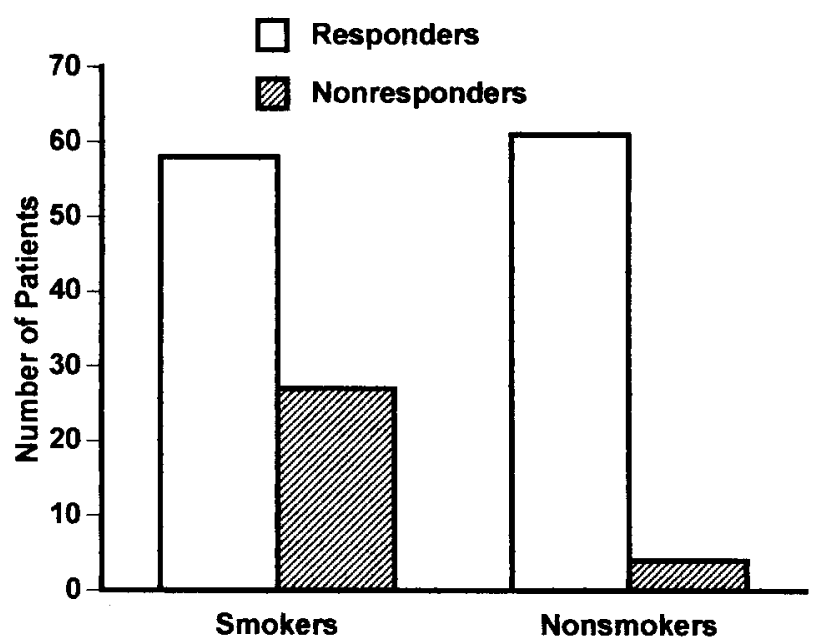

FIG. 7. Response of GO to orbital radiotherapy and high-dose prednisone in relation to smoking habits. [Derived from L. Bartalena et al.: Ann Intern Med 129:632-635, 1998 (212).]

to whatever substance or antibody that can trigger GO (258). However, so far there is no definite evidence that any of these mechanisms are effectively involved. Since smoking is associated with increased thyroglobulin levels (259), a rise in serum antithyroglobulin autoantibodies might play a role in the pathogenesis of eye disease. This is because of the reported homology between thyroglobulin and acetylcholinesterase, which is particularly abundant in the nerve-nerve and nerve-muscle junctions of the extraocular muscles (260). The role of this homology between thyroglobulin and acetylcholinesterase in GO pathogenesis, however, has been questioned (261).

As previously mentioned (see Section II), cytokines are currently believed to play an important role in the pathogenesis of ophthalmopathy. Smoking might influence cytokine-mediated paracrine and autocrine actions, because smoking-induced hypoxia in the orbital tissue has been shown to induce the release of cytokines (262). Hypoxia might also increase the release of cytokines by endothelial cells $(263,264)$ and thereby enhance the expression of adhesion molecules (24). It is worth mentioning that serum levels of soluble interleukin-1 (IL-1) receptor antagonist, an anticytokine antagonizing the effects of IL-1 (265), were reported to be lower in GO patients who smoked than in those who did not smoke, and to have a lower surge after orbital radiotherapy: this was associated with a lack of response to irradiation (266). The in vitro counterpart of this finding is that orbital fibroblasts from GO patients express lower levels of IL-1 RA than orbital fibroblasts from normal controls (267).

In conclusion, the mechanisms by which cigarette smoking affects GO remain a matter of argument, but the relationship between smoking and eye disease appears to be well established. Accordingly, patients should be strongly urged to stop smoking (268). Although some data suggest that refraining from smoking might favorably influence the course of ophthalmopathy (256), this remains to be established by appropriate prospective studies.

\section{Other risk factors}

The role of cigarette smoking in the development and progression of GO is well established, and it is likely that early diagnosis and treatment of hyperthyroidism may decrease the prevalence and severity of eye disease. However, other risk factors need to be better characterized. We discussed above the possible role of radioiodine therapy in the progression of ophthalmopathy, especially if patients have preexisting ocular involvement (192). The presence of very high pretreatment serum $\mathrm{T}_{3}$ levels (206), as well as very high posttreatment TSH-R antibody $(188)$ or TSH levels $(188,213)$ may enhance the likelihood of GO progression. Identification of high-risk patients has prompted us either to select antithyroid drugs as the treatment of choice of hyperthyroidism (211) or to combine glucocorticoids with radioiodine therapy (192). The goals of future research should include the identification of other currently unknown environmental risk factors for the development of GO, as well as a better definition of its genetic background. This should help to understand why only a minority of Graves' patients develop severe ocular manifestations.

\section{Therapeutic Perspectives}

\section{A. Anticytokine therapy}

As mentioned previously (see Section II), cytokines appear to play an important role in GO pathogenesis $(3,21)$, intervening both in its initiation and maintenance. Cytokines have a similar relevance in other diseases of autoimmune origin, such as rheumatoid arthritis (269). The latter has been and currently is the object of clinical trials evaluating the use of cytokine antagonists (see Ref. 270 for review). Biological agents aimed at blocking the proinflammatory effects of cy- 
tokines [especially tumor necrosis factor- $\alpha$ (TNF- $\alpha$ ) and IL-1] include cytokine receptor antagonists, monoclonal antibodies to cytokines, soluble cytokine receptors fused with human Fc constructs, and counterregulatory cytokines (271). In one study, 73 patients with rheumatoid arthritis were randomly treated with either an infusion of monoclonal antiTNF- $\alpha$ antibody or placebo; although the initial response to treatment was dramatic, relapse of the disease occurred within a few weeks (272). Favorable results were reported using monoclonal anti-TNF- $\alpha$ antibody by Rankin et al. (273). Results using the soluble IL-1 receptor for rheumatoid arthritis are controversial $(274,275)$.

As far as GO is concerned, studies in vitro by Tan et al. (265) showed that GAG synthesis by cultured human orbital fibroblasts could be inhibited in a dose-dependent manner by the soluble IL-1 receptor and IL-1 receptor antagonist. An indirect, cytokine-antagonist effect might be exerted by nicotinamide, which decreases in vitro the activation and proliferation of orbital fibroblasts induced by cytokines (276). However, data on the possible effect of cytokine antagonists in vivo are lacking. It is of interest to mention a recently published study on the effect of pentoxifylline on GO (277). This substance was previously reported to have an in vitro inhibitory effect on HLA-DR expression and on GAG secretion, both basal (278) and induced by IL-1, TNF- $\alpha$, and interferon- $\gamma$ (279). In the in vivo study by Balazs et al. (277) pentoxifylline was administered intravenously (200 mg/ day) and then orally (initial dose, 1,800 mg/day for 4 weeks) to 10 GO patients; after 12 weeks, 8 patients showed an improvement of soft tissue involvement and, to a lesser degree, of proptosis and extraocular muscle involvement, with a reduction in the total eye score. These changes were associated with a decrease in serum GAG levels in responders but not in nonresponders (277). Although potentially interesting, this study was neither randomized nor controlled and involved a small number of patients. Thus, definite conclusions cannot be drawn, because the observed ocular changes might merely reflect the natural history of the disease.

Clinical trials on the use of cytokine antagonists similar to those ongoing in the field of rheumatoid arthritis are lacking for GO. However, the above in vitro and in vivo preliminary studies may lend support to a novel approach for the management of the disease. This may be regarded as a form of immunotherapy of GO. Oral tolerance after oral administration of thyroglobulin has been reported to be an approach suppressing the development of experimental autoimmune thyroiditis in mice (280). However, a recent report has shown that oral tolerization with human thyroglobulin does not affect spontaneous or iodine-induced lymphocytic thyroiditis or serum thyroglobulin autoantibodies in the BB/Wor rat (281). Whether oral tolerization may be applied also to GO in the future is difficult to say in view of the uncertainties on the primary pathogenetic events in this disease. Downregulation of cytokines by the use of cytokine antagonists may well be important tools in the management of GO in the future. However, the question then arises as to which of many could or should be chosen. This is particularly due to the redundant action of cytokines and the complexity of the mechanisms intervening in the initiation and perpetuation of GO. In addition, properly controlled and randomized studies are needed also to establish the safety, effectiveness, and cost/benefit ratio of cytokine antagonists. To return to rheumatoid arthritis, the use of disease-modifying biological agents has been associated with adverse effects in a few patients, including lymphoma, infections, and development of antinuclear antibodies (271). Whether these adverse effects are related to cytokine inhibition or represent a complication of the underlying disease remains to be ascertained, but they must be taken into account before these agents are launched too enthusiastically into the application to GO.

\section{B. Somatostatin analogs}

As pointed out in Section V.C.1, a few recent studies have evaluated the effects of somatostatin analogs on GO (159165). Results seem promising and the rationale for this treatment is rather sound, but controlled and randomized studies enrolling a large number of patients are needed to verify the true effectiveness of these drugs and their superiority over established methods of treatment of the disease.

\section{Colchicine}

Colchicine is an effective antiinflammatory agent that inhibits phagocytosis of the macrophage, reduces chemotaxis of polymorphonucleate leukocytes, and decreases the expression of IL-2 receptors. In addition, it decreases the formation of leukotrienes, stimulates the release of PGE, and inhibits immunoglobulin secretion. A recent, preliminary report on $6 \mathrm{GO}$ patients has shown favorable results on soft tissue changes, and subjective symptoms, with a concomitant decrease in T2 relaxation time at MRI (282). Since this study was uncontrolled, it is difficult to establish whether these changes are related to the natural history of the ophthalmopathy or to the effects of the drug. Also in this case controlled, randomized studies will be required to assess whether this drug may represent a novel therapeutic option for GO.

\section{Concluding Remarks}

GO is a disease that profoundly affects the quality of life. In the evaluation of 70 consecutive GO patients with varying degrees of ocular involvement, Gerding et al. (2) found low scores for several measures exploring the quality of life, such as physical functioning, role functioning, social functioning, mental health, health perception, pain, and energy (Fig. 8). Interestingly, GO patients scored lower than patients with diabetes mellitus, pulmonary emphysema, or heart failure (2). In addition, the low scores did not correlate with severity and activity of ophthalmopathy (2), suggesting that the negative impact of this disfiguring disease is somehow unrelated to its clinical assessment. Furthermore, in the long-term follow-up of GO patients in an incidence cohort study (283), at the end of the story approximately one third of patients, even after treatment, were dissatisfied with their ultimate appearance (Fig. 9). Thus, although GO is often self-limited and apparently nonsevere, nevertheless the disease quite frequently imposes a severe psychological, social, and economic burden on the patient, and this may occur even in forms of 


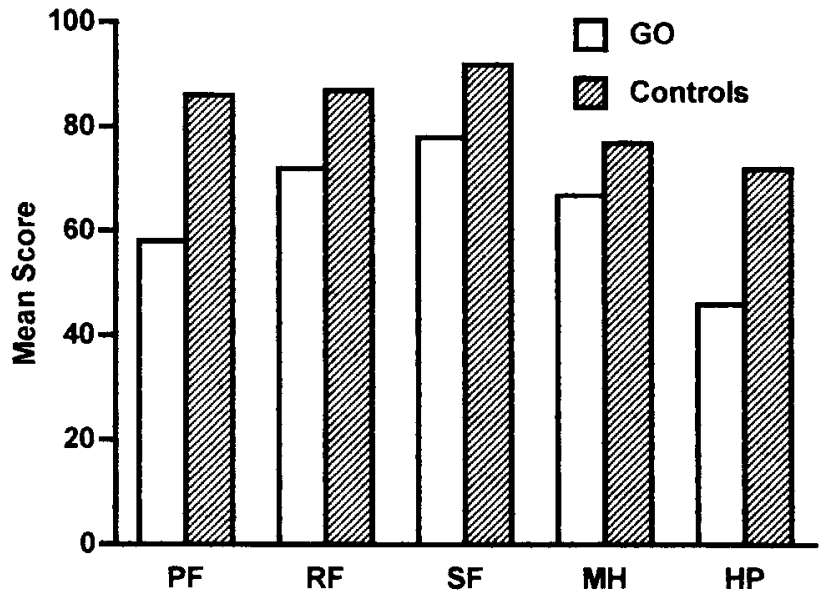

FIG. 8. Quality of life in patients with GO and in a control population. $\mathrm{PF}$, Personal functioning; $\mathrm{RF}$, role functioning; $\mathrm{SF}$, social functioning; MH, mental health; HP, health perception. [Derived from M. N. Gerding et al.: Thyroid 7:885-889, 1997 (2).]

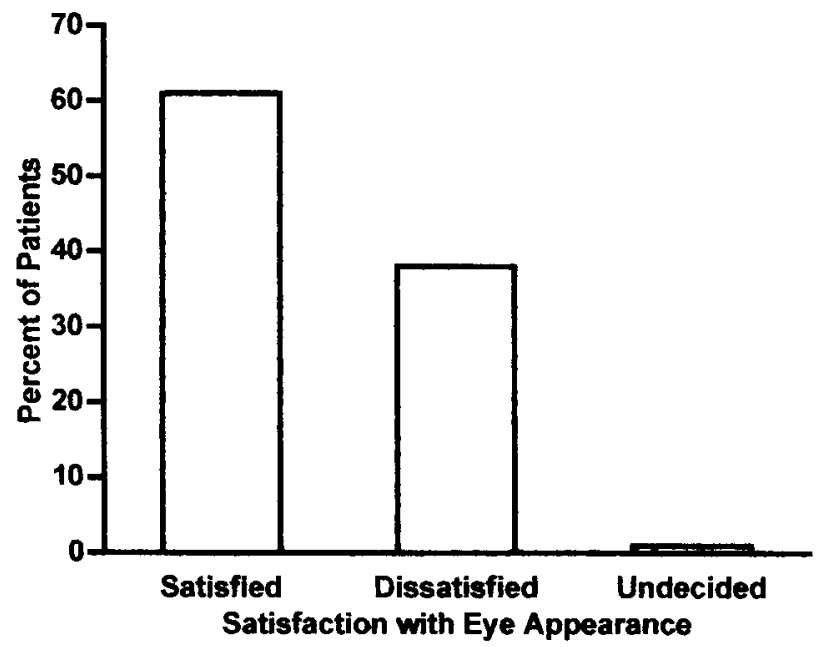

FIG. 9. Satisfaction with eye appearance at the end of follow-up in a cohort of 120 patients with GO. [Derived from G. B. Bartley et al.: Ophthalmology 103:958-962, 1996 (283).]

the disease that may not appear particularly severe to the physician.

The last few years have witnessed relevant developments in our understanding of the pathogenesis of the disease. Progress in the management of GO has not been equally impressive, but novel treatments, such as anticytokine therapy or somatostatin analogs, based on our wider knowledge of the disease mechanisms, are being proposed. The coordinated effort of basic researchers, clinical endocrinologists, ophthalmologists, epidemiologists, orbit surgeons, and radiotherapists should be to define completely the pathogenesis of eye disease and its relationship with thyroid disease, to design impeccable clinical studies (in terms of design of the study and of the assessment of results) on the use of novel drugs, to identify all the correctable risk factors for the development or progression of ophthalmopathy, and to refine the surgical and radiotherapeutic techniques to optimize the final outcome. This is what is really required to improve the management of a disease that is often frustrating not only for the patient but also for the physician.

\section{Acknowledgments}

Our gratitude goes to the long list of colleagues at the Department of Endocrinology of the University of Pisa who in the last $25 \mathrm{yr}$ have been members of the Graves' Ophthalmopathy Group or have contributed with their criticisms and comments to amend our errors. Since management of Graves' ophthalmopathy is typically multidisciplinary, we wish to thank our colleagues who have been collaborating with us for many years, ophthalmologists, radiotherapists, radiologists, and orbit surgeons. In particular we thank Drs. Francesco Cartei, Salvatore Mazzeo, Marco Nardi, and Stefano Sellari-Franceschini, all of whom work in our university.

\section{References}

1. Burch HB, Wartofsky L 1993 Graves' ophthalmopathy: current concepts regarding pathogenesis and management. Endocr Rev 14:747-793

2. Gerding MN, Terwee CB, Dekker FW, Koornneef L, Prummel MF, Wiersinga WM 1997 Quality of life in patients with Graves' ophthalmopathy is markedly decreased: measurement by the Medical Outcomes Study Instrument. Thyroid 7:885-889

3. Bahn RS, Heufelder AE 1993 Pathogenesis of Graves' ophthalmopathy. N Engl J Med 329:1468-1475

4. Gorman CA 1994 Pathogenesis of Graves' ophthalmopathy. Thyroid 4:379-383

5. Heufelder AE 1995 Pathogenesis of Graves' ophthalmopathy: recent controversies and progress. Eur J Endocrinol 132:532-541

6. Bartalena L, Marcocci C, Pinchera A 1997 Treating severe Graves' ophthalmopathy. Bailliere's Clin Endocrinol Metab 11:521-536

7. Marcocci C, Bartalena L, Bogazzi F, Panicucci M, Pinchera A 1989 Studies on the occurrence of ophthalmopathy in Graves' disease. Acta Endocrinol (Copenh) 120:473-478

8. Weetman AP, Cohen SL, Gatter KC, Fells P, Shine B 1989 Immunohistochemical analysis of the retrobulbar tissues in Graves' ophthalmopathy. Clin Exp Immunol 75:222-227

9. Davies TF 1995 Seeing T cells behind the eye. Eur J Endocrinol 132:264-265

10. Otto EA, Ochs K, Hansen C, Wall JR, Kahaly GJ 1996 Orbital tissue-derived T lymphocytes from patients with Graves' ophthalmopathy recognize autologous orbital antigens. J Clin Endocrinol Metab 81:3045-3050

11. Pappa A, Calder V, Ajjan R, Fells P, Ludgate M, Weetman AP, Lightman S 1997 Analysis of extraocular muscle-infiltrating T cells in thyroid-associated ophthalmopathy (TAO). Clin Exp Immunol 109:362-369

12. Heufelder AE, Scriba PC 1996 Characterization of adhesion receptors on cultured microvascular endothelial cells derived from the retroorbital connective tissue of patients with Graves' ophthalmopathy. Eur J Endocrinol 134:51-60

13. Pappa A, Calder V, Fells P, Lightman S 1997 Adhesion molecules expression in vivo on extraocular muscles (EOM) in thyroid-associated ophthalmopathy (TAO). Clin Exp Immunol 108:309-313

14. Heufelder AE, Herterich S, Ernst G, Bahn RS, Heufelder AE 1995 Analysis of retroorbital $\mathrm{T}$ cell antigen receptor variable region gene usage in patients with Graves' ophthalmopathy. Eur J Endocrinol 132:266-277

15. Heufelder AE 1998 T-cell restriction in thyroid eye disease. Thyroid 8:419-422

16. Wiersinga WM 1997 Graves' ophthalmopathy. Thyroid International 3:1-15

17. De Carli D'Elios MM, Mariotti S, Marcocci C, Pinchera A, Ricci M, Romagnani S, Del Prete G 1993 Cytolytic T cells with Th1-like cytokine profile predominate in retroorbital lymphocytic infiltrates of Graves' ophthalmopathy. J Clin Endocrinol Metab 77:1120-1124

18. Grubeck-Loebenstein B, Trieb K, Sztankay A, Holter W, Anderl H, Wick G 1994 Retrobulbar T cells from patients with Graves' 
ophthalmopathy are CD8+ and specifically recognize autologous fibroblasts. J Clin Invest 3:2738-2743

19. McLachlan SM, Prummel MF, Rapoport B 1994 Cell-mediated or humoral immunity in Graves' ophthalmopathy? Profiles of T-cell cytokines amplified by polymerase chain reaction from orbital tissue. J Clin Endocrinol Metab 78:1070-1074

20. Forster G, Otto E, Hansen C, Ochs K, Kahaly G 1998 Analysis of orbital $\mathrm{T}$ cells in thyroid-associated ophthalmopathy. Clin Exp Immunol 112:427-434

21. Bartalena L, Marcocci C, Pinchera A 1996 Cytokine antagonists: new ideas for the management of Graves' ophthalmopathy. J Clin Endocrinol Metab 81:446-448

22. Bahn RS 1996 Graves' ophthalmopathy: the role of cytokines in pathogenesis. In: Gass GH, Kaplan HM (eds) Handbook of Endocrinology, ed 2. CRC Press Inc, Boca Raton, FL, vol 1:287-295

23. Heufelder AE, Smith TJ, Gorman CA, Bahn RS 1991 Increased induction of HLA-DR by interferon- $\gamma$ in cultured retroocular fibroblasts derived from patients with Graves' ophthalmopathy and pretibial myxedema. J Clin Endocrinol Metab 73:307-313

24. Heufelder AE, Bahn RS 1992 Modulation of intercellular adhesion molecule-1 (ICAM-1) by cytokines and Graves' IgGs in cultured Graves' retroocular fibroblasts. Eur J Clin Invest 23:10-17

25. Smith TJ, Bahn RS, Gorman CA, Cheavens M 1991 Stimulation of glycosaminoglycan accumulation by interferon $\gamma$ in cultured retroocular fibroblasts. J Clin Endocrinol Metab 72:1169-1171

26. Korducki JM, Loftus SJ, Bahn RS 1992 Stimulation of glycosaminoglycan production in cultured human retroocular fibroblasts. Invest Ophthalmol Vis Sci 33:2037-2042

27. Heufelder AE, Bahn RS 1994 Modulation of Graves' orbital fibroblast proliferation by cytokines and glucocorticoid receptor agonists. Invest Ophthalmol Vis Sci 35:120-127

28. Mohacsi A, Trieb K, Anderl H, Grubeck-Loebenstein B 1996 Retrobulbar fibroblasts from patients with Graves' ophthalmopathy induce downregulation of APO-1 in T lymphocytes and protect $\mathrm{T}$ cells from apoptosis during coculture. Int Arch Allergy Immunol 109:327-333

29. Sorisky A, Pardasani D, Gagnon A, Smith TJ 1996 Evidence of adipocyte differentiation in human orbital fibroblasts in primary culture. J Clin Endocrinol Metab 81:3428-3431

30. Bahn RS 1996 A possible role for the thyrotropin receptor in thyroid-associated ophthalmopathy. Orbit 15:119-128

31. Heufelder AE 1997 Retro-orbital autoimmunity. Bailliere's Clin Endocrinol Metab 11:499-520

32. McGregor AM 1998 Has the target autoantigen for Graves' ophthalmopathy been found? Lancet 352: 595-596

33. Feliciello A, Porcellini A, Ciullo I, Bonavolontà G, Avvedimento EV, Fenzi G 1993 Expression of thyrotropin-receptor mRNA in healthy and Graves' disease retro-orbital tissue. Lancet 342:337-338

34. Endo T, Ohno M, Kotani S, Gunji K, Onaya T 1993 Thyrotropin receptor in non-thyroid tissue. Biochem Biophys Res Commun 190:774-779

35. Heufelder AE, Dutton CM, Sarkar G, Donovan KA, Bahn RS 1993 Detection of TSH receptor mRNA in cultured fibroblasts from patients with Graves' ophthalmopathy and pretibial dermopathy. Thyroid 3:297-300

36. Mengistu M, Lukes YG, Nagy EV, Burch HB, Carr FE, Lahiri S, Burman KD 1994 TSH receptor gene expression in retroocular fibroblasts. J Endocrinol Invest 17:437-441

37. Endo T, Ohta K, Haraguchi K, Onaya T 1995 Cloning and functional expression of a thyrotropin receptor cDNA from rat cells. J Biol Chem 270:10833-10838

38. Paschke R, Vassart G, Ludgate M 1995 Current evidence for and against the TSH receptor being the common antigen in Graves' disease and thyroid associated ophthalmopathy. Clin Endocrinol (Oxf) 42:565-589

39. Takeshita A, Nagayama Y, Fujiyama K, Yokoyama N, Namba H, Yamashita S, Izumi M, Nagataki S 1992 Molecular cloning and sequencing of an alternatively spliced form of the human thyrotropin receptor transcript. Biochem Biophys Res Commun 188: 1214-1219

40. Graves PN, Tomer Y, Davies TF 1992 Cloning and sequencing of a $1.3 \mathrm{kB}$ variant of the human thyrotropin receptor mRNA lacking the transmembrane domain. Biochem Biophys Res Commun 187: $1135-1143$

41. Paschke R, Metcalfe A, Alcalde L, Vassart G, Weetman A, Ludgate M 1994 Presence of non-functional thyrotropin receptor variant transcripts in retroocular and other tissues. J Clin Endocrinol Metab 79:1234-1238

42. Hunt N, Willey KP, Abend N, Baivers M, Jahner D, Northemann W, Ivell R 1995 Novel splicing variants of the human thyrotropin receptor encode truncated polypeptides without a membrane spanning domain. Endocrine 3:233-240

43. Chang T-C, Wu S-L, Hsiao Y-L, Kuo S-T, Chien L-F, Kuo Y-F, Chang C-C, Chang T-J 1994 TSH and TSH receptor antibody binding sites in fibroblasts of pretibial myxedema are related to the extracellular domain of entire TSH receptor. Clin Immunol Immunopathol 71:113-120

44. Burch HB, Sellitti D, Barnes SG, Nagy EV, Bahn RS, Burman KD 1994 Thyrotropin receptor antisera for the detection of immunoreactive protein species in retroocular fibroblasts obtained from patients with Graves' ophthalmopathy. J Clin Endocrinol Metab 78:1384-1391

45. Stadlmayr W, Spitzweg C, Bichlmair A-M, Heufelder AE 1997 TSH receptor transcripts and TSH receptor-like immunoreactivity in orbital and pretibial fibroblasts of patients with Graves' ophthalmopathy and pretibial myxedema. Thyroid 7:3-12

46. Crisp MS, Lane C, Halliwell M, Wynford-Thomas D, Ludgate M 1997 Thyrotropin receptor transcripts in human adipose tissue. J Clin Endocrinol Metab 82:2003-2005

47. Spitzweg C, Joba W, Hunt N, Heufelder AE 1997 Analysis of human thyrotropin receptor gene expression and immunoreactivity in human orbital tissue. Eur J Endocrinol 136:599-607

48. Bahn RS, Dutton CM, Natt N, Joba W, Spitzweg C, Heufelder AE 1998 Thyrotropin receptor expression in Graves' orbital adipose/ connective tissues: potential autoantigen in Graves' ophthalmopathy. J Clin Endocrinol Metab 83:998-1002

49. Ludgate M, Crisp M, Lane C, Costagliola S, Vassart G, Weetman A, Daunerie C, Many MC 1998 The thyrotropin receptor in thyroid eye disease. Thyroid 8:411-413

50. Costagliola S, Rodien P, Many M-C, Ludgate M, Vassart G 1998 Genetic immunization against the human thyrotropin receptor causes thyroiditis and allows production of monoclonal antibodies recognizing the native receptor. J Immunol 160:1458-1465

51. Valyasevi RW, Erickson DZ, Harteneck DA, Dutton CM, Heufelder AE, Jyonouchi SC, Bahn RS 1999 Differentiation of orbital preadipocyte fibroblasts induces expression of functional thyrotropin receptor. J Clin Endocrinol Metab 84:2557-2562

52. Costagliola S, Alcalde L, Ruj J, Vassart G, Ludgate M 1994 Overexpression of the extracellular domain of the thyrotropin receptor in bacteria - production of thyrotropin-binding inhibiting immunoglobulins. J Mol Endocrinol 13:11-21

53. Arnold K, Metcalfe R, Weetman AP 1995 Immunoglobulin A class fibroblast antibodies in patients with Graves' disease and pretibial myxedema. J Clin Endocrinol Metab 80:3427-3429

54. Mori S, Yoshikawa N, Tokoro T, Ikehara S, Inoue Y, Nishikawa M, Inada M 1996 Studies of retroorbital tissue xenografts from patients with Graves' ophthalmopathy in severe combined immunodeficient (SCID) mice: detection of thyroid-stimulating antibody. Thyroid 6:275-281

55. Costagliola S, Many M-C, Stalman-Falys M, Vassart G, Ludgate M 1996 Transfer of thyroiditis, with syngeneic spleen cells sensitized with the human thyrotropin receptor, to naive balb/c and nod mice. Endocrinology 137:4637-4643

56. Bahn RS, Dutton CM, Heufelder AE, Sarkar G 1994 A genomic point mutation in the extracellular domain of the thyrotropin receptor in patients with Graves' ophthalmopathy. J Clin Endocrinol Metab 78:256-260

57. Cuddihy RM, Dutton CM, Bahn RS 1995 A polymorphism in the extracellular domain of the thyrotropin receptor is highly associated with autoimmune thyroid disease in females. Thyroid 5:89-95

58. Bohr URM, Behr M, Loos U 1993 A heritable point mutation in an extracellular domain on the TSH receptor involved in the interaction with Graves' immunoglobulins. Biochim Biophys Acta 1216: 504-508

59. Watson PF, French A, Pickerill AP, McIntosh RS, Weetman AP 
1995 Lack of association between a polymorphism in the coding region of the thyrotropin receptor gene and Graves' disease. J Clin Endocrinol Metab 80:1032-1035

60. Kotsa KD, Watson PF, Weetman AP 1997 No association between a thyrotropin receptor gene polymorphism and Graves' disease in the female population. Thyroid 7:31-33

61. Salvi M, Miller A, Wall JR 1988 Human orbital tissue and thyroid membranes express a $64 \mathrm{kDa}$ protein which is recognized by autoantibodies in the serum of patients with thyroid-associated ophthalmopathy. FEBS Lett 232:135-139

62. Dong Q, Ludgate M, Vassart G 1991 Cloning and sequencing of a novel $64 \mathrm{kDa}$ autoantigen recognized by patients with autoimmune thyroid disease. J Clin Endocrinol Metab 72:1375-1381

63. Kendler DL, Rootman J, Huber GK, Davies TF 1991 A 64 KDa membrane antigen is a recurrent epitope for natural autoantibodies in patients with Graves' thyroid and ophthalmic disease. Clin Endocrinol (Oxf) 35:539-547

64. Wall JR, Scalise D, Hayes M, Stolarski C, Sato M, Salvi M, Nebes V 1995 Native gel electrophoresis of the $64 \mathrm{kDa}$ protein shows that is eye specific and an important target for autoantibodies in patients with thyroid-associated ophthalmopathy. J Clin Endocrinol Metab 80:1226-1232

65. Kubota S, Gunji K, Ackrell BAC, Cochran B, Stolarski C, Wengrowicz S, Kennerdell JS, Hiromatsu Y, Wall J 1998 The 64-kilodalton eye muscle protein is the flavoprotein subunit of mitochondrial succinate dehydrogenase: the corresponding serum antibodies are good markers of an immune-mediated damage to the eye muscle in patients with Graves' hyperthyroidism. J Clin Endocrinol Metab 83:444-447

66. Gunji K, De Bellis A, Kubota S, Swanson J, Wengrowicz S, Cochran B, Ackrell BAC, Salvi M, Bellastella A, Bizzarro A, Sinisi AA, Wall JR 1999 Serum antibodies against the flavoprotein subunit of succinate dehydrogenase are sensitive markers of eye muscle autoimmunity in patients with Graves' hyperthyroidism. J Clin Endocrinol Metab 84:1255-1262

67. Kubota S, Gunji K, Stolarski C, Kennerdell JS, Wall J 1998 Reevaluation of the prevalences of serum autoantibodies reactive with "64-kd eye muscle proteins" in patients with thyroid-associated ophthalmopathy. Thyroid 8:175-179

68. Gunji K, Kubota S, Swanson J, Kiljanski J, Bednarczuk T, Wengrowicz S, Salvi M, Wall JR 1998 Role of the eye muscles in thyroid eye disease: identification of the principal autoantigens. Thyroid 8:553-556

69. Zhang ZG, Wall JR, Bernard NF 1995 Identification of antigenic epitopes of 1D antigen recognized by antibodies in the serum of patients with thyroid-associated ophthalmopathy. Clin Immunol Immunopathol 77:193-200

70. Zhang ZG, Wall JR, Bernard NF 1996 Tissue distribution and quantitation of a gene expressing a $64 \mathrm{kDa}$ antigen associated with thyroid-associated ophthalmopathy. Clin Immunol Immunopathol 80:236-244

71. Wu YJ, Clarke EM, Shepherd P 1998 Prevalence and significance of antibodies reactive with eye muscle membrane antigens in sera from patients with Graves' ophthalmopathy and other thyroid and nonthyroid diseases. Thyroid 8:167-174

72. Atabay C, Tyutyunikov A, Scalise D, Stolarski C, Hayes MB, Kennerdell JS, Wall J 1995 Serum antibodies reactive with eye muscle membrane antigens are detected in patients with nonspecific orbital inflammation. Ophthalmology 102:145-153

73. Hiromatsu $Y$, Tanaka $K$, Ishisaka N, Kamachi J, Kuroki T, Hoshino T, Inoue Y, Wall JR, Nonaka K 1995 Human histocompatibility leukocyte antigen-DR and heat shock protein-70 expression in eye muscle tissue in thyroid associated ophthalmopathy. J Clin Endocrinol Metab 80:685-691

74. Molnar I, Kaczur V, Boros A, Krajczar G, Balazs C 1995 IgA autoantibodies against human eye muscle antigen detected by Western blotting and immunohistochemical methods in Graves' disease. J Endocrinol Invest 18:408-414

75. Koga M, Hiromatsu Y, Jimi A, Inoue Y, Nonaka K 1998 Possible involvement of Fas-mediated apoptosis in eye muscle tissue from patients with thyroid-associated ophthalmopathy. Thyroid 8:311318

76. Perros P, Crombie AL, Kendall-Taylor P 1995 Natural history of thyroid-associated ophthalmopathy. Clin Endocrinol (Oxf) 42:45-50

77. Bartley GB, Fatourechi V, Kadrmas EF, Jacobsen SJ, Ilstrup DM, Garrity JA, Gorman CA 1996 The treatment of Graves' ophthalmopathy in an incidence cohort. Am J Ophthalmol 121:200-206

78. Bartley GB, Fatourechi V, Kadrmas EF, Jacobsen SJ, Ilstrup DM, Garrity JA, Gorman CA 1996 Clinical features of Graves' ophthalmopathy in an incidence cohort. Am J Ophthalmol 121:284-290

79. Salvi M, Spaggiari E, Neri F, Macaluso C, Gardini E, Ferrozzi F, Minelli R, Wall JR, Roti E 1997 The study of visual evoked potentials in patients with thyroid-associated ophthalmopathy identifies asymptomatic optic nerve involvement. J Clin Endocrinol Metab 82:1027-1030

80. Mourits MP, Koornneef L, Wiersinga WM, Prummel MF, Berghout A, van der Gaag R 1989 Clinical criteria for the assessment of disease activity in Graves' ophthalmopathy: a novel approach. Br J Ophthalmol 73:639-644

81. Mourits MP, Prummel MF, Wiersinga WM, Koornneef L 1997 Clinical activity score as a guide in the management of patients with Graves' ophthalmopathy. Clin Endocrinol (Oxf) 47:9-14

82. Pinchera A, Wiersinga W, Glinoer D, Kendall-Taylor P, Koornneef L, Marcocci C, Schleusener H, Romaldini J, Niepominiscze H, Nagataki S, Izumi M, Inoue Y, Stockigt J, Wall J, Greenspan F, Solomon D, Garrity J, Gorman CA 1992 Classification of eye changes of Graves' disease. Thyroid 2:235-236

83. Gorman CA 1998 The measurement of change in Graves' ophthalmopathy. Thyroid 8:539-543

84. Prummel MF, Suttorp-Schulten MSA, Wiersinga WM, Verbeek AM, Mourits MP, Koornneef L 1993 A new ultrasonographic method to detect disease activity and predict response to immunosuppressive treatment in Graves' ophthalmopathy. Ophthalmology 100:556-561

85. Kahaly G, Schuler M, Sewell AC, Bernhard G, Beyer J, Krause U 1990 Urinary glycosaminoglycans in Graves' ophthalmopathy. Clin Endocrinol (Oxf) 33:35-44

86. Kahaly G, Hansen C, Beyer J, Winand R 1994 Plasma glycosaminoglycans in endocrine ophthalmopathy. J Endocrinol Invest 17: $45-50$

87. Kahaly G, Forster G, Hansen C 1998 Glycosaminoglycans in thyroid eye disease. Thyroid 8:429-432

88. Utech CJ, Khatibnia U, Winter PF, Wulle KG 1995 MR T2 relaxation time for the assessment of retrobulbar inflammation in Graves' ophthalmopathy. Thyroid 5:185-193

89. Postema PTE, Krenning EP, Wijngaarde R, Kooy PPM, Oei HY, van den Bosch WA, Reubi JC, Wiersinga WM, Hooijkaas $H$, van der Loos T, Poublon RML, Lamberts SWJ, Hennemann G 1994 [ ${ }^{111}$ In-DTPA-D-Phe1] octreotide scintigraphy in thyroidal and orbital Graves' disease: a parameter for disease activity? J Clin Endocrinol Metab 79:1845-1851

90. Kahaly G, Diaz M, Hahn K, Beyer J, Bockisch A 1995 Indium111-pentreotide scintigraphy in Graves' ophthalmopathy. J Nucl Med 36:550-554

91. Durak I, Durak H, Ergin M, Yurekli Y, Kaynak S 1995 Somatostatin receptors in the orbit. Clin Nucl Med 20:237-242

92. Bohuslavziki KH, Oberwohrmann S, Brenner W, Eberhardt JU, Monig H, Clausen M, Sippel C, Wolf H, Epe B, Henze E 1995 ${ }^{111}$ In-octreotide imaging in patients with long-standing Graves' ophthalmopathy. Nucl Med Commun 16:912-916

93. Moncayo R, Baldissera I, De Cristoforo C, Kendler D, Donnemiller E 1997 Evaluation of immunological mechanisms mediating thyroid-associated ophthalmopathy by radionuclide imaging using the somatostatin analog ${ }^{111}$ In-octreotide. Thyroid 7:21-29

94. Kahaly G, Gorges R, Diaz M, Hommel G, Bockisch A 1998 Indium-111-pentreotide in Graves' disease. J Nucl Med 39:533-536

95. Gerding MN, von der Zan FM, van Royen EA, Koornneef L, Krenning EP, Wiersinga WM, Prummel MF 1999 Octreotide-scintigraphy is a disease-activity parameter in Graves' ophthalmopathy. Clin Endocrinol (Oxf) 50:373-379

96. Wiersinga WM, Gerding MN, Prummel MF, Krenning EP 1998 Octreotide scintigraphy in thyroidal and orbital Graves' disease. Thyroid 8:433-436

97. Hudson HL, Levin L, Feldon SE 1991 Graves' exophthalmos unrelated to extraocular muscle enlargement. Superior rectus muscle 
inflammation may induce venous obstruction. Ophthalmology 98: 1495-1499

98. Benning H, Lieb W, Kahaly G, Grehn F 1994 Doppler ultrasound findings in patients with thyroid ophthalmopathology. Ophthalmology 91:20-25

99. Prummel MF, Wiersinga WM 1998 Immunomodulatory treatment of Graves' ophthalmopathy. Thyroid 8:543-546

100. Weetman A, Wiersinga WM 1998 Current management of thyroidassociated ophthalmopathy in Europe. Results of an international survey. Clin Endocrinol (Oxf) 49:21-28

101. Kendall-Taylor P 1998 Current management of thyroid-associated ophthalmopathy. Clin Endocrinol (Oxf) 49:11-12

102. Donaldson SS, Bagshaw MA, Kriss JP 1973 Supervoltage orbital radiotherapy for Graves' ophthalmopathy. J Clin Endocrinol Metab 37:276-285

103. Prummel MF, Mourits MP, Berghout A, Krenning EP, van der Gaag R, Koornneef L, Wiersinga WM 1989 Prednisone and cyclosporine in the treatment of severe Graves' ophthalmopathy. N Engl J Med 321:1353-1359

104. Rose GE 1998 Clinical activity score as a guide in the management of patients with Graves' orbitopathy. Clin Endocrinol (Oxf) 47:15

105. Char DH 1996 Thyroid eye disease. Br J Ophthalmol 80:922-926

106. Kulla S, Moore S 1979 Orthoptics in Graves' disease. Ophthalmology 86:2053-2058

107. Wiersinga WM 1990 Immunosuppressive treatment of Graves' ophthalmopathy. Trends Endocrinol Metab 1:377-381

108. Bartalena L, Marcocci C, Bogazzi F, Bruno-Bossio G, Pinchera A 1991 Glucocorticoid therapy of Graves' ophthalmopathy. Exp Clin Endocrinol 97:320-328

109. Smith TJ 1984 Dexamethasone regulation of glycosaminoglycan synthesis in cultured human fibroblasts: similar effects of glucocorticoid and thyroid hormone therapy. J Clin Invest 64:2157-2163

110. Smith TJ, Bahn RS, Gorman CA 1989 Hormonal regulation of hyaluronate synthesis in cultured fibroblasts; evidence for differences between retroocular and dermal fibroblasts. J Clin Endocrinol Metab 69:1019-1023

111. Kahaly G, Schrezenmeir J, Krause U, Schweikert B, Meuer S, Muller W 1986 Ciclosporin and prednisone v. prednisone in treatment of Graves' ophthalmopathy: a controlled, randomized and prospective study. Eur J Clin Invest 16:415-422

112. Prummel MF, Mourits MP, Blank L, Berghout A, Koornneef L, Wiersinga WM 1993 Randomised double-blind trial of prednisone vs. radiotherapy in Graves' ophthalmopathy. Lancet 342:949-954

113. Mori S, Yoshikawa N, Horimoto M, Yoshimura M, Ogawa Y, Nishikawa M, Inada M 1995 Thyroid stimulating antibody in sera of Graves' ophthalmopathy patients as a possible marker for predicting the efficacy of methylprednisolone pulse therapy. Endocr J 42:442-448

114. Colao A, Lastoria S, Ferone D, Pivonello R, Macchia PE, Vassallo P, Bonavolontà G, Muto P, Lombardi G, Fenzi G 1998 Orbital scintigraphy with [ ${ }^{111} \mathrm{In}$-diethylenetriamine pentaacetic acid-DPhe1]-octreotide predicts the clinical response to corticosteroid therapy in patients with Graves' ophthalmopathy J Clin Endocrinol Metab 83:3790-3794

115. Marcocci C, Bartalena L, Panicucci M, Marconcini C, Cartei F, Cavallacci G, Laddaga M, Campobasso G, Baschieri L, Pinchera A 1987 Orbital cobalt irradiation combined with retrobulbar or systemic corticosteroids for Graves' ophthalmopathy: a comparative study. Clin Endocrinol (Oxf) 27:33-42

116. Pinchera A, Bartalena L, Chiovato L, Marcocci C 1984 Radiotherapy of Graves' ophthalmopathy. In: Gorman CA, Waller RR, Dyer JA (eds) The Eye and Orbit in Thyroid Disease. Raven Press, New York, pp 301-316

117. Bartalena L, Marcocci C, Manetti L, Tanda ML, Dell'Unto E, Rocchi R, Cartei F, Pinchera A 1998 Orbital radiotherapy for Graves' ophthalmopathy. Thyroid 8:439-441

118. Kahaly G, Beyer J 1988 Immunosuppressant therapy of thyroid eye disease. Klin Wochenschr 66:1049-1059

119. Marcocci C, Bartalena L, Bruno-Bossio G, Vanni G, Cartei F, Bogazzi F, Pinchera A 1993 Orbital radiotherapy in the treatment of endocrine ophthalmopathy: when and why? In: Kahaly G (ed), Endocrine Ophthalmopathy-Molecular, Immunological and Clinical Aspects. Karger, Basel, pp 131-141
120. Marcocci C, Bartalena L, Bogazzi F, Bruno-Bossio G, Pinchera A 1991 Role of orbital radiotherapy in the treatment of Graves' ophthalmopathy. Exp Clin Endocrinol 97:332-337

121. Petersen IA, Kriss JP, McDougall IR, Donaldson SS 1990 Prognostic factors in the radiotherapy if Graves' ophthalmopathy. Int J Radiat Oncol Biol Phys 19:259-264

122. Nakahara H, Noguchi S, Murakami N 1995 Graves' ophthalmopathy: MR evaluation of 10-Gy vs. 24-Gy irradiation combined with systemic corticosteroids. Radiology 196:857-862

123. Kahaly GJ, Rösler H-P, Pitz S, Hommel G 2000 Low- versus highdose radiotherapy for Graves' ophthalmopathy: a randomized, single blind trial. J Clin Endocrinol Metab 85:102-108

124. Bartalena L, Marcocci C, Chiovato L, Laddaga M, Lepri G, Andreani D, Cavallacci G, Baschieri L, Pinchera A 1983 Orbital cobalt irradiation combined with systemic corticosteroids for Graves' ophthalmopathy: comparison with systemic corticosteroids alone. J Clin Endocrinol Metab 56:1139-1144

125. Miller ML, Goldberg SH, Bullock JD 1991 Radiation retinopathy after standard radiotherapy for thyroid-related ophthalmopathy. Am J Ophthalmol 112:600-601

126. Kinyoun JL, Kalina RE, Brower SA, Mills RP, Johnson RH 1984 Radiation retinopathy after orbital irradiation for Graves' ophthalmopathy. Arch Ophthalmol 102:1473-1476

127. Orcutt JC, Kinyoun JL 1995 Radiation and Graves' ophthalmopathy (letter). J Clin Endocrinol Metab 80:2543

128. Tallstedt L, Lundell G, Lundell M, Blomgren $\mathbf{H}$, Is there a risk of retinopathy after retrobulbar radiotherapy for Graves' ophthalmopathy? A preliminary report. Proceedings of the VIth International Symposium on Graves' ophthalmopathy, Amsterdam, November 27-28, 1998, p 21 (Abstract OR-12)

129. Nygaard B, Specht L 1998 Transitory blindness after retrobulbar irradiation of Graves' ophthalmopathy. Lancet 351:725-726

130. Snijders-Keilholz A, De Keizer RJW, Goslings BM, Van Dam EWCM, Jansen JTM, Broerse JJ 1996 Probable risk of tumor induction after retro-orbital irradiation for Graves' ophthalmopathy. Radiother Oncol 38:69-71

131. Blank LECM, Barendsen GW, Prummel MF, Stalpers L, Wiersinga W, Koorneef L 1996 Probable risk of tumor induction after retro-orbital irradiation for Graves' ophthalmopathy (letter). Radiother Oncol 40:187-188

132. Gorman CA 1999 Double-blind prospective controlled study of orbital radiotherapy for Graves' ophthalmopathy: results at one year. J Endocrinol Invest 22 (Suppl to issue 6):102 (Abstract)

133. Wiersinga WM, Prummel MF 1995 Retrobulbar radiation in Graves' ophthalmopathy. J Clin Endocrinol Metab 80:345-347

134. Marcocci C, Bartalena L, Bogazzi F, Bruno-Bossio G, Lepri A, Pinchera A 1991 Orbital radiotherapy combined with high-dose systemic glucocorticoids for Graves' ophthalmopathy is more effective than orbital radiotherapy alone: results of a prospective study. J Endocrinol Invest 14:853-860

135. Garrity JA, Fatourechi V, Bergstralh EJ, Bartley GB, Beatty CW, DeSanto LW, Gorman CA 1993 Results of transantral orbital decompression in 428 patients with severe Graves' ophthalmopathy. Am J Ophthalmol 116:533-547

136. Fatourechi V, Garrity JA, Bartley GB, Bergstralh EJ, DeSanto LW, Gorman CA 1994 Graves opthalmopathy. Results of transantral orbital decompression performed primarily for cosmetic indications. Ophthalmology 101:938-942

137. Lyons CJ, Rootman J 1994 Orbital decompression for disfiguring exophthalmus in thyroid orbitopathy. Ophthalmology 110:223-230

138. Kalmann R, Mourits MP, van der Pol JP, Koornneef L 1997 Coronal approach for rehabilitative orbital decompression in Graves' ophthalmopathy. Br J Ophthalmol 81:41-45

139. McCord CD 1985 Current trends in orbital decompression. Ophthalmology 92:21-33

140. Tallstedt L 1998 Surgical treatment of thyroid eye disease. Thyroid 8:447-452

141. Nunery WR, Nunery CW, Martin RT, Truong TV, Osborn DR 1997 The risk of diplopia following orbital floor and medial wall decompression in subtypes of ophthalmic Graves' disease. Ophthal Plast Reconstr Surg 13:153-160

142. Hutchinson BM, Kyle PM 1995 Long-term visual outcome fol- 
lowing orbital decompression for dysthyroid eye disease. Eye 9:578-581

143. Weissman RA, Osguthorpe JD 1994 Orbital decompression in Graves' disease. Arch Otolaryngol Head Neck Surg 120:831-834

144. Shepard KG, Levin PS, Terris DJ 1998 Balanced orbital decompression for Graves' ophthalmopathy. Laryngoscope 108: $1648-1653$

145. Trokel S, Kazim M, Moore S 1993 Orbital fat removal. Decompression for Graves' orbitopathy. Ophthalmology 100:674-682

146. Olivari N 1991 Transpalpebral decompression of endocrine ophthalmopathy (Graves' disease) by removal of intraorbital fat: experience with 147 operations over 5 years. Plast Reconstr Surg 87:627-641

147. Adenis JP, Robert PY, Lasudry JG, Dalloul Z 1998 Treatment of proptosis with fat removal orbital decompression in Graves' ophthalmopathy. Eur J Ophthalmol 8:246-252

148. Tremolada C, Aschero Tremolada M 1997 The "triple technique" for treating stable Graves' ophthalmopathy. Plast Reconstr Surg 100:40-48

149. Borel JF, Ryffel B 1985 The mechanism of action of ciclosporin: a continuing puzzle. In: Schindler R (ed) Cyclosporin in Autoimmune Disease. Springer Verlag, Berlin, pp 25-32

150. Editorial 1985 Cyclosporin in autoimmune disease. Lancet 1 : 909-911

151. Weetman AP, Ludagte M, Mills PV, McGregor AM, Beck L, Lazarus JH, Hall R 1983 Cyclosporine improves Graves' ophthalmopathy. Lancet 3:486-489

152. Dandona P, Marshall NJ, Bidey SP, Nathan A, Havard CWH 1979 Exophthalmos and pretibial myxoedema not responding to plasmapheresis. Br Med J 2:667-668

153. Glinoer D, Etienne-Decerf J, Schrooven M, Sand G, Hoyoux P, Mahieu P, Winand R 1986 Beneficial effects of intensive plasma exchange followed by immunosuppressive theraoy in severe Graves' ophthalmopathy. Acta Endocrinol (Copenh) 111:30-38

154. Berlin G, Hjelm H, Lieden G, Tegler L 1990 Plasma exchange in endocrine ophthalmopathy. J Clin Apheresis 5:192-196

155. Sawers JSA, Irvine WJ, Toft AD, Urbaniak SJ, Donaldson AA 1981 Plasma exchange in conjunction with immunosuppressive drug therapy in the treatment of endocrine exophthalmos. J Clin Lab Immunol 6:245-250

156. Kelly W, Longson D, Smithard D, Fawcitt R, Wensley R, Noble J, Keeley J 1983 An evaluation of plasma exchange for Graves' ophthalmopathy. Clin Endocrinol (Oxf) 18:485-493

157. Campion EW 1992 Desperate diseases and plasmapheresis. N Engl J Med 326:1425-1427

158. Krenning EP, Kwekkeboom DJ, Bakker WH, Breeman WAP, Kooij PPM, Oei HY, van Hagen M, Postema PTE, deJong M, Reubi JC, Visser TJ, Reijs AEM, Hofland LJ, Koper JW, Lamberts SWJ 1993 Somatostatin receptor scintigraphy with [ ${ }^{111}$ In-DTPAD-Phe1]- and [123I-Tyr3]-octreotide: the Rotterdam experience with more than 1000 patients. Eur J Nucl Med 20:716-731

159. Krassas GE 1998 Somatostatin analogues in the treatment of thyroid eye disease. Thyroid 8:443-445

160. Chang TC, Kao SCS, Huang KM 1992 Octreotide and Graves' ophthalmopathy and pretibial myxoedema. Br Med J 304:158

161. Krassas GE, Dumas A, Pontikides N, Kaltsas T 1995 Somatostatin receptor scintigraphy and octreotide treatment in patients with thyroid eye disease. Clin Endocrinol (Oxf) 42:571-580

162. Kung AWC, Michon J, Tai KS, Chan FL 1996 The effect of somatostatin vs. corticosteroid in the treatment of Graves' ophthalmopathy. Thyroid 6:381-384

163. Ozata M, Bolu E, Sengul A, Tasar M, Beyhan Z, Corakci A, Gundogan MA 1996 Effects of octreotide treatment on Graves' ophthalmopathy and circulating sICAM-1 levels. Thyroid 6: 283-288

164. Krassas GE, Kaltsas T, Dumas A, Pontikides N, Tolis G 1997 Lanreotide in the treatment of patients with thyroid eye disease. Eur J Endocrinol 136:416-422

165. Krassas GE, Doumas A, Kaltsas T, Halkias A, Pontikides N 1999 Somatostatin receptor scintigraphy before and after treatment with somatostatin analogues in patients with thyroid eye disease. Thyroid 9:47-52

166. Hansson HA, Petruson B, Skottnerm A 1986 Somatomedin C in the pathogenesis of malignant exophthalmos of endocrine origin. Lancet 1:218-219

167. Kekow J, Rheinhold D, Pap T, Ansorge S 1998 Intravenous immunoglobulins and transforming growth factor- $\beta$. Lancet 351:184185

168. Antonelli A, Saracino A, Alberti B, Canapicchi R, Cartei F, Lepri A, Laddaga M, Baschieri L 1992 High-dose intravenous immunoglobulin treatment in Graves' ophthalmopathy. Acta Endocrinol (Copenh) 126:13-23

169. Kahaly G, Pitz S, Muller-Forell W, Hommel G 1996 Randomized trial of intravenous immunoglobulins versus prednisolone in Graves' ophthalmopathy. Clin Exp Immunol 106:197-202

170. Seppel T, Schlaghecke R, Becker A, Engelbrecht V, Feldkamp J, Kornely E 1996 High-dose intravenous therapy with 7S immunoglobulins in autoimmune endocrine ophthalmopathy. Clin Exp Rheumatol 14[Suppl 15]: S109-S114

171. Baschieri L, Antonelli A, Nardi S, Alberti B, Lepri A, Canapicchi R, Fallahi P 1997 Intravenous immunoglobulin vs. corticosteroid in treatment of Graves' ophthalmopathy. Thyroid 7:579-585

172. Kolodziej-Maciejewska H, Reterski Z 1985 Positive effect of bromocriptine treatment in Graves' disease orbitopathy. Exp Clin Endocrinol 86:241-245

173. Lopatynsky MO, Krohel GB 1989 Bromocriptine therapy for thyroid ophthalmopathy. Am J Ophthalmol 107:680-681

174. Harden RM, Chisolm CJS, Cant JS 1967 The effect of metrodinazole on thyroid function and exophthalmos in man. Ophthalmology 16:890-898

175. Zesen W, Shubai J, Zutong Z 1985 The effect of acupuncture in 40 cases of endocrine ophthalmopathy. J Trad Chinese Med 5:19-21

176. Rogvi-Hansen B, Perrild H, Christensen T, Detmar SE, SiersbaekNielsen K, Hansen JEM 1991 Acupuncture in the treatment of Graves' ophthalmopathy. A blinded randomized study. Acta Endocrinol (Copenh) 124:143-145

177. Coats DK, Payne EA, Piager DA, Wallace DK 1999 Early strabismus surgery for thyroid ophthalmopathy. Ophthalmology 106: 324-329

178. Dyer JA 1984 Ocular muscle surgery. In: Gorman CA, Waller RR, Dyer JA (eds) The Eye and Orbit in Thyroid Disease. Raven Press, New York, pp 253-262

179. Putterman AM 1997 Thyroid ophthalmopathy: surgical management. In: Bardin CW (ed) Current Therapy in Endocrinology and Metabolism, ed 6. Mosby, St. Louis, p 85-90

180. Mourits MP, Koornneef L, van Mourik-Noordenbos A, van der Meulen-Schot HM, Prummel MF, Wiersinga WM, Berghout A 1990 Extraocular muscle surgery for Graves' ophthalmopathy: does prior treatment influence surgical outcome? Br J Ophthalmol 74: 481-483

181. Lueder GT, Scott WE, Kutsche PJ, Keech RV 1992 Long-term results of adjustable suture surgery for strabismus secondary to thyroid ophthalmopathy. Ophthalmology 99:993-997

182. Kraus DJ, Bullock JD 1993 Treatment of thyroid ocular myopathy with adjustable and nonadjustable suture strabismus surgery. Trans Am Ophthalmol Soc 91:67-79

183. Garrity JA 1992 Graves' ophthalmopathy: an ophthalmologist's perspective. Thyroid Today 15:1-9

184. Olver JM 1998 Botulinum toxin A treatment of overactive corrugator supercilii in thyroid eye disease. Br J Ophthalmol 82:528-533

185. Mourits MP, Koornneef L 1991 Lid lengthening by sclera interposition for eyelid retraction in Graves' ophthalmopathy. Br J Ophthalmol 75:344-347

186. DeGroot LJ, Mangklabruks A, McCormick M 1990 Comparison of $\mathrm{RA}^{131}$ I treatment protocols for Graves' disease. J Endocrinol Invest 13:111-118

187. Gwynup G, Elias AN, Anscher MS 1982 Effect on exophthalmos of various methods of treatment of Graves' disease. JAMA 247: 2136-2138

188. Karlsson AF, Wetermark K, Dahlberg PA, Jansson R, Enoksson P 1989 Ophthalmopathy and thyroid stimulation. Lancet 2:691

189. Prummel MF, Wiersinga WM, Mourits MP, Koornneef L, Berghout A, van der Gaag R 1989 Amelioration of eye changes of Graves' ophthalmopathy by achieving euthyroidism. Acta Endocrinol (Copenh) 121[Suppl 2]:185-189

190. Prummel MF, Wiersinga WM, Mourits MP, Koornneef L, Berg- 
hout A, van der Gaag R 1990 Effect of abnormal thyroid function on the severity of Graves' ophthalmopathy. Arch Intern Med 150: 1098-1101

191. Marcocci C, Bartalena L, Bogazzi F, Bruno-Bossio G, Pinchera A 1992 Relationship between Graves' ophthalmopathy and type of treatment of Graves' hyperthyroidism. Thyroid 2:171-178

192. Bartalena L, Marcocci C, Bogazzi F, Manetti L, Tanda ML, Dell'Unto E, Bruno-Bossio G, Nardi M, Bartolomei MP, Lepri A, Rossi G, Martino E, Pinchera A 1998 Relation between therapy for hyperthyroidism and the course of Graves' ophthalmopathy. N Engl J Med 338:73-78

193. Vitti P, Rago T, Chiovato L, Pallini S, Santini F, Fiore E, Rocchi R, Martino E, Pinchera A 1997 Clinical features of patients with Graves' disease undergoing remission after antithyroid drug treatment. Thyroid 7:369-375

194. Hashizume K, Ichikawa K, Sakurai A, Suzuki S, Takeda T, Kobayashi M, Miyamoto T, Arai M, Nagasawa T 1991 Administration of thyroxine in Graves' disease: effects on the level of antibodies to thyroid-stimulating hormone receptors and on the risk of recurrence of hyperthyroidism. N Engl J Med 324:947-953

195. Edmonds CJ, Tellez M 1994 Treatment of Graves' disease by carbimazole: high dose with thyroxine compared to titration dose. J Endocrinol 131:120-124

196. Tamai H, Hayaki I, Kawai K, Komaki G, Matsubayashi S, Kuma K, Kumagai LP, Nagataki S 1995 Lack of effect of thyroxine administration on elevated thyroid stimulating receptor antibody levels in treated Graves' disease patients. J Clin Endocrinol Metab 80:1481-1485

197. McIver B, Rae P, Beckett G, Wilkinson E, Gold A, Toft A 1996 Lack of effect of thyroxine in patients with Graves' hyperthyroidism who are treated with an antithyroid drug. N Engl J Med 334:220-224

198. Lucas A, Salinas I, Rius F, Pizarro E, Granada ML, Foz M, Sanmarti A 1997 Medical therapy of Graves' disease-does thyroxine prevent recurrence of hyperthyroidism? J Clin Endocrinol Metab 82: 2410-2413

199. Pujol P, Osman A, Grabar S, Daurès J-P, Gaitier-Dereure F, Boegner C, Baldet L, Raye R, Bringer J, Jaffiol C 1998 TSH suppression combined with carbimazole for Graves' disease: effect on remission and relapse rates. Clin Endocrinol (Oxf) 48:635-640

200. Marcocci C, Bartalena L, Pinchera A 1998 Ablative or non-ablative therapy for Graves' hyperthyroidism in patients with ophthalmopathy? J Endocrinol Invest 21:468-471

201. Solomon B, Glinoer D, Lagasse R, Wartofsky L 1990 Current trends in the management of Graves' disease. J Clin Endocrinol Metab 70:1518-1524

202. Gorman CA 1995 Radioiodine therapy does not aggravate Graves' ophthalmopathy. J Clin Endocrinol Metab 80:340-342

203. Pinchera A, Bartalena L, Marcocci C 1995 Radioiodine may be bad for Graves' ophthalmopathy, but .... J Clin Endocrinol Metab 80:342-345

204. Marcocci C, Bartalena L, Bogazzi F, Bruno-Bossio G, Tanda ML, Manetti L, Dell'Unto E, Pinchera A 1996 Radioiodine and thyroidassociated ophthalmopathy. Orbit 15:197-203

205. Bartalena L, Marcocci C, Bogazzi F, Panicucci M, Lepri A, Pinchera A 1989 Use of corticosteroids to prevent progression of Graves' ophthalmopathy after radioiodine therapy for hyperthyroidism. N Engl J Med 321:1349-1352

206. Tallstedt L, Lundell G, Torring O, Wallin G, Ljunggren J-G, Blomgren H, Taube A, and the Thyroid Study Group 1992 Occurrence of ophthalmopathy after treatment for Graves' hyperthyroidism. N Engl J Med 326:1733-1738

207. Tallstedt L, Lundell G, Blomgren H, Bring J 1994 Does early administration of thyroxine reduce the development of Graves' ophthalmopathy after radioiodine treatment? Eur J Endocrinol 130: 494-497

208. Tallstedt L, Lundell G 1997 Radioiodine treatment, ablation, and ophthalmopathy: a balanced perspective. Thyroid 7:241-245

209. Vàzquez-Chàvez C, Nishimura Megura E, Espinosa Said L, Delgado Falfari A, Sàinz de Viteri M 1992 Influencia del tratamento del hipertiroidismo en el curso del exoftalmos. Rev Invest Clin 44:241-247
210. Gorman CA, Offord KP 1998 Therapy for hyperthyroidism and Graves' ophthalmopathy (letter). N Engl J Med 338:1546

211. Wiersinga WM 1998 Preventing Graves' ophthalmopathy. N Engl J Med 338:121-122

212. Bartalena L, Marcocci C, Tanda ML, Manetti L, Dell'Unto E, Bartolomei MP, Nardi P, Martino E, Pinchera A 1998 Cigarette smoking and treatment outcomes in Graves ophthalmopathy. Ann Intern Med 129:632-635

213. Kung AWC, Yau CC, Cheng A 1994 The incidence of ophthalmopathy after radioiodine therapy for Graves' disease: prognostic factors and the role of methimazole. J Clin Endocrinol Metab 79: $542-546$

214. Marcocci C, Bartalena L, Pinchera A 1996 Recent progress in Graves' ophthalmopathy. Curr Opin Endocrinol Metab 3:417-422

215. Wasnich RD, Grumet FC, Payne RO, Kriss JP 1973 Graves' ophthalmopathy following external neck irradiation for nonthyroidal neoplastic disease. J Clin Endocrinol Metab 37:703-713

216. Jackson R, Rosenberg C, Kleinmann R, Vagenakis AG, Braverman LE 1979 Ophthalmopathy after neck irradiation therapy for Hodgkin's disease. Cancer Treat Rep 63:1393-1395

217. Bartalena L, Bogazzi F, Pecori F, Martino E 1996 Graves' disease occurring after subacute thyroiditis: report of a case and review of the literature. Thyroid 6:345-348

218. Ozata M, Bayhau H, Bingol N, Dundar S, Beyhan Z, Corakci A, Gundogan MA 1995 Sequential changes in serum thyroid peroxidase following radioiodine therapy of patients with differentiated thyroid carcinoma. J Clin Endocrinol Metab 80:3634-3638

219. Pinchera A, Liberti P, Martino E, Fenzi GF, Grasso L, Rovis L, Baschieri L, Doria G 1969 Effects of antithyroid therapy on the long-acting thyroid stimulator and the antithyroglobulin antibodies. J Clin Endocrinol Metab 29:231-238

220. Teng W-P, Stark R, Munro AJ, Young SM, Borysiewicz LK, Weetman AP 1990 Peripheral blood T cell activation after radioiodine treatment for Graves' disease. Acta Endocrinol (Copenh) 122:233240

221. Aizawa Y, Yoshida K, Kaise N, Fukazawa H, Kiso Y, Mori K, Sayama N, Kikuchi K, Abe K 1995 Long-term effects of radioiodine on thyrotrophin receptor antibodies in Graves' disease. Clin Endocrinol (Oxf) 4:517-522

222. Bartalena L, Marcocci C, Pinchera A 1998 Therapy for hyperthyroidism and Graves' ophthalmopathy (letter). N Engl J Med 338: 1546-1547

223. Sridama V, DeGroot LJ 1989 Treatment of Graves' disease and the course of ophthalmopathy. Am J Med 87:70-73

224. Frilling A, Goretzki PE, Grussendorf M, Erbsloh M, Roher H-D 1990 The influence of surgery on endocrine ophthalmopathy. World J Surg 14:442-446

225. Fernàndez-Sànchez JR, Rosell Pradas J, Carazo Martinez $\mathrm{O}$, Torres Vela E, Escobar Jimenez F, Garbin Fuentes I, Vara Thorbeck R 1993 Graves' ophthalmopathy after subtotal thyroidectomy and radioiodine therapy. Br J Surg 80:1134-1136

226. Patwardhan NA, Moront M, Rao S, Rossi S, Braverman LE 1993 Surgery still has a role in Graves' hyperthyroidism. Surgery 114: $1108-1113$

227. Winsa B, Rastad J, Akerstrom G, Johansson H, Westermark K, Karlsson FA 1995 Retrospective evaluation of subtotal and total thyroidectomy in Graves' disease with and without endocrine ophthalmopathy. Eur J Endocrinol 132:406-412

228. Miccoli P, Vitti P, Rago T, Iacconi P, Bartalena L, Bogazzi F, Fiore E, Valeriano R, Chiovato L, Rocchi R, Pinchera A 1996 Surgical treatment of Graves' disease: subtotal or total thyroidectomy? Surgery 120:1020-1024

229. Abe Y, Sato H, Noguchi M, Mimura T, Sugino K, Ozaki O, Yoshimura H, Ito K 1998 Effect of subtotal thyroidectomy on natural history of ophthalmopathy in Graves' disease. World J Surg 22:714-717

230. Marcocci C, Bruno-Bossio G, Manetti L, Tanda ML, Miccoli P, Iacconi P, Bartolomei MP, Nardi M, Pinchera A, Bartalena L 1999 The course of Graves' ophthalmopathy is not influenced by neartotal thyroidectomy: a case-control study. Clin Endocrinol (Oxf) 51:503-506

231. Pacini F, Mariotti S, Formica N, Elisei R, Anelli S, Capotorti E, Pinchera A 1988 Thyroid autoantibodies in thyroid cancer: inci- 
dence and relationship with tumour outcome. Acta Endocrinol (Copenh) 119:373-380

232. Weetman AP, Harrison BJ 1998 Ablative or non-ablative therapy for Graves' hyperthyroidism in patients with ophthalmopathy? J Endocrinol Invest 21:472-475

233. DeGroot LJ 1997 Radioiodine and the immune system. Thyroid 7:259-264

234. DeGroot LJ, Benjasuratwong Y 1996 Evaluation of thyroid ablative therapy for ophthalmopathy of Graves' disease. Orbit 15:187-196

235. Chiovato L, Santini F, Pinchera A 1995 Treatment of hyperthyroidism. Thyroid International 2:1-10

236. Tomer Y, Davies TF 1997 The genetic susceptibility to Graves' disease. Bailliere's Clin Endocrinol Metab 11:431-450

237. Farid NR, Balazs C 1998 The genetics of thyroid associated ophthalmopathy. Thyroid 8:407-409

238. Perros P, Crombie AL, Matthews JNS, Kendall-Taylor P 1993 Age and gender influence the severity of thyroid-associated ophthalmopathy: a study of 101 patients attending a combined thyroid-eye clinic Clin Endocrinol (Oxf) 38:367-372

239. Kendler DL, Lippa J, Rootman J 1993 The initial clinical characteristics of Graves' orbitopathy vary with age and sex. Arch Ophthalmol 111:197-201

240. Kendall-Taylor P, Perros P 1998 Clinical presentation of thyroid associated orbitopathy. Thyroid 8:427-428

241. Bartley GB 1994 The epidemiology characteristics and clinical course of ophthalmopathy associated with autoimmune thyroid disease in Olmsted County, Minnesota. Trans Am Ophthalmol Soc 92:477-588

242. Perros P, Kendall-Taylor P 1998 Natural history of thyroid eye disease. Thyroid 8:423-425

243. Bertelesen JB, Hegedus L 1994 Cigarette smoking and the thyroid. Thyroid 4:327-331

244. Bartalena L, Bogazzi F, Tanda ML, Manetti L, Dell'Unto E, Martino E 1995 Cigarette smoking and the thyroid. Eur J Endocrinol 133:507-512

245. Prummel MF, Wiersinga WM 1993 Smoking and risk of Graves' disease. JAMA 269:479-482

246. Bartalena L, Martino E, Marcocci C, Bogazzi F, Panicucci M, Velluzzi F, Loviselli A, Pinchera A 1989 More on smoking habits and Graves' ophthalmopathy. J Endocrinol Invest 12:733-737

247. Ericsson U-B, Lingaarde F 1991 Effects of cigarette smoking on thyroid function and the prevalence of goitre, thyrotoxicosis and autoimmune thyroiditis. J Intern Med 229:67-71

248. Shine B, Fells P, Edwards OM, Weetman AP 1990 Association between Graves' ophthalmopathy and smoking. Lancet 1:12611263

249. Fung HM, Kologlu M, Collison K, John R, Richards CJ, Hall R, McGregor AM 1988 Postpartum thyroid dysfunction in Mid Glamorgan. Br Med J 296:241-244

250. Regius O, Lengyel E, Borzsonnyi L, Beregi E 1988 The effect of smoking on the presence of antinuclear antibodies and the morphology of lymphocytes in aged subjects. Z Gerontol 21:161-163

251. Othman S, Phillips DW, Parkes AB, Richards CJ, Harris B, Fung H, Lazarus JH 1990 A long-term follow-up of post-partum thyroiditis. Clin Endocrinol (Oxf) 32:559-564

252. Hagg E, Asplund K 1987 Is endocrine ophthalmopathy related to smoking? Br Med J 295:634-635

253. Balazs C, Stensky V, Farid NR 1990 Association between Graves' ophthalmopathy and smoking (letter). Lancet 2:754

254. Winsa B, Mandahl A, Karlsson FA 1993 Graves' disease, endocrine ophthalmopathy and smoking. Acta Endocrinol (Copenh) 128: $156-160$

255. Tallstedt L, Lundell G, Taube A 1993 Graves' ophthalmopathy and tobacco smoking. Acta Endocrinol (Copenh) 129:147-150

256. Pfeilschifter J, Ziegler R 1996 Smoking and endocrine ophthalmopathy: impact of smoking severity and current vs. lifetime cigarette consumption. Clin Endocrinol (Oxf) 45:477-481

257. Tellez M, Cooper J, Edmonds C 1992 Graves' ophthalmopathy in relation to cigarette smoking and ethnic origin. Clin Endocrinol (Oxf) 36:291-294

258. Utiger RD 1998 Effects of smoking on thyroid function. Eur J Endocrinol 138:368-369

259. Borup-Christensen S, Ericcson U-B, Janzon L, Tibblin S, Me- lander A 1984 Influence of cigarette smoking on goiter formation, thyroglobulin, and thyroid hormone levels in women. J Clin Endocrinol Metab 58:615-618

260. Ludgate M, Swillens S, Mercken L, Vassart G 1986 Homology between thyroglobulin and acetylcholinesterase: an explanation for pathogenesis of Graves' ophthalmopathy? Lancet 2:219-220

261. Weetman AP, Tse CK, Randall WR, Tsim KWK, Barnard EA 1988 Acetylcholinesterase antibodies and thyroid autoimmunity. Clin Exp Immunol 71:96-99

262. Metcalfe RA, Weetman AP 1994 Stimulation of extraocular muscle fibroblasts by cytokines and hypoxia: possible role in thyroidassociated ophthalmopathy. Clin Endocrinol (Oxf) 40:67-72

263. Ala Y, Palluy O, Favero C, Modat G, Dormand I 1992 Hypoxia/ reoxygenation stimulates endothelial cells to promote interleukin-1 and interleukin-6 production. Effects of free radical scavengers. Agents Action 37:134-139

264. Shreeniwas R, Koga S, Karakurum M, Pinsky D, Kaiser E, Brett J 1992 Hypoxia-mediated induction of endothelial cells interleukin$1 \alpha$. J Clin Invest 90:2333-2339

265. Tan GH, Duttyon CM, Bahn RS 1996 Interleukin-1 (IL-1) receptor antagonist and soluble IL-1 receptor inhibit IL-1-induced glycosaminoglycan production in cultured human orbital fibroblasts from patients with Graves' ophthalmopathy. J Clin Endocrinol Metab 81:449-452

266. Hofbauer LC, Muhlberg T, Konig A, Heufelder G, Schworm H-D, Heufelder AE 1997 Soluble interleukin-1 receptor antagonist serum levels in smokers and nonsmokers with Graves' ophthalmopathy undergoing orbital radiotherapy. J Clin Endocrinol Metab 82:2244-2247

267. Muhlberg T, Heberling H-J, Joba W, Schworm H-D, Heufelder AE 1997 Detection and modulation of interleukin-1 receptor antagonist messenger ribonucleic acid and immunoreactivity in Graves' orbital fibroblasts. Invest Ophthalmol Vis Sci 38:1018-1028

268. Keltner JL 1998 Is Graves ophthalmopathy a preventable disease? Arch Ophthalmol 116:1106-1107

269. Houssiau FA 1995 Cytokines in rheumatoid arthritis. Clin Rheumatol 14 [Suppl 2]:10-13

270. Fox DA 1995 Biological therapies: a novel approach to the treatment of autoimmune disease. Am J Med 99:82-88

271. Koopman WJ, Moreland LW 1998 Rheumatoid arthritis: anticytokine therapies on the horizon. Ann Intern Med 128:231-233

272. Elliott MJ, Maini RN, Feldmann M, Kalden JR, Antoni C, Smolen JS, Leeb B, Breedveldt FC, MacFarlane JD, Bijl H 1994 Randomized double-blind comparison of chimeric monoclonal antibody to tumor necrosis factor $\alpha$ (cA2) vs. placebo in rheumatoid arthritis. Lancet 344:1105-1110

273. Rankin ECC, Choy EHS, Kassimos D, Kingsley GH, Sopwith AM, Isenberg DA, Panayi GS 1995 The therapeutic effects of an engineered human antitumor necrosis factor alpha antibody (CDP571) in rheumatoid arthritis. Br J Rheumatol 34:334-342

274. Drevlow BE, Lovis R, Haag MA, Sinacore JM, Jacobs C, Blosch C, Landay A, Moreland LW, Pope RM 1996 Recombinant human interleukin-1 receptor type I in the treatment of patients with active rheumatoid arthritis. Arthritis Rheum 39:257-265

275. McQueen FM 1997 The use of biologics in the treatment of rheumatoid arthritis - the good news and the bad news. Aust NZ J Med 27:175-184

276. Hiromatsu Y, Yang D, Miyake I, Koga M, Kameo J, Sato M, Inoue Y, Nonaka K 1998 Nicotinamide decreases cytokine-induced activation of orbital fibroblasts from patients with thyroid-associated ophthalmopathy. J Clin Endocrinol Metab 83:121-124

277. Balazs C, Kiss E, Vamos A, Molnar I, Farid NR 1998 Beneficial effect of pentoxyfilline on thyroid-associated ophthalmopathy. J Clin Endocrinol Metab 82:1999-2002

278. Chang CC, Chang TC, Kao SC, Kuo YF, Chien LF 1993 Pentoxyfilline inhibits the proliferation and and glycosaminoglycan synthesis of cultured fibroblasts derived from patients with Graves' ophthalmopathy and pretibial myxoedema. Acta Endocrinol (Copenh) 129:322-327

279. Balazs C, Kiss E, Farid NR 1998 Inhibitory effect of pentoxyfilline on HLA-DR and glycosaminoglycan synthesis of retrobulbar fibroblasts induced by interleukin-1, tumor necrosis factor $\alpha$ and interferon $\gamma$. Horm Metab Res 30:496-499 
280. Guimaraes VC, Quintans J, Fisfalen ME, Straus FH, Wilhelm K, Medeiros-Neto G, DeGroot LJ 1995 Suppression of development of experimental autoimmune thyroiditis by oral administration of thyroglobulin. Endocrinology 136:3353-3359

281. Colzani RM, Alex S, Dunn AD, Dunn JT, Stone S, Braverman LE 1999 The oral administration of human thyroglobulin does not affect the incidence of lymphocytic thyroiditis in the biobreeding Worcester rat. Thyroid 9:831-835
282. Stamato FJC, Manso PG, Maciel JR, Wolosker AMB, Maciel RMB, Furlanetto RP, Colchicine as a new option for the clinical treatment of Graves' ophthalmopathy. Proceedings of the VIth International Symposium on Graves' Ophthalmopathy, Amsterdam, 1998, p 22 (Abstract)

283. Bartley GB, Fatourechi V, Kadrmas EF, Jacobsen SJ, Ilstrup DM, Garrity JA, Gorman CA 1996 Long-term follow-up of Graves ophthalmopathy in an incidence cohort. Ophthalmology 103:958-962

\section{ESCI 2000. 34 ${ }^{\text {th }}$ Annual Scientific Meeting of European Society for Clinical Investigation, The University of Aarhus, Aarhus, Denmark, May 17-20, 2000}

Sponsor: European Society for Clinical Investigation.

Topics: Postgraduate course: Base Methods in Molecular Biology. Plenary Lectures: Identification of the sodium-potassium ATPase pump and its significance by Jens Christian Skou, Nobel Laureate, Denmark. Neuroendocrine gastrointestinal tumors: diagnosis and treatment by Barbro Eriksson, Sweden. Drosophila host defense and the evolution of innate immunity by Jules A. Hoffmann, France. The cytoplasmatic transport of amphipathic molecules by Richard A. Weisiger, USA. ESCI award for excellence in clinical science lecture 2000. Winner to be announced. 17 workshops on basic mechanisms and pathophysiology of diseases to clinical therapy.

Contact: Susanne Keiding, MD (Meeting President), PET-Centre and Department of Medicine V, Aarhus University Hospital, DK-8000 Aarhus C, Denmark.

Tel: +45 8949 3031, Fax: +45 8949 3020, E-mail: esci2000@pet.auh.dk

Homepage: http://www.pet.au.dk/esci2000 